\title{
STOCHASTIC FEATURE CHARTS \\ Uma Extensão Estocástica para os Statecharts
}

\author{
Carlos Renato Lisboa Francês
}

Orientador: Prof. Dr. Marcos José Santana

Dissertação apresentada ao Instituto de Ciências Matemáticas e de Computação da Universidade de São Paulo - ICMC/USP, como parte dos requisitos para a obtenção do título de Mestre em Ciências - Área de Ciências de Computação e Matemática Computacional. 
"O homem se designou a si próprio como um ser que mede e valora, como o animal estimador" (Nietzsche, F.) 
À Regiane Kawasaki, a pessoa mais nobre que já conheci, que "me deu a idéia de uma nova consciência e juventude".

A Emílio e Nagib Francês (in memoriam). 


\section{AGRADECIMENTOS}

A Deus, por ter me possibilitado a chegada desse momento, mesmo que, às vezes, por caminhos ligeiramente tortuosos.

Aos meus pais, que se sacrificaram na tarefa de educar os filhos em um país que contribui com grande força para que isso não seja possível.

Ao Prof. Marcos José Santana, que me atendeu nos horários mais incômodos, e, apesar disso, sempre conseguiu me mostrar uma visão entusiasta do poder do pensamento, da oratória e da representação de ambos através das palavras.

À Profa. Regina H. C. Santana, minha co-orientadora, pela dicas e pela visão corretamente pragmática nas horas certas.

A todos os amigos do grupo de Sistemas Distribuídos e Programação Concorrente do ICMC, pela convivência feliz e extremamente proveitosa que eu pude desfrutar.

Aos amigos Afonso, Alex, Aletéia, Paulo Sampaio e João Caldas, por toda ajuda que me deram.

À CAPES e ao CNPq, pelo apoio financeiro parcial.

Às amigas da secretaria da Pós-Graduação Beth, Laura e Marília, por fazerem sempre o possível para ajudar a todos os alunos.

Aos amigos da UNAMA e CESUPA/CESAM, pelo breve e proveitoso convívio.

A todas as pessoas que contribuíram direta ou indiretamente com a realização deste trabalho. 


\section{SUMÁRIO}

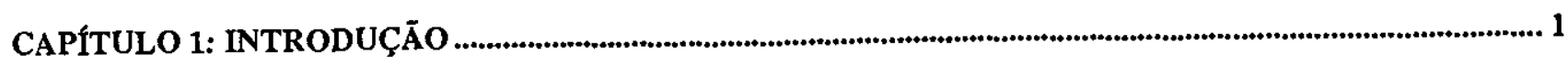

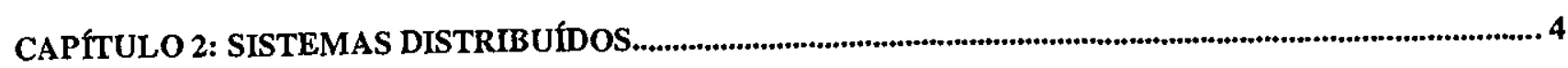

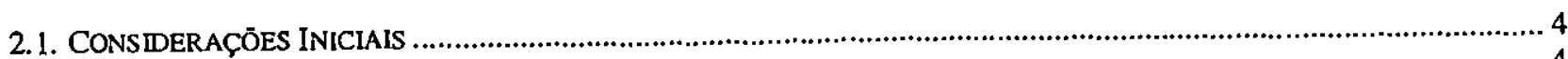

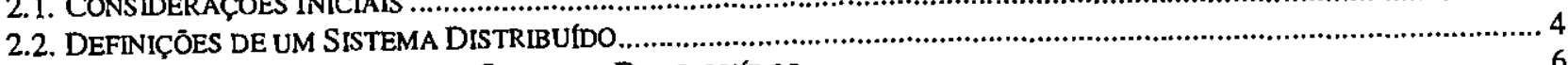

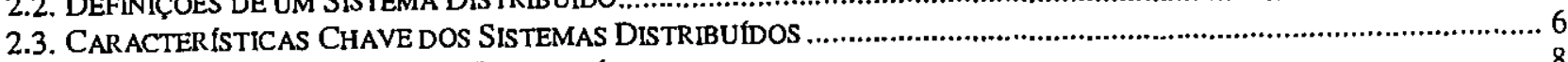

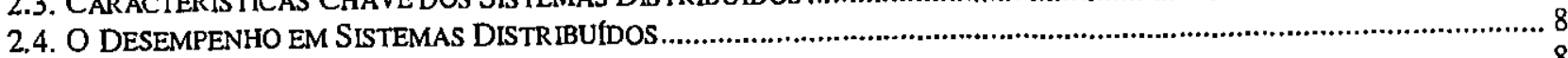

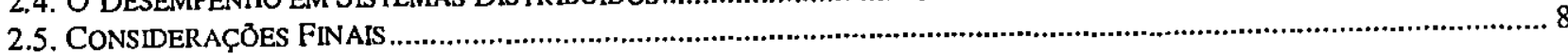

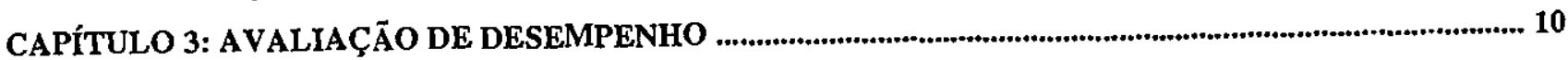

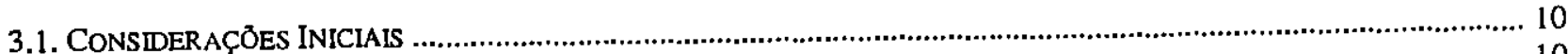

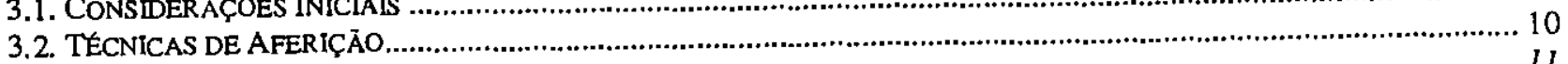

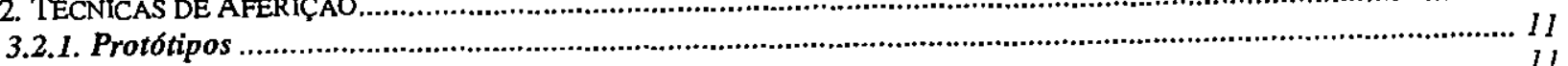

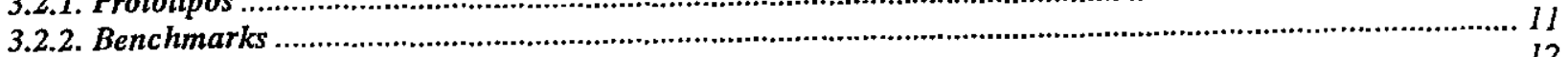

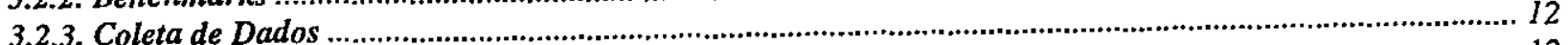

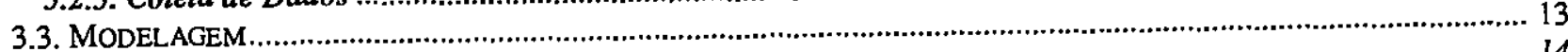

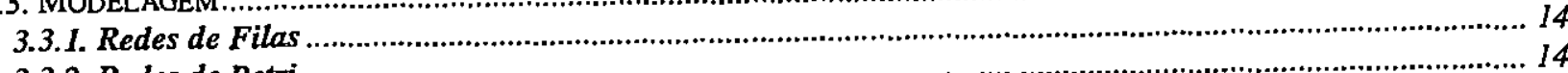

3.3.2. Redes de Petri

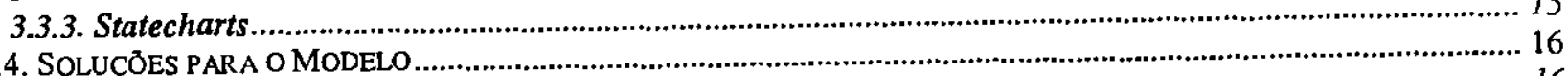

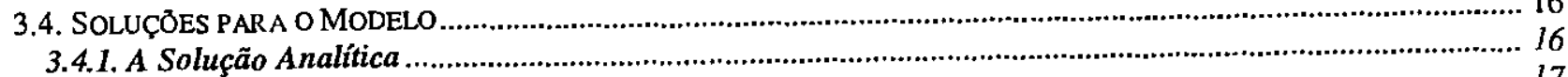

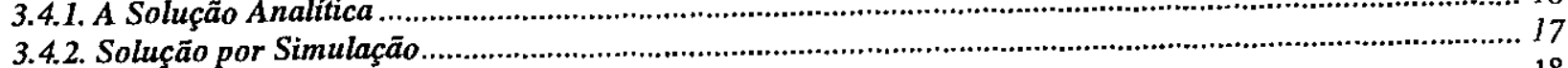

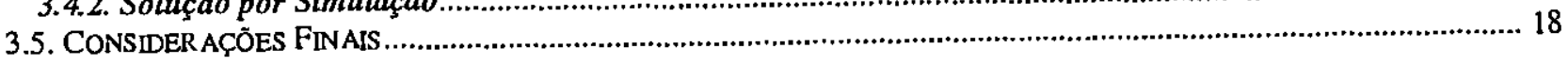

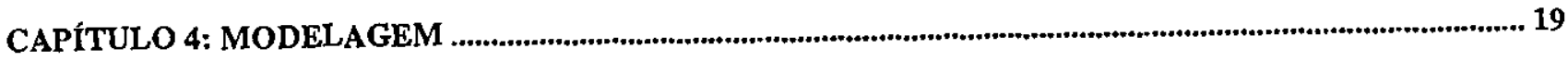

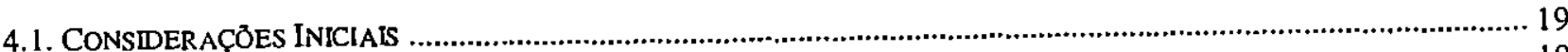

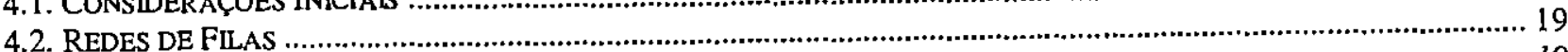

4.2.1. Definição e Terminologia ................................................................................................................... 19

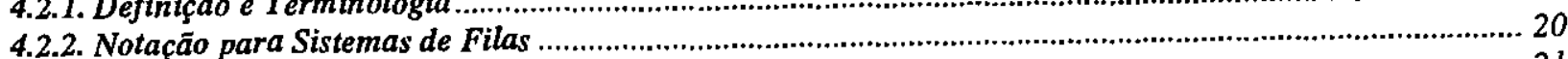

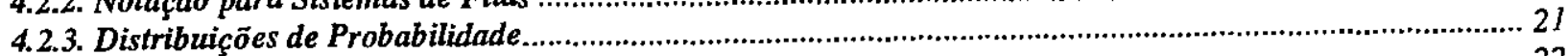

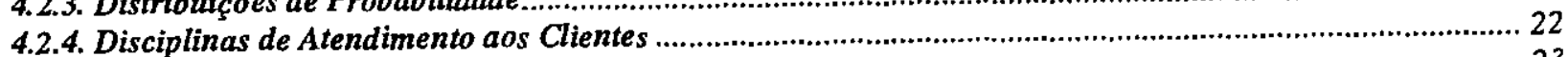

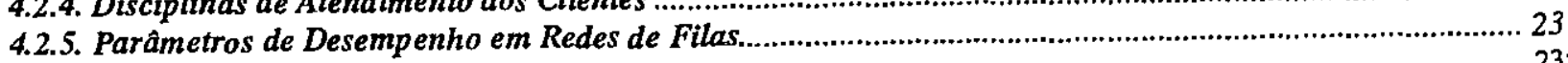

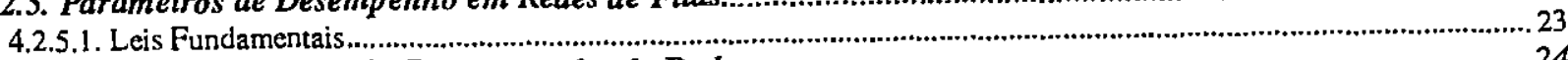

4.2.6. Aplicaçōes de Redes de Filas em Redes de Dados ...................................................................................2. 24

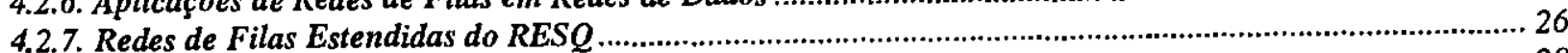

4.2.8. Restrições às Soluçōes Analíticas em Redes de Filas ..................................................................................29

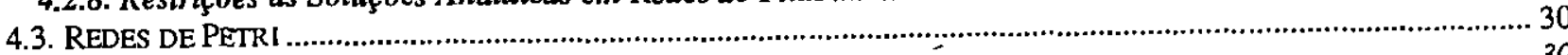

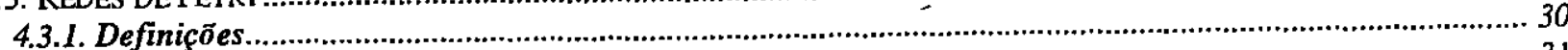

4.3.1.1. Fundamenaçôes para Redes de Petri .................................................................................................................31

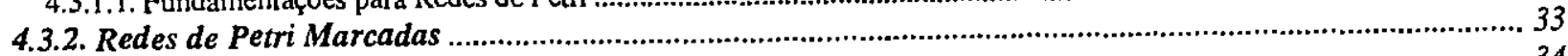

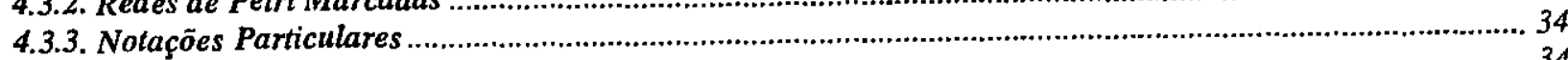

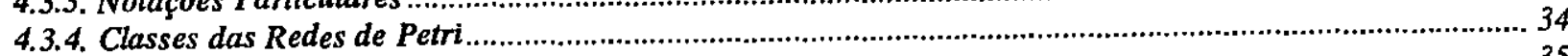

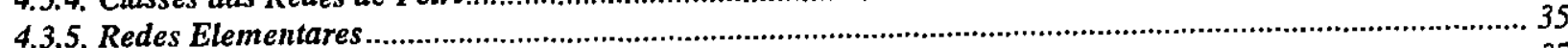

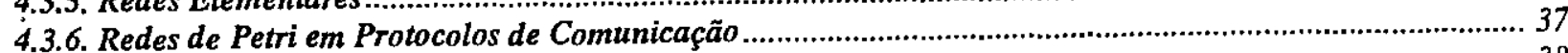

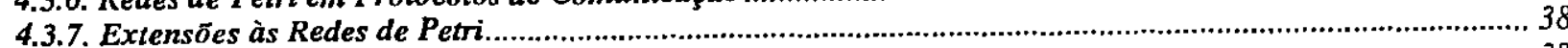

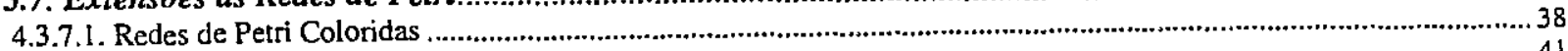

4.3.7.2. Redes Hierárquicas.................................................................................................................................................4

4.3.7.3. Rede de Perti Temporizada Determinística .......................................................................................................4 42

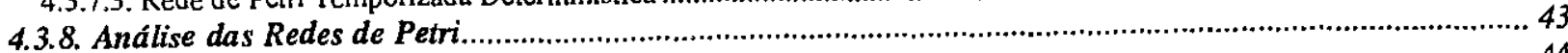

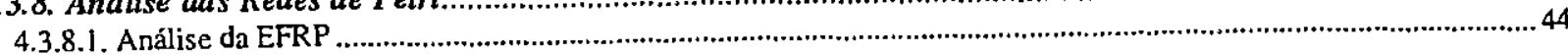




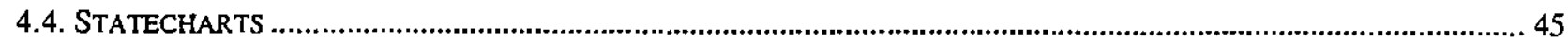

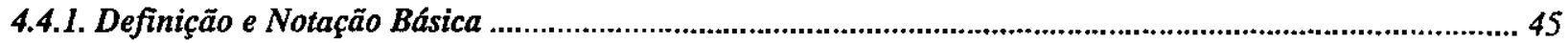

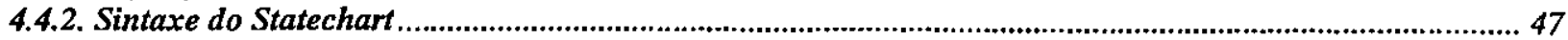

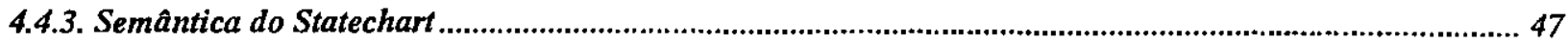

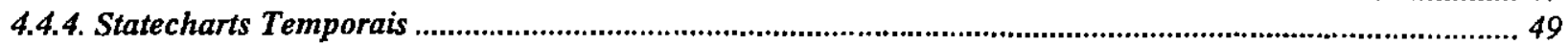

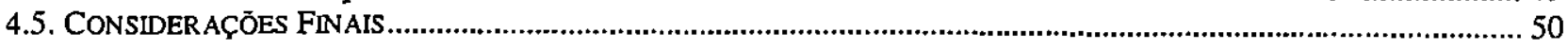

CAPÍTULO 5: SIMULAÇÃO

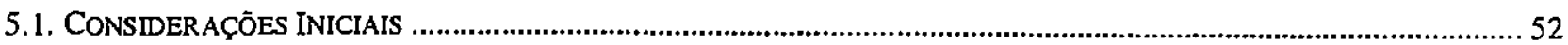

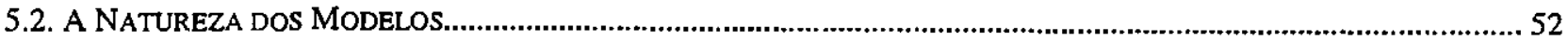

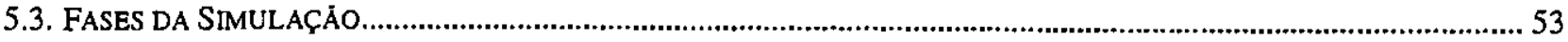

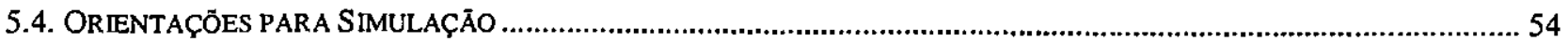

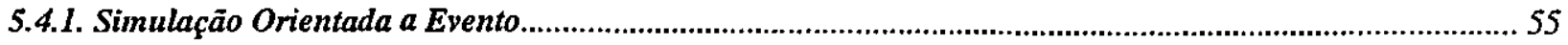

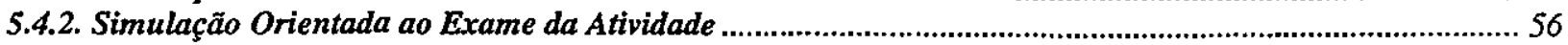

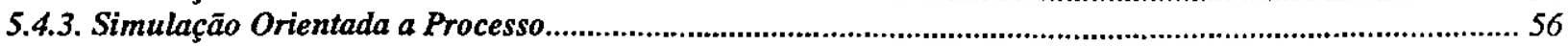

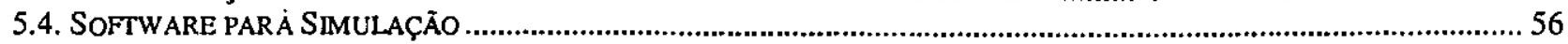

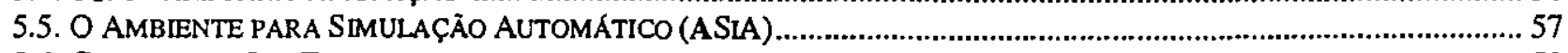

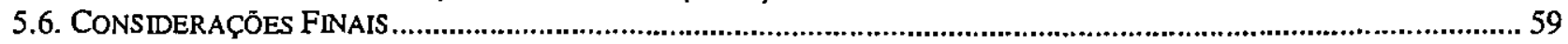

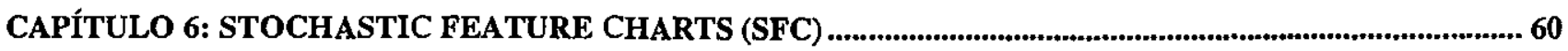

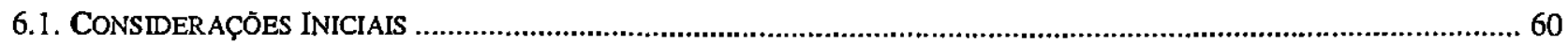

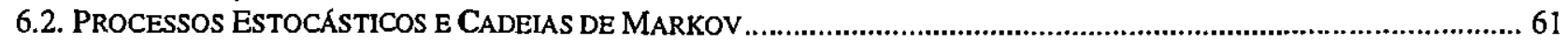

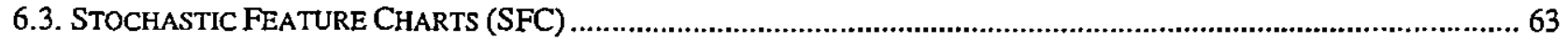

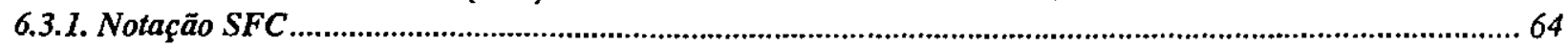

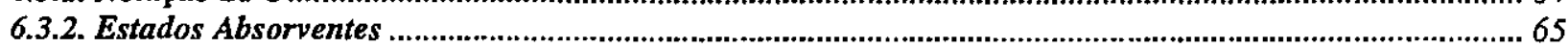

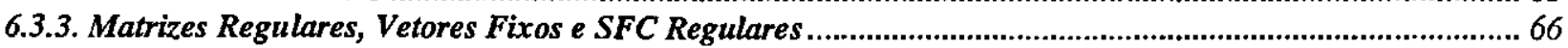

6.3.4. Probabilidade de Transição em Várias Etapas...................................................................................... 70

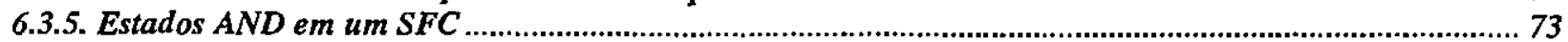

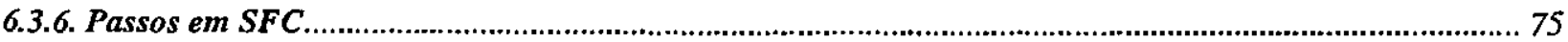

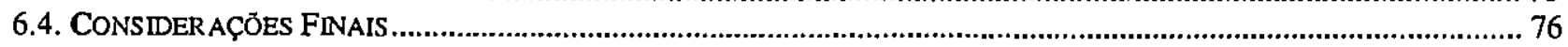

CAPITULO 7: CASO DE ESTUDO: SERVDOR DE ARQUIVOS BASEADO EM REDE LOCAL ................... 78

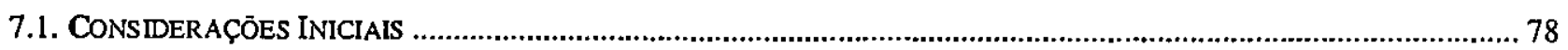

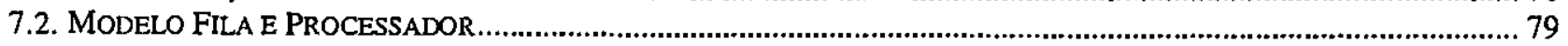

7.3. MODELO FILA DO PROCESSADOR + PROCESSADOR + FILA DO DISCO + DISCO

7.4. MODELO FILA DO PROCESSADOR + PROCESSADOR + FILA DO DISCO + DISCO +

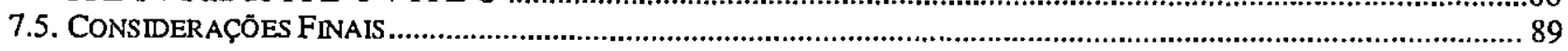

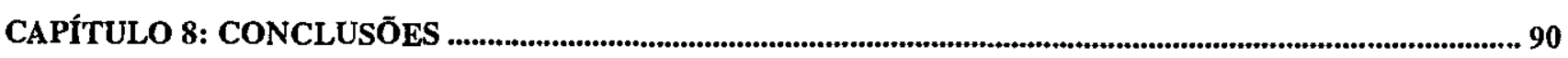

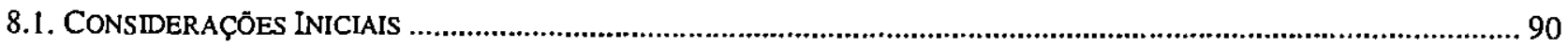

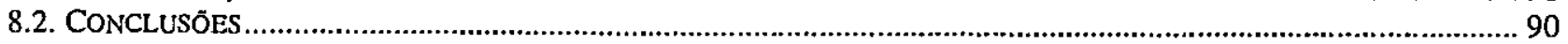

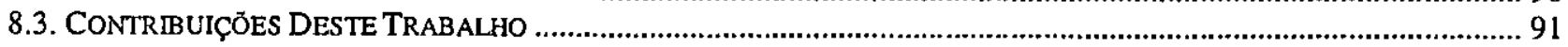

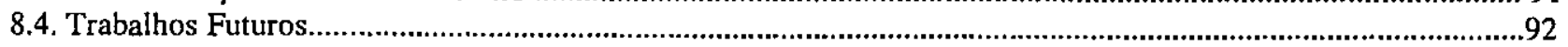

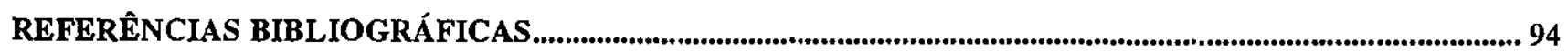




\section{RESUMO}

Esta dissertação apresenta uma discussão geral sobre técnicas de avaliação de desempenho de sistemas computacionais, levando em consideração duas áreas principais: as técnicas que envolvem experimentação com os sistemas (técnicas de aferição) e a criação de abstrações para representar os sistemas (técnicas de modelagem).

O trabalho enfoca as técnicas de modelagem, especialmente as redes de fila, as redes de Petri e os statecharts. Algumas das abordagens preferidas para essas técnicas são discutidas na revisão bibliográfica mas, como essas técnicas são de propósito geral, elas podem ser aplicadas a qualquer sistema computacional. O objetivo principal é mostrar as vantagens e desvantagens na adoção de uma ou outra técnica, considerando as mesmas situações com diferentes modelos de sistemas.

Uma extensão estocástica original para statecharts é proposta (Stochastic Feature Charts $S F C$ ), cujo objetivo é prover uma avaliação probabilística, através da incorporação de cadeia de Markov nos statecharts. Assim, um sistema pode ser visualizado através de seus estados e transições entre esses estados. O objetivo principal é estender os statecharts e criar uma ferramenta com características similares àquelas encontradas em redes de fila e redes de Petri.

A extensão proposta, SFC, é usada para avaliar o desempenho de um servidor de arquivos usado em rede local, considerando três modelos diferentes, com complexidade diferente. $O$ comportamento das probabilidades é observado e os resultados obtidos são discutidos visando a validação da extensão dos statecharts proposta. 


\begin{abstract}
This dissertation presents a general discussion about computing system performance evaluation techniques taking into consideration two major areas: the adoption of system experimentation techniques (the measuring techniques) and the creation of abstractions to represent the systems (the modelling techniques).

The work focuses on modelling techniques, especially on queueing networks, Petri networks and statecharts. Some of the preferred approaches for these techniques are discussed in the literature review, but as these techniques are all general purpose they can be applied to any computing system. The main objective is to show the advantages and disadvantages in adopting one or another technique, considering the same situations with different system models.

An original stochastic extension for statecharts is proposed (Stochastic Feature Charts $\mathrm{SFC}$ ), which aims to provide a probabilistic evaluation by incorporating Markov's chains into the statecharts. Thus, a system can be visualised by its states and transitions among these states. The main goal is to extend statecharts and create a tool with similar features to those found in queueing and Petri networks.

The extension proposed, SFC, is used to evaluate the performance of a LAN-based file server, considering three different models with different complexity. The behaviour of the probabilities is observed and the results obtained are discussed in order to validate the statechart extension proposed.
\end{abstract}




\section{Capítulo 1}

\section{Introdução}

A evolução experimentada pela computação nas últimas décadas trouxe à tona uma revolução sem precedentes. Nos dias de hoje, uma grande gama das atividades humanas está condicionada às facilidades provenientes da utilizaçāo dos computadores. O computador, de maneira irreversível, tomou posição de destaque no mundo moderno. Mas, apesar da inegável contribuição da informática para todas as áreas do conhecimento humano, o computador está longe de ser uma panacéia. Junto às benesses advindas com o mundo dos computadores, também veio uma avalanche de problemas peculiares à nova tecnologia. Para agravar esse panorama, no final da década de sessenta, plantou-se a semente da interconexão dos computadores, no limiar da tecnologia das redes. No início de toda essa transformação, várias falhas eram aceitas em nome do estágio primário em que se encontrava a ciência da computação.

Com o decorrer do tempo, os sistemas computacionais evoluíram em vários sentidos (desempenho, confiabilidade, interface com o usuário, entre outros.). Essa evolução, entretanto, teve um preço alto: o nítido crescimento de complexidade para se projetar, analisar e entender esses sistemas. Como exemplificação desse aumento de complexidade, pode-se considerar o surgimento dos sistemas distribuídos. Esses sistemas, além da complexidade inerente aos sistemas computacionais centralizados, pressupõem a existência de características próprias (como transparência, abertura, etc.) (Coulouris et. al., 83), que aumenta de certa forma a dificuldade para estudá-los.

Existem várias técnicas destinadas à observação do comportamento de sistemas computacionais (distribuídos ou centralizados). Esses métodos de análise podem ser classificados em dois grupos: as técnicas de aferição e a de modelagem (Orlandi, 95). Via de regra, essas técnicas são de aplicação geral, isto é, elas podem ser utilizadas em um sistema computacional qualquer. Entretanto, mesmo possuindo uma utilização genérica, há situações em que a adoção de uma determinada técnica pode ser mais proveitosa. Tomando-se como referência apenas o domínio que compreende as técnicas' de modelagem, pode-se perceber que, por exemplo, os statecharts foram desenvolvidos com o objetivo básico de modelar sistemas de tempo real (Harel, 87), apesar de nada impedir que essa técnica também seja usada para modelagem de um sistema sem restrições para tempos de resposta. Esse exemplo ilustra que as técnicas de avaliação de um sistema possuem uma aplicação preferencial, na qual se podem explorar, ao máximo, as suas potencialidades.

Com o objetivo de servir de base para a escolha e adoção de uma das citadas técnicas, este trabalho se propõe a traçar um mapa que exponha as aplicações preferenciais de cada método aqui abordado, isto é, fornecer um levantamento de vantagens e desvantagens de uma abordagem em relação às demais. Logicamente, o escopo deste estudo não possui o caráter abrangente das técnicas. Ele se restringe, na maioria dos casos, a problemas relacionados aos sistemas distribuídos (em geral, ao desempenho desses sistemas). Desta forma, esta dissertaçāo visa servir de alicerce para um estudo que deverá propor diretrizes que auxiliem na escolha de uma determinada técnica de avaliação, para determinadas situaçōes de caráter específico (uma escolha preferencial para um caso particular de problema). Este trabalho enfatiza as técnicas de modelagem, extrapolando o escopo da abordagem mostrada em (Orlandi, 95), a respeito dessa classe de técnicas. Tal predileção é atribuída à possibilidade de, aqui, realizar-se um estudo mais específico sobre a utilização dos modelos em situaçōes típicas de sistemas distribuídos (como. 
avaliação de desempenho de protocolos ou de servidores especializados). Toda essa exposição das técnicas de modelagem culmina com a proposição de uma extensão a uma das técnicas abordadas no decorrer do trabalho, além da apresentação de um caso de estudo mostrando a aplicação dos preceitos da proposta.

Após o capítulo introdutório (capítulo 1), o capítulo 2 faz uma discussão a respeito dos sistemas computacionais distribuídos. Săo apresentadas algumas definições encontradas na literatura especializada (Tanenbaum, 95)(Coulouris et. al., 83)(Müllender, 94), assim como características chave que singularizam os sistemas distribuídos (Tanenbaum, 95)(Coulouris et. al., 83). Na sequência do capítulo, há uma breve discussão sobre alguns fatores que podem deteriorar o aspecto do desempenho em um sistema desse tipo. Por fim, são abordadas algumas experiências de software e hardware para sistemas distribuídos, mostrando a dificuldade da elaboração de software para esses sistemas, enfatizando-se que o software se constitui no maior desafio dos sistemas distribuídos.

No capítulo seguinte (terceiro), é realizada uma visão geral sobre a avaliação de desempenho e as técnicas utilizadas para esse fim. São apresentadas duas grandes classes de metodologias utilizadas para a avaliação: as técnicas de aferição e de modelagem. Das técnicas de aferição, são discutidos os protótipos, os benchmarks e a coleta de dados, mostrando-se a utilizaçăo preferencial de cada uma dessas técnicas. Da modelagem, são apresentados os principais métodos para esse fim. Um primeiro contato com modelos baseados em redes de filas (Soares, 92), redes de Petri (Maciel et. al., 96) e statecharts (Harel, 87), é estabelecido. Após a apresentação desses modelos, são expostas as maneiras de resolvê-los: as soluções analíticas e por simulação. Ainda há uma breve análise sobre utilização preferencial de cada uma dessas soluções.

Pela importância para este trabalho, um capítulo inteiro (capítulo 4) é destinado à modelagem. Em suas seções, o capítulo provê uma visão detalhada de cada técnica de modelagem. Primeiro, as redes de filas são apresentadas a partir da teoria de filas (Kleinrock, 75), definindo-se uma base matemática suficiente para a elucidação dos conceitos dessa abordagem. Um exemplo mais específico é apresentado como forma de demonstrar a aplicação de redes de filas em redes de dados (Bertsekas \& Gallager, 92). Uma extensão às redes de filas denominada RESQ (que possibilita maior poder de representação ao modelo) é também exposta. Para finalizar a modelagem baseada em redes de filas, são apresentadas algumas restrições que essa técnica apresenta em relação às soluções analíticas do modelo. O próximo modelo discutido no capítulo é o baseado em redes de Petri. São definidas as fundamentações que esse modelo pode tomar como base (bags, matrizes e relações). Em seguida, algumas das redes elementares são apresentadas e, a partir delas, é derivado um exemplo de utilização em protocolos de comunicação. Posteriormente, algumas extensões às redes de Petri são discutidas (coloridas, hierárquicas e temporizadas determinísticas). Finalizando a abordagem sobre redes de Petri, uma análise através da equação fundamental dessas redes é realizada. Encerrando o capítulo sobre modelagem, são abordados os statecharts. Assim como nas outras técnicas, são discutidas definição e filosofia (sintaxe e semântica) dessa técnica. Ainda é apresentada uma extensão dos statecharts, denominadas statecharts temporais, a qual aumenta o poder de representação desse método de modelagem.

O capítulo 5 expõe uma discussão sobre a solução do modelo através de simulação. Primeiro, são apresentadas as fases que uma simulação deve seguir (Soares, 92), assim como as orientações ao exame da atividade, a evento e a processo. Após isso, os software para simulação são discutidos (linguagens de programação convencionais, linguagens de simulação, extensões funcionais e pacotes de uso específico). Por fim, o capítulo expõe as principais características do Ambiente de Simulação Automático (ASiA) (Santana et. al., 96a)(Santana et. al., 96b)(Spolon, 
94a)(Spolon, 94b), desenvolvido no ICMSC-USP, que utiliza redes de filas e a extensão SMPL como suporte.

O capítulo 6 apresenta a formalização da técnica denominada Stochastic Feature Charts (SFC), que é uma extensão estocástica dos statecharts (abordados nos capítulos 3 e 4). O SFC é apresentado e baseado na teoria das Cadeias de Markov para tempo discreto, com o objetivo primordial de possibilitar que se faça uma avaliação de desempenho através dos statecharts. assim como a realizada com a teoria de filas e redes de Petri estocásticas, isto é, utilizando-se probabilidades e suas distribuiçōes. Além da analogia das cadeias de Markov com os statecharts que é proposta, também são ilustradas algumas situações computacionais, nas quais essa associação seria interessante.

O capítulo 7 traz um caso de estudo para mostrar a aplicabilidade dos SFC. A abordagem propõe o estudo probabilístico de um servidor de arquivos baseado em redes locais. São apresentadas três variações de um servidor de arquivos, objetivando aumentar a complexidade do modelo e, consequientemente, da análise pretendida.

Finalmente, o capítulo 8 explicita algumas conclusões a respeito do assunto, mais especificamente, consideraçōes relacionadas aos SFC. Após, são apresentadas algumas contribuiçōes que este trabalho pode trazer, e sugerem-se algumas possibilidades de pesquisas para trabalhos futuros, a partir da presente pesquisa. 


\section{Capítulo 2}

\section{Sistemas Distribuídos}

\subsection{Considerações Iniciais}

"A situação do homem está bem definida (categoricamente!) pelo fato dele se encontrar inserido num "mundo". Convém, contudo, delimitar o alcance da palavra "mundo" ". Essa citação de Julián Marías (Marías, 85) poderia parecer um tanto nebulosa às primeiras aglomerações humanas. Entretanto, após a disseminação da espécie humana por todo o planeta, a dimensão da palavra "mundo" certamente se tomou muito mais abrangente.

Assim como a humanidade se distribuiu por sobre a Terra, também houve necessidade de distribuir-se todos os "dotes" acumulados pelo homem através de sua história. Desta forma, riquezas, conhecimentos e poder foram descentralizados, dando origem a vários sistemas sociais distribuídos.

Analogamente aos sistemas sociais humanos, os sistemas computacionais vêm, ao longo do tempo, experimentando mudanças radicais no que se refere à organização de suas estruturas. No início da era da informática, os computadores eram máquinas muito grandes e caras, que operavam de maneira independente por falta de uma forma confiável de interligá-los (Tanenbaum, 95). O cenário começou a se modificar graças ao avanço tecnológico de dois componentes chave da computação: os microprocessadores e as redes de interconexão.

Os microprocessadores progrediram de maneira vertiginosa. A potência de um microprocessador atual pode representar um poder computacional compatível com muitos mainframes de algum tempo atrás. Por outro lado, a tecnologia das LANs (Local Area Networks) permite que sejam factíveis transmissões de milhões de bits por segundo (por exemplo, as redes baseadas em fibra ótica), inimagináveis há algum tempo atrás.

O resultado da associação dessas tecnologias originou a possibilidade de hoje ser mais fácil construir sistemas de computação compostos por um grande número de processadores, ligados através de redes de alta velocidade.

Efetivamente, há um caso especial de sistema computacional baseado em rede de interconexão, cujo software lhe dá maior grau de coesão e transparência. Esse tipo particular de sistema é denominado Sistema Distribuído (Tanenbaum, 95).

Porém, a revolução dos sistemas distribuídos trouxe em seu ceme várias preocupações peculiares. Uma das principais preocupações é como manter (ou às vezes melhorar) o desempenho desses sistemas.

\subsection{Definições de um Sistema Distribuído}

Apesar de não haver na literatura especializada, uma definição que seja consensual, a maioria delas é concordante no que se refere à filosofia dos sistemas distribuídos. A seguir são apresentadas duas das mais referenciadas definições desses sistemas.

Coulouris (Coulouris et. al., 83) define um sistema distribuído como sendo "uma coleção de computadores autônomos, ligados por uma rede de comunicação e equipados com software de 
sistema distribuído". Coulouris ainda acrescenta que se o referido sistema tiver sido bem projetado, ele deve possuir características de um sistema computacional único e integrado.

Tanenbaum (Tanenbaum, 95) afirma que um sistema distribuído é "uma coleção de computadores independentes que aparecem aos usuários do sistema como um único computador".

Mesmo não sendo completamente idênticas, as definições acima convergem em dois pontos fundamentais. O primeiro ponto reside no fato de que os sistemas distribuídos devem ser compostos por computadores autônomos (ou independentes), isto é, não deve haver uma relação de mestre-escravo entre eles (Tanenbaum, 96). O segundo ponto de concordância está na transparência, evidenciada no fato de que os usuários devem sempre ter a ilusão de que estão trabalhando com um sistema único. A figura 2.1 (Coulouris et. al., 83) ilustra um modelo de um sistema distribuído simples.

Schroeder (Müllender, 94) apresenta uma definição simplista, caracterizando um sistema distribuído como sendo um "conjunto de computadores fazendo algo juntos. Assim, um sistema distribuído possui três características básicas: (1)múltiplos computadores, (2)interconexões entre eles, e (3)um estado comum, o qual é obtido através da cooperação entre os computadores".

Apesar das características acima citadas serem realmente fundamentais, elas são de certa forma óbvias, mostrando-se insuficientes para representar um sistema distribuído em sua plenitude. A seguir será apresentado um conjunto de seis características chave (Coulouris et. al., 83), que descreve com maior propriedade os sistemas distribuídos.

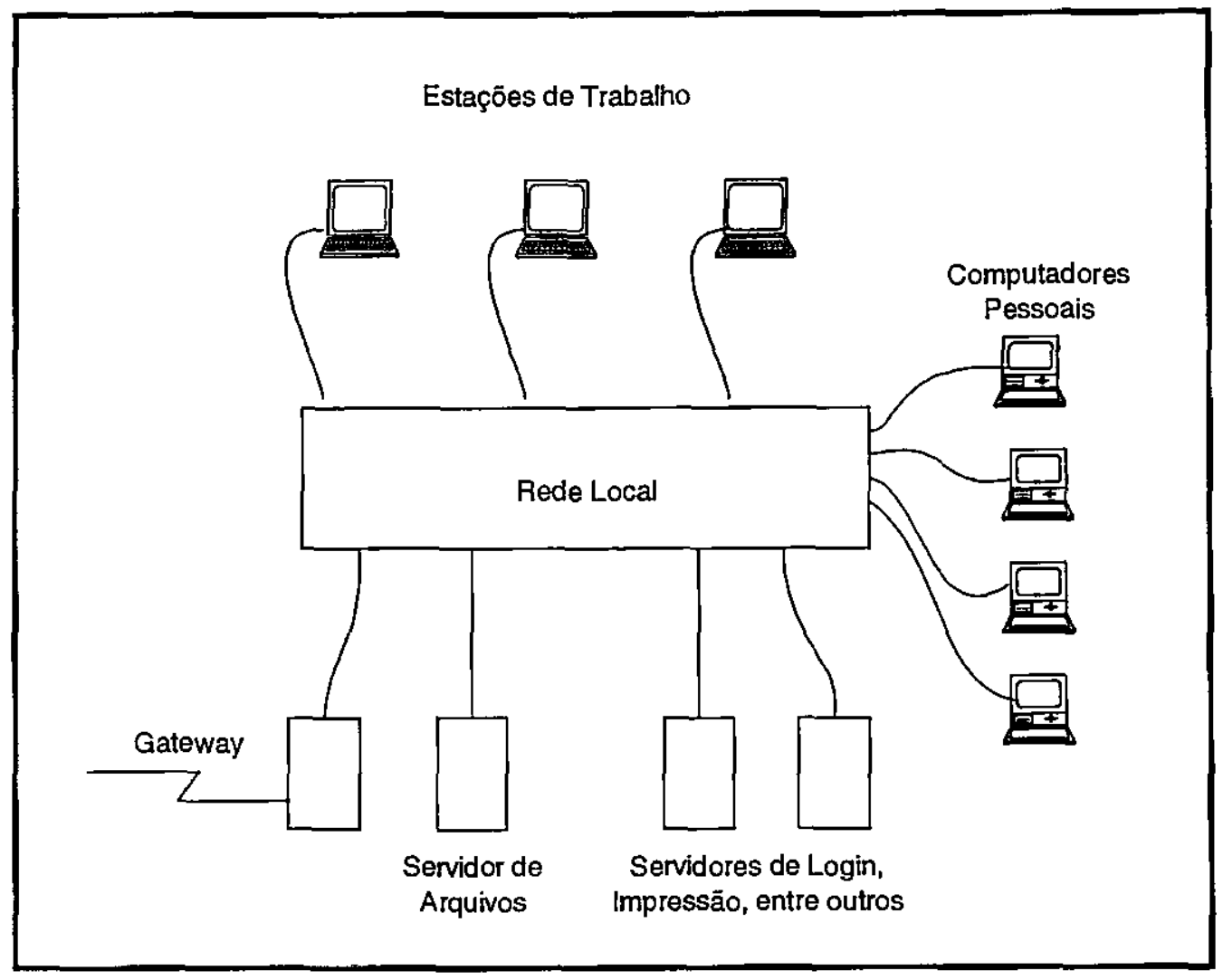

Figura 2.1. Modelo de um Sistema Distribuído Simples. 


\subsection{Características Chave dos Sistemas Distribuídos}

Para prover suporte à filosofia dos sistemas distribuídos, algumas características se fazem necessárias a todo sistema distribuído bem projetado (Coulouris et. al., 83).

- Compartilhamento de Recursos: O termo genérico "recurso" aqui é usado para denotar uma certa entidade computacional, isto é, software, hardware e dados. O compartilhamento de recursos é um dos estímulos à implantação dos sistemas distribuídos. Há um número elevado de situações em que compartilhar recursos é, além de interessante, fundamental.

- Abertura: É a característica que possibilita que um sistema computacional não se degenere, caso venham a ser adicionadas novas extensōes de hardware (por exemplo, periféricos, memória e interface de comunicação) ou de software (como novas características de sistemas operacionais ou protocolos de comunicação). Portanto, um sistema aberto é caracterizado pelo fato de suas interfaces serem totalmente definidas e disponíveis. Para que um sistema distribuído seja considerado aberto, além das interfaces públicas, ele deve possuir mecanismos de comunicação interprocessos uniformes, os quais possibilitem acessos a recursos compartilhados. A inclusão de um conjunto de chamadas de sistema no BSD UNIX para dar suporte à comunicação interprocessos (no início dos anos 80 ) é um exemplo clássico de aplicação do conceito de "abertura através de comunicação".

- Escalabilidade: A escala de um sistema distribuído pode variar de um pequeno conjunto de computadores (por exemplo, um par), até centenas de computadores interligados através de uma ou mais redes. Se, à medida que são inclusos novos componentes (computadores, rede de comunicação, entre outros) o sistema não modifica o seu comportamento, então diz-se que esse sistema possui a característica de escalabilidade. Em dezembro de 1969, a Agência para Projetos de Pesquisa Avançados (Advanced Research Projects Agency - ARPA), do Departamento de Defesa dos EUA, criou uma rede experimental composta, inicialmente, por quatro nós. A rede, denominada de ARPANET, sofreu uma expansão súbita, chagando a interligar diversas centenas de computadores, do Havaí à Suécia (Tanenbaum, 96). Apesar da ARPANET não poder ser considerada um sistema distribuído em sua plenitude, ela mostrou a possibilidade e a necessidade de escalabilidade nos sistemas de computadores interligados em rede.

- Tolerância a Falhas: As falhas em sistemas computacionais podem tanto ocasionar conseqüências simples, quanto as conseqüências mais drásticas possíveis. Nos sistemas centralizados, possivelmente, há um elemento que, na presença de uma falha, pode ocasionar a queda de todo o sistema. Os sistemas distribuídos devem prover condições para que o sistema resista à ocorrência de falhas. Esses sistemas, mesmo que na presença de falhas, devem possuir um alto grau de disponibilidade aos seus usuários. Apesar de toda a redundância de hardware disponível atualmente, não há, normalmente, redundância das redes que interligam os computadores. Falhas na rede, portanto, podem tornar o sistema indisponível aos seus usuários. Muito esforço vem sendo empreendido para possibilitar que as redes sejam tolerantes a falhas (Coulouris et. al., 83). Geralmente, essa resistência às falhas se processa sob duas abordagens: 
Redundância de Hardware: não deve haver componentes únicos em um sistema, ou seja, aqueles componentes cuja queda venha a provocar a queda de todo o sistema, devem ser replicados, apesar do custo do hardware ser duplicado em virtude do provimento dessa redundância. Um bom exemplo dessa abordagem de tolerância a falhas é a redundância dos servidores especializados (como por exemplo, os servidores de arquivos).

Recuperação de Software: um sistema computacional tolerante a falhas deve possibilitar que um programa, quando da ocorrência de uma falha, possa retornar ao estado consistente anterior à falha. Caso, por exemplo, haja dados que sejam compartilhados por vários processos diferentes, e um desses processos venha a falhar, o sistema deve possibilitar que essa falha não interfira na execução dos outros processos.

- Concorrência: o conceito de concorrência, na verdade, transcende os sistemas distribuídos. Pode-se obter concorrência a partir de um único processador, intercalando-se a execução de diversos processos, através da atribuição de parcelas de tempo de processamento a cada um deles. O caso de processos intercalando-se na utilizaçāo de um único processador é denominado de paralelismo lógico. Caso exista mais de um processador, diz-se que ocorre o paralelismo físico. Os sistemas distribuídos, por possuírem vários elementos de processamento, são naturalmente propícios à execução paralela de processos. A execução de programas paralelos, antes restritos às arquiteturas paralelas, podem ser realizados em sistemas distribuídos através da criação das chamadas máquinas paralelas virtuais (Beguelin, 94). Há uma série de vantagens em se emular máquinas paralelas através da utilização dos sistemas distribuídos. A heterogeneidade dos componentes das redes de computadores já existentes e o custo mais baixo (em relação às máquinas paralelas) são alguns dos maiores atrativos às pesquisas nessa área. Estudos interessantes a respeito da utilização de ambientes de passagem de mensagens têm sido desenvolvidos pelo grupo de Sistemas Distribuídos e Programação Concorrente do ICMSC-USP (Souza, 96) (Souza, 97).

- Transparência: a possibilidade de um sistema, apesar de ser distribuído, parecer ao usuário um sistema com uma única imagem (Tanenbaum, 95) se constitui em um dos maiores "dogmas", tanto dos usuários, quanto dos projetistas dos sistemas distribuídos. Tanenbaum (Tanenbaum, 95) descreve essa característica através de cinco aspectos: localização, replicação, migração, concorrência e paralelismo. Na transparência de localização, os objetos de informação, independente se locais ou remotos, devem ser obtidos e tratados de maneira análoga. Na transparência de replicação, com o intuito de aumentar o desempenho e a confiabilidade do sistema, os objetos de informação são replicados sem que o usuário se dê conta desse fato. A transparência de migração permite que objetos de informação migrem dentro do sistema sem a intervenção do usuário. $O$ aspecto de transparência de concorrência permite que processos tenham acesso a objetos de informação de maneira compartilhada, sem que, no entanto, a ação de um se reflita de maneira maléfica na execução dos outros. Por fim, a transparência de paralelismo permite a ocorrência de eventos de maneira paralela (paralelismo físico).

A adoção de todas as características chave dos sistemas distribuídos nem sempre se processa de maneira pouco traumática. Alguns aspectos devem sempre ser levados em consideração, quando se pretende realizar um projeto de um. sistema distribuído que seja elaborado a contento. Um dos aspectos de projeto mais suscetíveis à negligência e mais perceptíveis pelos usuários está relacionado ao desempenho do sistema. 


\subsection{O Desempenho em Sistemas Distribuídos}

A implementação de características como a transparência ou tolerância a falhas pode demandar um preço elevado. A efetivação dessas características, muitas vezes, dá-se em detrimento do desempenho do sistema. Seria considerado intolerável o fato de uma determinada aplicação comportar-se, em um sistema distribuído, de maneira pior do que se rodasse em um único processador (Tanenbaum, 95). Assim, considera-se como um aspecto fundamental para os projetos de sistemas distribuídos o seu desempenho.

Alguns fatores influenciam de maneira direta o desempenho de um sistema distribuído. Um primeiro fator relevante a ser considerado é a comunicação, que não se faz presente nos sistemas com um único processador. O tratamento do protocolo, tanto no transmissor quanto no receptor de uma mensagem, consome grande parte do tempo de tráfego de uma mensagem. O problema da comunicação cria um dilema: diminuir-se o fluxo de mensagens pela rede e, conseqüentemente, diminuir-se também o número de aplicaçōes executando em paralelo em diferentes processadores, ou vice-versa.

Outro fator que exerce influência na performance dos sistemas distribuídos está relacionado com a granularidade do processamento que irá ser executado remotamente, ou seja, o overhead introduzido pela comunicação pode inviabilizar qualquer outra vantagem advinda de tal processamento (Tanenbaum, 95). Em suma, em princípio, o processamento de aplicações que possuam um paralelismo de granularidade grossa produz melhores resultados em sistemas computacionais distribuídos.

Deve-se, ainda, levar em consideração que uma das premissas dos sistemas distribuídos, a tolerância a falhas, pode ser naturalmente um elemento degenerador do desempenho. Tolerância a falhas, muitas vezes, implica na utilização de vários servidores que cooperam para a solução de uma requisição. A troca de mensagens entre esses servidores normalmente custa tempo e absorve parte da capacidade da rede (Tanenbaum, 95).

Porém, apesar de toda dificuldade que ronda a manutenção ou às vezes a melhoria do desempenho dos sistemas distribuídos, o aspecto desempenho năo pode ser relegado. $O$ fato do desempenho refletir de maneira direta no usuário, torna o seu estudo imprescindível num projeto que não deseje estar fadado ao insucesso. A avaliação de desempenho dos sistemas distribuídos, assim como as técnicas destinadas à realização dessa análise, são objeto de estudo deste trabalho.

\subsection{Considerações Finais}

Nos últimos anos, os sistemas distribuídos despontaram como uma solução alternativa bastante atrativa aos sistemas centralizados. Grande parte desse crédito pode ser atribuída ao grande avanço de componentes de hardware (microprocessadores e rede de interconexão).

Entretanto, enquanto o hardware experimentou uma evolução sem precedentes, o progresso em relação ao software foi menos acelerado. O software, hoje, constitui-se no grande desafio às pesquisas relativas aos sistemas computacionais distribuídos. Ainda há incompatibilidades entre as características chave que um sistema distribuído deve proporcionar $\mathrm{e}$ a efetivação delas na prática.

Apesar de já haver experiências em estágio avançado, com o intuito de possibilitar a existência de um sistema distribuído em sua plenitude, essas pesquisas são restritas à utilização de hardware e software que são, de certa forma, peculiares e específicos a determinadas situações. Um exemplo da dificuldade de aplicacação generalizada desses software é o sistema 
distribuído Amoeba (Tanenbaum, 95). O Amoeba provê todos os aspectos de projetos vistos neste capítulo; entretanto, isso ocorre somente graças à utilização de hardware e software bastante específicos (como banco de processadores, grandes quantidades de memória disponíveis, protocolo de comunicação específico, balanceamento de carga automático), que não podem ser considerados como regra nos ambientes computacionais atuais. 


\section{Capítulo 3}

\section{Avaliação de Desempenho}

\subsection{Considerações Iniciais}

Quando se pretende avaliar o desempenho de um sistema computacional, certamente surgem questões delicadas relativas à metodologia que deve ser empregada para a realização dessa análise. A escolha da metodologia poderá ser um dos fatores determinantes do êxito ou do fracasso da análise pretendida, apesar de, num primeiro momento, a fronteira que delimita a escolha de uma das metodologias parecer um tanto quanto tênue. Então, torna-se fundamental observar algumas peculiaridades do sistema a ser analisado. O primeiro grande desafio de uma análise é o pleno e prévio conhecimento do sistema que se deseja estudar (Soares, 92). Apesar de parecer óbvia, essa peculiaridade, quando negligenciada, pode condenar uma avaliação ao insucesso.

Assim, conhecer o sistema a ser analisado implica em poder delimitar a sua complexidade, isto é, poder inferir a respeito de quão complexo é o conjunto de informações que o sistema deve manipular. É imprescindível, ainda, levar-se em consideração qual é o objetivo basilar da análise. Por exemplo, se a análise pretende estudar um sistema ainda inexistente, devese adotar uma metodologia que suporte essa restrição.

Este capítulo aborda as principais técnicas de avaliação de desempenho. Podem-se agrupar as técnicas de avaliação de desempenho de sistemas em duas grandes classes: as Técnicas de Aferição e de Modelagem. As subdivisões, características e aplicaçăo preferencial de cada uma das técnicas são apresentadas a seguir. Entretanto, pela importância de determinadas técnicas (principalmente dos métodos de modelagem), algumas delas voltarão a ser discutidas em capítulos subseqüentes, de maneira mais detalhada.

\subsection{Técnicas de Aferição}

Há situações em que, ou já existe um sistema computacional, ou ele se encontra em fase final de desenvolvimento. Assim, através da experimentação do mesmo, pode-se deduzir a respeito de seu desempenho. Esse fato é bastante comum: a realização de uma avaliação em um ambiente computacional já estabelecido. Essa experimentação realizada sobre o sistema pode ser efetivada através de hardware ou de software.

Como é de regra, as técnicas de aferição não são incontestes e apresentam vantagens e desvantagens em relação à modelagem. Os métodos de aferição oferecem resultados mais precisos (quando confrontados com aqueles obtidos através da modelagem), desde que a própria experimentação não influencie no comportamento do sistema $e$, consequientemente, nos resultados obtidos. Uma grande dificuldade de utilizar essa abordagem reside no fato de necessitar-se efetivamente de um sistema existente disponível. Mesmo diante da disponibilidade de um sistema, ainda haverá o esforço de realizar a experimentação sem afetar o funcionamento natural do sistema.

Algumas das principais técnicas de aferição são (Orlandi, 95): os protótipos, os benchmarks e a coleta de dados. 


\subsubsection{Protótipos}

A prototipação representa uma simplificação de um sistema computacional, mantendo, contudo, a mesma funcionalidade. Os protótipos desprezam as características consideradas irrelevantes ao sistema. Assim, apenas as características essenciais do sistema serão representadas. O protótipo pode ser considerado um meio termo entre o sistema final e as expectativas que se tem dele, quando ele ainda não existe. Essa técnica possui um custo menor do que a construção do sistema real, contudo esse valor não pode ser considerado desprezível. Além do custo relativamente elevado (em relação às demais técnicas de aferição), existe uma outra dificuldade ao se construir um protótipo: determinar quais características são essenciais ao sistema.

Boar (Boar, 84) define uma série de seis passos, que devem ser levados em consideração, quando se deseja efetivar a prototipação de um software. Apesar de terem sidos formulados especificamente para software, os passos foram naturalmente estendidos para um sistema computacional qualquer:

Passo 1. Deve-se avaliar se o sistema é um bom candidato à prototipação.

Passo 2.0 desenvolvedor do protótipo deve delimitar e conhecer perfeitamente os domínios funcionais e comportamentais do sistema.

Passo 3. O protótipo é desenvolvido.

Passo 4. O protótipo é testado e aprimorado.

Passo 5. Após o passo 4, o protótipo já provê uma idéia do sistema real. Nesse instante, o desenvolvedor pode inferir sobre as características fundamentais do sistema e, se for o caso, fazer modificações no protótipo.

Passo 6.Os passos 4 e 5 são repetidos iterativamente até que se tenha toda a funcionalidade do sistema representada no protótipo.

\subsubsection{Benchmarks}

Benchmarks são padrões de desempenho, ou seja, programas usados para testar o desempenho de software ou hardware ou um sistema computacional (Collin, 93). A mesma tarefa (ou programa) é submetida a diferentes sistemas (ou subsistemas), e seus resultados são comparados entre si. Programas de ordenação e de atualização de arquivos são exemplos típicos de benchmarks (Tanenbaum, 95).

Benchmarks utilizam freqüentemente, para mensurar sistemas computacionais, tanto tarefas mais gerais (como por exemplo, realização de $\mathrm{I} / \mathrm{O}$ ), quanto tarefas específicas (como representação de polígonos ou operações sobre matrizes) (Price, 89). Em suma, qualquer aspecto de desempenho de um sistema computacional que importe aos usuários pode ser objeto de medição através de benchmarks.

Para se executar um benchmark, deve-se ter conhecimento exato da configuração de alguns elementos chave do sistema. Os principais elementos que devem ser plenamente conhecidos são: processador (modelo, velocidade, cache, etc.), memória, versões de software 
(sistemas operacionais, compiladores e outras aplicações relevantes), estado do sistema (monousuário, multiusuário, etc.) e periféricos (Weicker, 90).

Todavia, alguns cuidados devem ser observados em relação à utilização dos benchmarks. Deve-se, por exemplo, analisar se a própria execução do benchmark não influenciará nos resultados obtidos. Outra dificuldade reside na escolha da unidade usada como referência para realização da comparação. Por exemplo, benchmarks utilizados para efetuar comparaçōes entre processadores algumas vezes utilizam unidades como MIPS (Millions of Instructions Per Second) ou FLOPS (FLoating Point Operations Per Second). Essas unidades geram bastante controvérsia, pois fornecem valores perigosamente absolutos, mesmo diante de fatores distintos (como arquiteturas RISC e CISC), que podem influenciar sobremaneira os resultados. A tabela 3.1 (Price, 89) apresenta um quadro com três benchmarks e suas principais características.

\begin{tabular}{|c|c|l|}
\hline Benchmarks & Finalidade & \multicolumn{1}{c|}{ Peculiaridades } \\
\hline Bonnie & $\begin{array}{c}\text { Aplicações de I/O } \\
\text { intensivas }\end{array}$ & $\begin{array}{l}\text { Desenvolve uma série de testes em um arquivo de tamanho } \\
\text { conhecido; } \\
\text { Utilizado no projeto do novo dicionário de inglês Oxford, } \\
\text { na Universidade de Waterloo. }\end{array}$ \\
\hline Stanford & $\begin{array}{c}\text { Comparação entre } \\
\text { arquiteturas RISC } \\
\text { e CISC }\end{array}$ & $\begin{array}{l}\text { Desenvolvido pela Universidade de Stanford, em 1988; } \\
\text { Dois módulos: um de aplicações de inteiros e outro de } \\
\text { aplicações de ponto flutuante; } \\
\text { Linguagem de implementação: C. }\end{array}$ \\
\hline TTCP & $\begin{array}{c}\text { TCPempenho de UDP entre } \\
\text { dois sistemas }\end{array}$ & $\begin{array}{l}\text { Criado no US Army Ballistics Research Lab (BRL); } \\
\text { Desenvolvido em Cray; } \\
\text { Mede tempos de transmissão e recepção de dados entre } \\
\text { dois sistemas usando protocolos UDP ou TCP; } \\
\text { Domínio Público. }\end{array}$ \\
\hline
\end{tabular}

Tabela 3.1. Três Benchmarks e Algumas de suas Características.

\subsubsection{Coleta de Dados}

As técnicas de aferição são os métodos que fornecem os resultados mais precisos. Dentre as técnicas de aferição, a mais precisa de todas é a coleta de dados (Oriandi, 95), ou seja, a coleta de dados é a mais precisa de todas as técnicas, quando o objetivo for tão somente o de avaliação de desempenho através da obtenção direta dos dados no sistema computacional.

Entretanto, nem sempre uma coleta de dados em um sistema é uma tarefa trivial. Uma coleta sem certas precauções pode interferir na produção dos resuitados, tornando-os imprecisos.

Uma outra utilizaçăo bastante interessante pode ser dada à coleta de dados. Pode-se usar a coleta de dados de um sistema existente com o objetivo de comparar os valores obtidos com os valores fornecidos por um modelo do mesmo sistema. Esse procedimento viabiliza a possibilidade de validação do modelo, através de uma comparação da realidade com o sistema que foi modelado.

A técnica de coleta de dados pode ser realizada através de dois recursos: os monitores de hardware e os monitores de software.

Monitores de hardware são hardware específicos empregados para coletar e analisar alguns dados pertinentes ao objeto em estudo (Orlandi, 95). Os monitores de hardware devem ser utilizados nos sistemas cujo número de sinais capturados por esse dispositivo, não excedam a sua 
capacidade de gerenciamento. Monitores de hardware devem ser também não intrusivos (Trindade \& Zaluska, 94), isto é, esses dispositivos devem se limitar a obter os sinais sem alterálos, mantendo fidelidade aos valores originais.

Monitores de software são usados nos casos em que se deseja observar características específicas de software, como por exemplo a verificação da existência ou inexistência de uma fila de espera, associada a um recurso do sistema. Essas características muito peculiares ao software não poderiam ser detectadas por monitores de hardware. Informações obtidas pelos monitores de software podem ser muito úteis, por exemplo, para estudos de como algumas características dos sistemas operacionais podem influenciar o desempenho de um sistema (políticas de escalonamento de CPU, de alocação de memória, entre outros.).

A figura 3.1 (Orlandi, 95) mostra as utilizações preferencial e secundária de cada uma das técnicas de aferição; ressalvando-se, contudo, que a utilização preferencial não implica em obrigatoriedade de utilização.

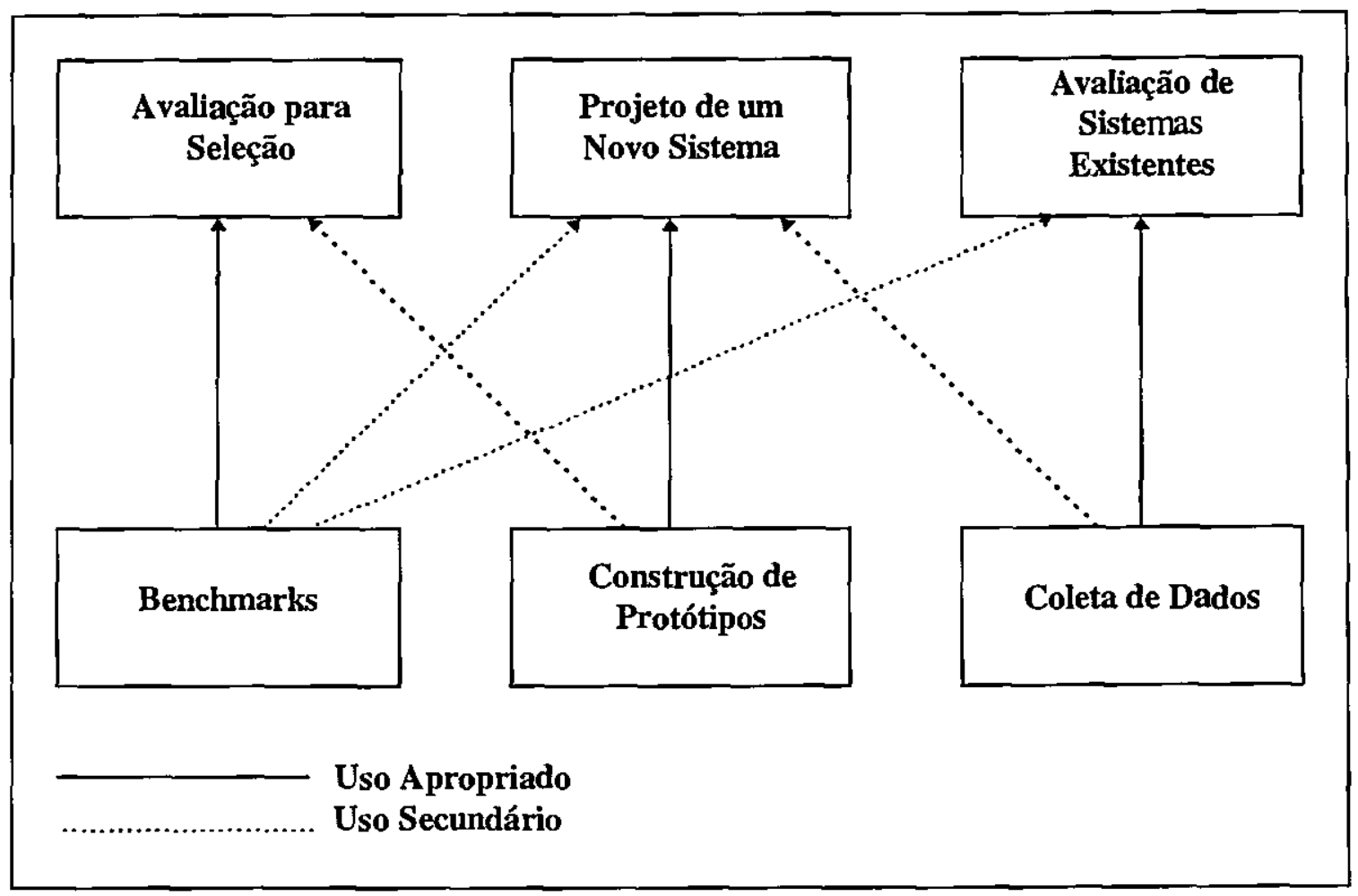

Figura 3.1. Relação entre Propostas de Avaliação e Técnicas de Aferição.

\subsection{Modelagem}

As indústrias, centros de pesquisas, órgãos públicos, enfim, as instituições de um modo geral, não estão particularmente interessadas em realizar experiências em seus sistemas computacionais. Um bom alvitre é ter-se uma idéia prévia do que o sistema poderá proporcionar. Atualmente, é de suma importância que seja possível "antever" as características de um sistema computacional, antes mesmo que ele exista. Para situaçōes em que se deseja testar um sistema ainda inexistente, possibilitando tecer-se várias considerações a seu respeito, é que se propõe a modelagem. 
Um modelo nada mais é do que uma descrição de um determinado sistema, tendo-se a preocupação de abstrair as características relevantes do sistema real (Soares, 92). Os modelos devem sofrer alterações no decorrer do tempo, pois as variáveis de estado de um sistema, via de regra, são dependentes do tempo. Assim, podem-se classificar os modelos quanto ao comportamento de suas variáveis de estado em relação ao tempo. Essas variáveis podem comportar-se de duas maneiras: discreta ou continuamente. As mudanças de comportamento de um modelo serão elucidadas com maiores detalhes no capítulo 4.

A representação de um determinado sistema em forma de um modelo é, efetivamente, a realização da modelagem desse sistema. Existem várias técnicas para modelar um sistema computacional. Nesta dissertação, são enfocadas apenas três dessas técnicas: redes de filas, redes de Petri e statecharts. A seguir, essas técnicas são apresentadas de maneira concisa, objetivando tão somente uma introdução ao assunto. No capítulo posterior, porém, elas serão apresentadas com maior riqueza de detalhes.

\subsubsection{Redes de Filas}

Em computação, há várias situações em que usuários concorrem pela utilização de um determinado recurso do sistema computacional. Essa situação ocasiona o surgimento de filas de clientes que requisitam um determinado serviço. Para modelar sistemas nos quais a ocorrência de filas é um fenômeno inevitável, foi criada uma técnica baseada na teoria de filas (Kleinrock, 75) (um ramo das probabilidades) denominada rede de filas.

Uma rede de filas consiste em entidades que oferecem serviços, denominadas centros de serviços e de entidades chamadas usuários (clientes), que recebem serviços nesses centros (Soares, 92). Um centro de serviço pode ser constituído por um ou mais servidores, os quais correspondem a recursos no sistema modelado, e uma área de espera (fila) para aqueles usuários que estão requisitando o serviço. Com o intuito de exemplificação, uma situação muito cotidiana em sistemas computacionais é a existência de vários processos disputando um processador. A figura 3.2 representa de maneira pictórica um centro de serviço que ilustra essa situação.

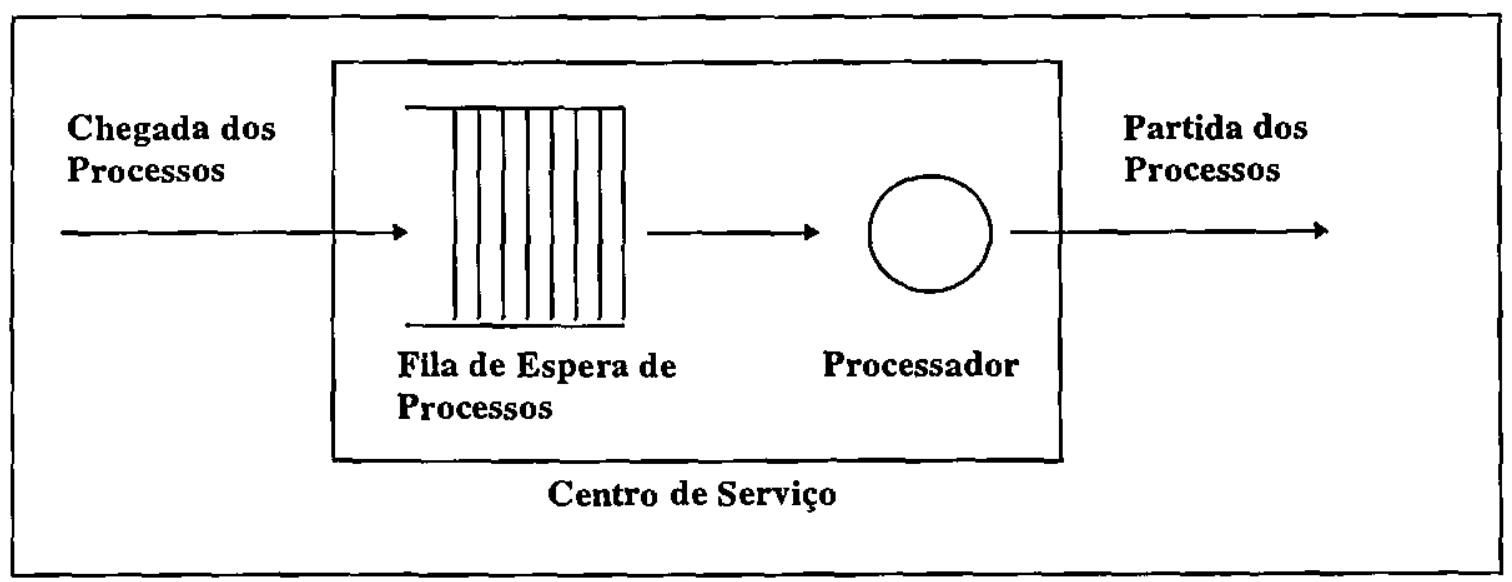

Figura 3.2. Rede de Filas Mlustrando Processos Competindo pelo Processador.

\subsubsection{Redes de Petri}

Rede de Petri, numa definição informal, é uma técnica de especificação de sistemas que possibilita uma representação matemática e possui mecanismos de análise poderosos, que 
permitem a verificação de propriedades e a verificação da correção do sistema especificado (Maciel et. al., 96). Essa técnica de modelagem possui a particularidade de permitir modelar sistemas paralelos, concorrentes, assíncronos e não-determiníticos (Valette \& Courvoisier, 80), o que é absolutamente conveniente e desejável na modelagem dos sistemas atuais.

A representação gráfica de uma rede de Petri básica, ilustrando a mesma situação anteriormente modelada através de redes de filas, é mostrada na figura 3.3. O gráfico possui dois componentes fundamentais: um ativo (transição) representado pelas barras e outro passivo (lugar) representado pelos círculos. Os lugares equivalem às variáveis de estado e as transições correspondem às ações realizadas pelo sistema (Maciel et. al., 96).

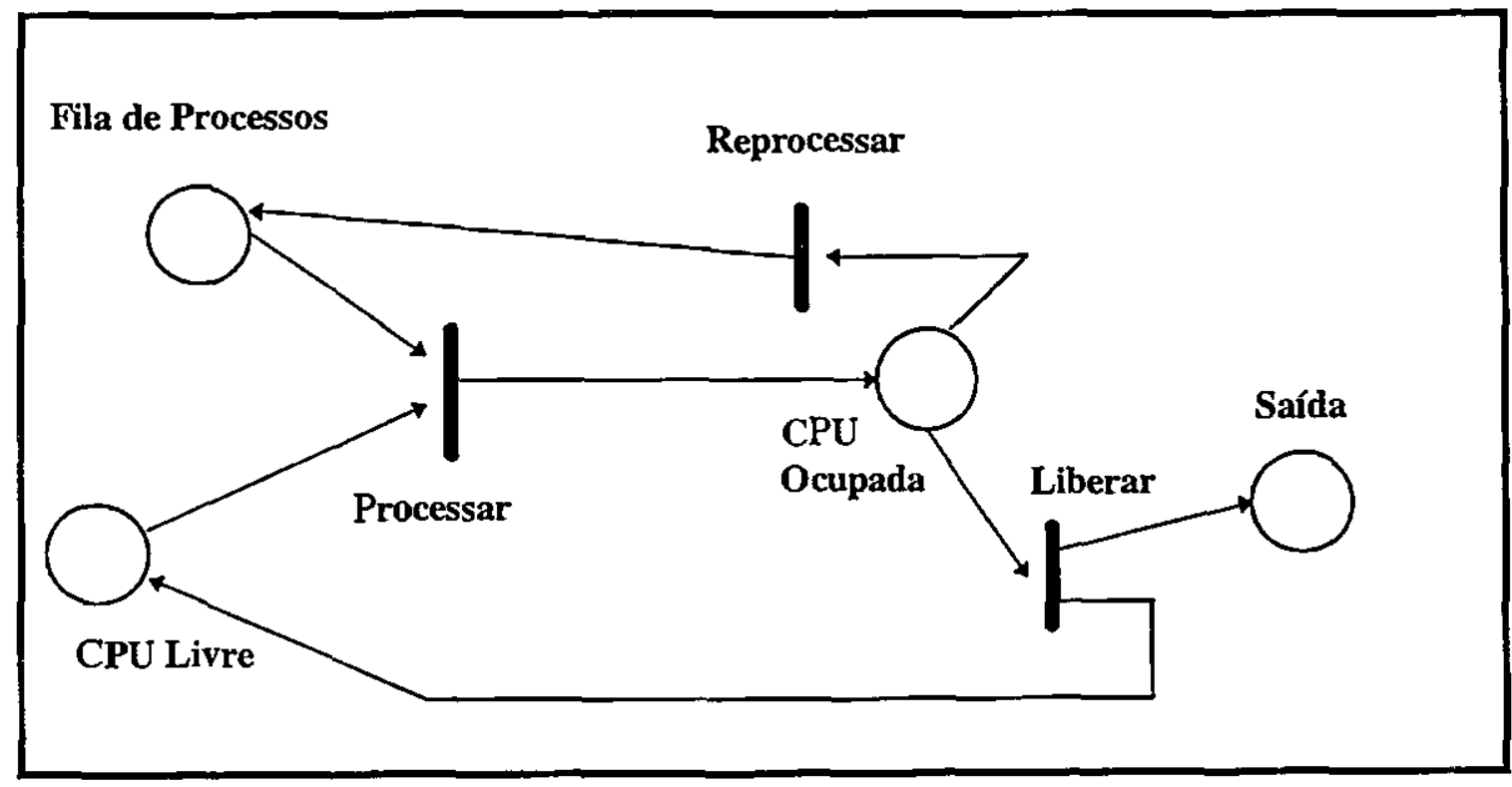

Figura 3.3. Uma Rede de Petri Ilustrando Processos Competindo pelo Processador.

Alguns detalhes fundamentais ao entendimento do modelo foram omitidos propositadamente no exemplo acima. Por exemplo, qual o arco que deve ser percorrido após o sistema passar pelo lugar "CPU Ocupada"? Conflitos desse tipo são solucionados através de algumas extensões elaboradas posteriormente às redes de Petri originais. Algumas dessas extensões serão objeto de estudo deste trabalho.

\subsubsection{Statecharts}

A técnica statecharts é uma extensão às máquinas de estado finito, que possibilita a representação de hierarquia, concorrência e comunicação entre os diversos estados de um determinado sistema (Harel, 87). Os statecharts têm, preferencialmente, a finalidade de especificar sistemas reativos, ou seja, sistemas que devem reagir a estímulos externos e internos, normalmente sob condiçôes críticas em relação ao tempo.

A idéia central do statechart é suprir a deficiência dos diagramas de estado em representar sistemas complexos. Sistemas complexos requerem uma estrutura de representação hierárquica (com agrupamento e refinamento de estados) e de concorrência, de maneira que seja facilmente visível o movimento através dos estados do sistema no decorrer do tempo. A figura 3.4 apresenta o exemplo anteriormente expresso em redes de filas e de Petri, agora ilustrado em statecharts. 


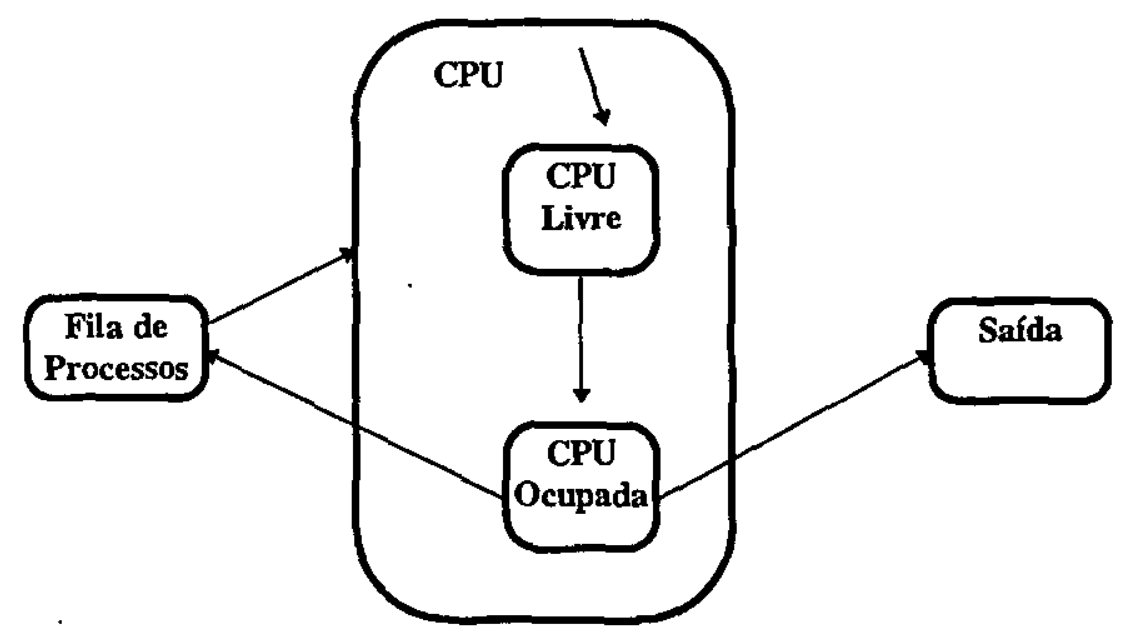

Figura 3.4. Processos Competindo por um Processador (statecharts).

Assim como as outras técnicas de modelagem, os statecharts também foram estendidos com o intuito de possibilitar mais flexibilidade à técnica. Os statecharts temporais (timed statecharts, seção 4.4.4 (Pnuelli \& Kensten, 92)) são um exemplo de extensão para representação específica de sistemas de tempo real, os quais necessitam de delimitações rígidas de limites máximos e mínimos de tempo para disparo de transições.

\subsection{Soluções para o Modelo}

Após proceder-se à escolha da técnica utilizada para a representação do modelo, deve-se decidir qual a resolução a ser dada ao modelo. Existem, basicamente, duas técnicas de solução disponíveis: a analítica e a simulação. As duas técnicas têm suas vantagens e desvantagens, que normalmente são os fatores determinantes na escolha de uma das duas.

\subsubsection{A Solução Analítica}

Kleinrock (Kleinrock, 76) afirma que o método analítico é geralmente mais rápido e, por isso, o preferido; porém, nem sempre ele é aplicável. Uma solução analítica nem sempre é aplicável em virtude de, geralmente, ser necessário fazer um certo número de simplificações para poder-se resolver o modelo. Deve-se entender por simplificações algumas restrições impostas pela solução analítica, que geralmente não correspondem às situações verificadas nos sistemas reais. Apesar de ser um método que propicie resultados expressivamente exatos, as simplificações introduzidas podem fazer com que o modelo não seja uma representação fiel do sistema real (Soares, 92), fato que pode simplesmente tornar sem sentido a utilização do modelo.

Para exemplificar a dificuldade imposta por certas restrições, na solução analítica de modelos baseados em redes de filas não se pode estabelecer prioridades para as disciplinas de filas (Soares, 92), ou seja, todos os usuários de um determinado recurso possuem a mesma prioridade, o que inviabilizaria, por exemplo, a representação do esquema de prioridades do 
sistema UNIX. Ainda há várias outras várias restrições impostas à solução analítica do modelo de filas. A posse simultânea de recursos, não permitida, e a capacidade infinita das filas são alguns exemplos das várias restrições, que em sua maioria são violadas em sistemas reais.

Nas situações em que várias simplificaçōes (restrições) comprometem a exatidão dos resultados do modelo, pode ser mais conveniente adotar-se a solução por simulação.

\subsubsection{Solução por Simulação}

A possibilidade de poder prever certos fenômenos sempre foi uma ambição do ser humano. Porém, ter-se a possibilidade de simular o comportamento de um objeto (ou um sistema de objetos) transcende a fronteira do fascínio e, de forma cada vez mais constante, torna-se uma necessidade. Se o modelo proposto para o sistema envolve uma grande gama de informações e/ou exige que se faça algumas das simplificações vistas na seção anterior, o modelador pode optar por resolver o modelo através de simulação.

Em computação, a simulação refere-se ao emprego de um processo computacional para implementar um modelo de algum fenômeno ou sistema dinâmico (sistemas cujos estados se alteram com o tempo) (Orlandi, 95).

A simulação tem sido muito aceita e empregada por alguns fatores que lhe são, de certa maneira, favoráveis (por exemplo, flexibilidade, facilidade de utilização e custo relativamente baixo). As utilizações da simulação são as mais diversas possíveis. Entre as principais utilizações, destacam-se as aplicações médicas, engenharia aeronáutica, engenharia de transportes, engenharia nuclear, etc. Dentre as aplicações da simulação na área da computação, o interesse capital deste trabalho está na análise de desempenho dos sistemas computacionais distribuídos.

A figura 3.5. apresenta o inter-relacionamento entre as duas soluções de um modelo, assim como as variantes que determinam quando, preferencialmente, utilizar uma solução em detrimento da outra.

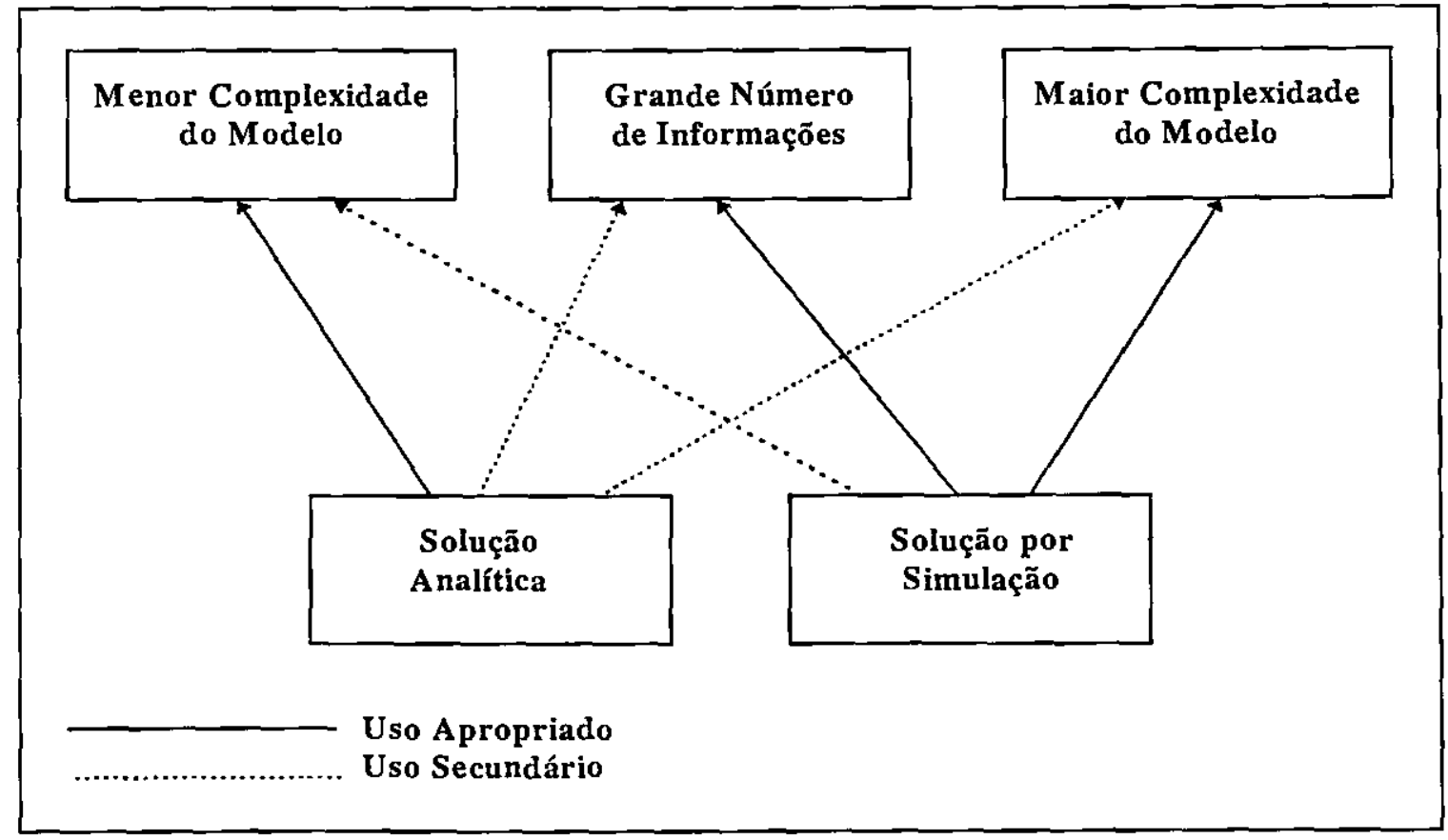

Figura 3.5. Solução Preferencial para um Modelo. 


\subsection{Considerações Finais}

Este capítulo propôs uma discussão introdutória às técnicas para avaliação de desempenho em sistemas computacionais. Em alguns momentos, não se aprofundou em determinados detalhes de algumas técnicas.

A escolha de uma das técnicas dentre as disponíveis para a análise de um sistema computacional (distribuído ou centralizado) está diretamente relacionada ao estado de desenvolvimento do sistema que se deseja avaliar. Como foi exposto, as técnicas de aferição são bastante satisfatórias para sistemas já existentes ou em fase final de implementação. Porém, exceto os sistema que já existem, é pouco provável que, no atual estado da arte dos ambientes computacionais, o modelador corra o risco de desenvolver um sistema para depois analisá-lo. Nesse caso específico, são preferíveis técnicas de modelagem às de aferição.

Ainda há outro aspecto a ser considerado após a escolha da técnica de modelagem: a solução do modelo (se analítica ou por simulação). Apesar da decisão ficar a critério do modelador, há algumas premissas que devem ser levadas em consideração e, que, em certos casos, podem inviabilizar a utilização de uma das soluções. A principal premissa é relativa ao grau de complexidade do modelo a ser resolvido, isto é, para modelos menos complexos é mais recomendável a utilização de soluções analíticas, pois são situações que, normalmente, podem admitir alguns tipos de restrições. Para modelos mais complexos, é mais recomendável a utilização de simulação. Ainda pode-se levar em consideração a quantidade de informaçóes que deseja-se que o modelo manipule. Para um número menos significativo de informações, é mais apropriada a solução analítica. Para modelos que manipulem uma gama maior de informações, é mais recomendável o uso de simulação.

A análise de desempenho está em franco desenvolvimento e tende a se tornar uma prática recomendável em todos os sistemas distribuídos futuros, fato que pode contribuir para o maior desenvolvimento desses sistemas. 


\section{Capítulo 4}

\section{Modelagem}

\subsection{Considerações Iniciais}

Quando se pretende analisar o desempenho de um sistema computacional, pode-se enveredar por vários caminhos. Um dos caminhos possíveis é seguir a intuição do analisador. Porém, para esse método ser considerado seguro, pressupõe-se que o analisador possua uma vasta experiência e que ela sirva de alicerce para a avaliação. $O$ grande problema desse caminho reside no fato de ser muito difícil encontrar uma pessoa que possua um alto grau de experiệncia, a ponto de poder ser guiada pela intuição.

No outro extremo se encontra o caminho da avaliação através da experimentação (como as técnicas de aferição, vistas no capítulo anterior), que oferece resultados precisos, mas também vários fatores limitantes. Experimentação, via de regra, é mais laboriosa e menos flexível que os outros métodos de análise.

Entre esses dois caminhos extremos, há um terceiro método: a modelagem (Lazowska et. al., 84). Este capítulo aborda as três técnicas de modelagem vistas no capítulo 3, enfocadas, aqui, de maneira mais abrangente.

\subsection{Redes de Filas}

A teoria de filas é um ramo da probabilidade que estuda o fenômeno da formação de filas de solicitantes de serviços, que são providos por um determinado recurso. Há vários sistemas que são propícios à formação de filas (por exemplo, o sistema bancário). Um sistema computacional naturalmente também é um exemplo típico desses sistemas, pois, normalmente, há mais requisitantes do que prestadores de serviços.

Um sistema real (computacional ou não), contudo, geralmente possui mais de um recurso propício à formação de filas (Kleinrock, 75). Denomina-se rede um conjunto desses recursos interconectados de alguma forma. Por sua vez, uma fila é uma linha de espera pela utilização de um determinado recurso. Assim, um modelo de redes de filas é uma representação em alto nível dos recursos de um dado sistema (Soares, 92).

Pode-se concluir, então, que modelagem de rede de filas em computação, constitui-se em um método particular de utilização da teoria de filas, onde se associa um sistema computacional a uma rede de filas, para então poder avaliá-lo (Lazowska et. al., 84).

\subsubsection{Definição e Terminologia}

Uma rede de filas é uma coleção de centros de serviço, os quais representam recursos do sistema, e clientes que representam usuários ou transaçőes dispostos em áreas de espera (filas), os quais, de alguma forma, solicitam a prestação de um serviço a um determinado servidor, dentro dos centros(Soares, 92)(Lazowska et. al., 84). 
Centros de serviço são entidades prestadoras de serviços aos clientes solicitantes. Esses centros podem possuir servidores únicos ou múltiplos, dependendo do número de recursos disponíveis no modelo. A figura 4.1 ilustra possibilidades de representação de redes de filas com um ou mais servidores.

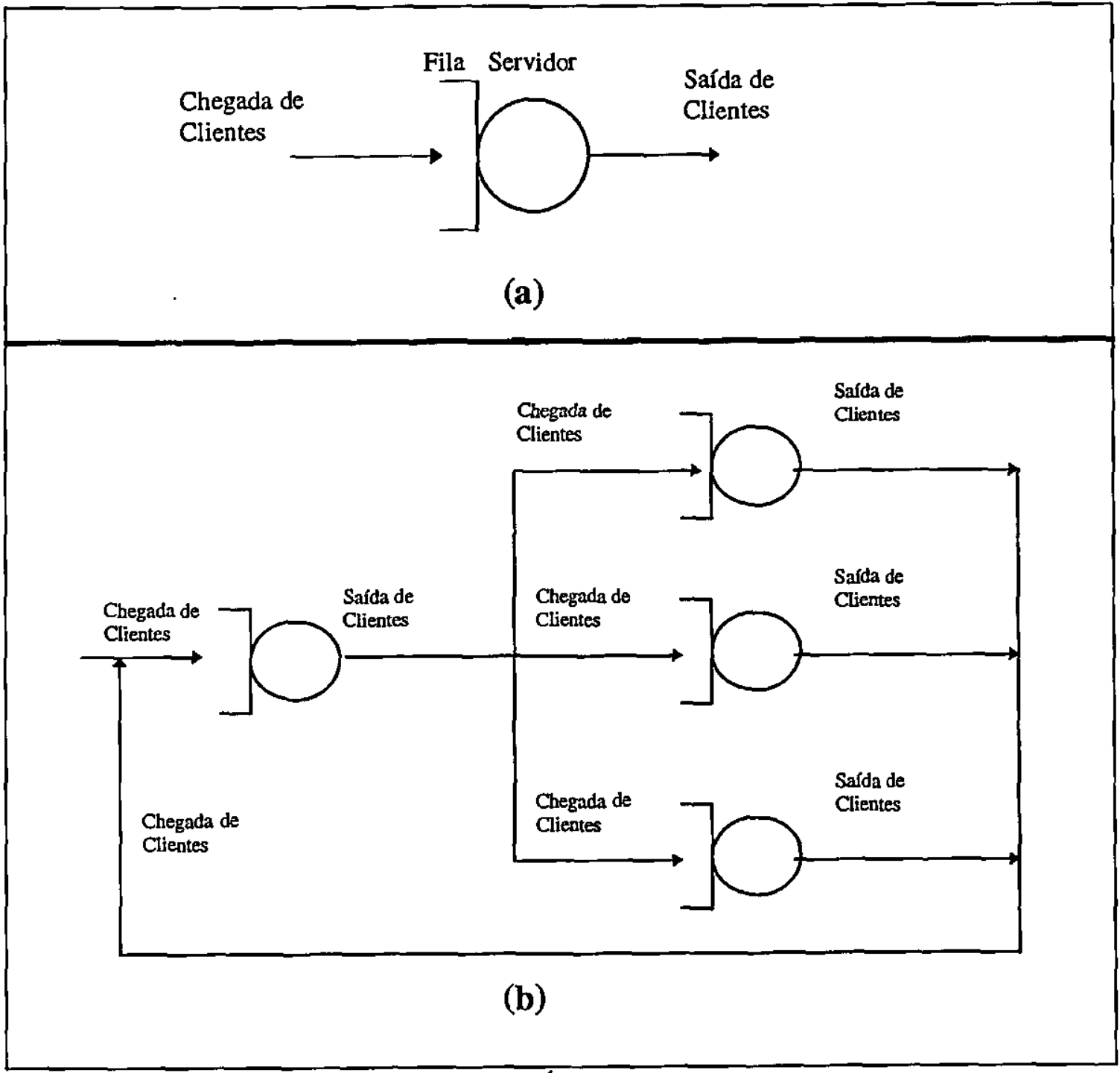

Figura 4.1. (a) Um centro de Serviço com um Único Servidor e

(b) Redes de Filas com Múltiplos Servidores.

\subsubsection{Notação para Sistemas de Filas}

A notação de um sistema de filas é baseada em seis parâmetros: a distribuição dos tempos entre chegadas (A), a distribuição do tempo de serviço (B), o número de servidores (c), a capacidade do sistema (K), o número de clientes na fonte $(\mathrm{m})$ e a disciplina de fila (Z) (Kleinrock, 76)(Newwell, 82). A associação de tais parâmetros origina a notação $\mathrm{A} / \mathrm{B} / \mathrm{c} / \mathrm{K} / \mathrm{m} / \mathrm{Z}$. Os símbolos (e seus significados) usados para A e B são:

G distribuição de tempo entre chegadas geral ou tempo de serviço geral;

H distribuição de tempo de serviço ou de tempo entre chegadas hiperexponencial; 
E distribuição de tempo de serviço ou de tempo entre chegadas Erlang;

M distribuição de tempo de serviço ou de tempo entre chegadas exponencial;

D distribuição de tempo de serviço ou de tempo entre chegadas determinístico.

Uma simplificação da notação $\mathrm{A} / \mathrm{B} / \mathrm{c} / \mathrm{K} / \mathrm{m} / \mathrm{Z}$ usualmente empregada é a notação $\mathrm{A} / \mathrm{B} / \mathrm{c}$, onde admite-se que não existe limite para o tamanho da fila, a fonte de clientes é infinita, e a disciplina da fila é FCFS (First Come - First Served, primeiro a chegar, primeiro a ser servido) (Orlandi, 95). Assim, um sistema de fila M/M/1 é aquele caracterizado por apresentar taxas de chegadas entre clientes e tempo de serviço obedecendo à distribuição exponencial e possuindo um único servidor (Kleinrock, 76). A notação $\mathrm{G}$ denota a utilização de distribuiçōes arbitrárias (Kleinrock, 76), que, por exemplo, pode não ser nenhuma das distribuições já citadas ou um conjunto delas.

Pelo fato dos elementos representativos de um sistema de fila sempre obedecerem a uma forma de distribuição de probabilidade, as principais distribuições são discutidas a seguir.

\subsubsection{Distribuições de Probabilidade}

Nesta seção são apresentadas algumas das principais distribuições de probabilidade (contínua e discreta). Objetivando tão somente fornecer subsídios aos interesses deste trabalho, são apresentadas as seguintes distribuições: Uniforme, Exponencial, Hiperexponencial, de Erlang e de Poisson. As distribuições são discutidas de maneira abreviada (para obtenção de maiores detalhes, consultar (Farias et. al., 91)).

- Distribuição Uniforme: é a distribuição contínua que especifica que valores compreendidos entre um máximo e um mínimo são equiprováveis (Soares, 92). O uso dessa distribuição geralmente se processa quando há um total desconhecimento da variável aleatórial, conhecendo-se apenas seus limites.

- Distribuição Exponencial: é a distribuição cuja probabilidade de acontecer um evento em um pequeno intervalo de tempo é proporcional ao tamanho desse intervalo. Se a probabilidade de ocorrência de mais de um evento nesse intervalo é nula e se a probabilidade de ocorrência de um evento é independente da ocorrência de outros, então o intervalo entre ocorrências possui uma distribuição exponencial (Farias et. al., 91). Essa distribuição possui algumas características interessantes à modelagem (principalmente quando se utiliza a solução analítica). Uma característica que interessa à resolução analítica é o fácil tratamento matemático dessa distribuição, sendo por isso, muitas vezes assumida em vários estudos (Soares, 92). A distribuição exponencial possui uma variância elevada, ou seja, admite uma grande disparidade entre valores, fato que é interessante em um estudo de filas. Outra propriedade interessante dessa distribuição é denominada memoryless (Allen, 90), isto é, o

'É uma regra de associação de um valor numérico a cada ponto de um espaço amostral. Por exemplo, em um lançamento de duas moedas $(\mathrm{k}=$ cara e $\mathrm{C}=$ coroa $)$, o espaço amostral é $\mathrm{E}=\{\mathrm{KK}, \mathrm{KC}, \mathrm{CK}, \mathrm{CC}\}$ e $\mathrm{KK}$ pode ser associada à variável aleatória de valor 2 (Farias et. al, 91). 
tempo de serviço (provido por um servidor) destinado a um cliente independe do tempo de serviço gasto com os clientes anteriores.

- Distribuição Hiperexponencial: é um caso particular de distribuição exponencial que admite uma variância muito grande em relação à média (Allen, 90). Essa distribuição pode ser utilizada para descrever o tempo de serviço que um servidor dispensa a um cliente, pois os tempos de atendimento podem ser muito discrepantes em relação às suas média.

- Distribuição de Erlang: é a distribuição derivada da soma de um número inteiro de variáveis aleatórias independentes e exponencialmente distribuídas. Essa distribuição é utilizada em teoria de filas, quando uma atividade ou tempo de serviço ocorre em fases, com cada fase sendo exponencialmente distribuída (Soares, 92).

- Distribuição de Poisson: é a distribuição discreta que estabelece que se a duração do intervalo de tempo entre chegadas é exponencialmente distribuído e se as chegadas ocorrem uma de cada vez, então o número de chegadas em um intervalo fixo qualquer possui uma distribuição de Poisson (Soares, 92). As chegadas de clientes em uma fila geralmente se dão de maneira discreta (e não contínua), por esse motivo, a distribuição de Poisson é bastante representativa às chegadas de clientes a um sistema de filas.

As distribuições de probabilidades representam o padrão em que os clientes chegam a um centro de serviço e também o padrão de tempo de serviço destinado a cada cliente. Entretanto, elas não definem qual a ordem de atendimento dos clientes. Essa ordem é estabelecida através de algoritmos de escalonamento denominados disciplina de filas (Kleinrock, 75)(Kleinrock, 76)(Soares, 92). Os principais escalonamentos são discutidos a seguir.

\subsubsection{Disciplinas de Atendimento aos Clientes}

A disciplina de fila é o mecanismo responsável por decidir qual deverá ser o próximo cliente a ser atendido pelo servidor (Allen, 90)(Soares, 92). Algumas das técnicas mais usuais são:

FCFS (First Come - First Served) é uma disciplina bastante comum e muito usada. Ela baseia o seu atendimento na ordem de chegada dos clientes, isto é, o primeiro a chegar será o primeiro a sair. Essa disciplina não é apropriada para filas cujos clientes possuam prioridade, ou seja, clientes mereçam um tratamento diferenciado.

A disciplina LCFS (Last Come - First Served) é exatamente o oposto da FCFS, ou seja, o últimó a chegar será o primeiro a ser atendido pelo servidor. Essa disciplina possui a estrutura de uma pilha.

RR (Round Robin) é a disciplina na qual um cliente é atendido durante um pequeno intervalo de tempo, denominado quantum. Caso esse intervalo não seja suficiente para a realização de todo o serviço requisitado pelo cliente, este é colocado no final da fila novamente, até que o seu serviço seja completado.

As filas, entretanto, podem requerer a atribuição de prioridades para os clientes. As prioridades podem ser preemptivas, isto é, o atendimento de um cliente é interrompido caso 
chegue um cliente com maior prioridade, ou não preemptivas, ou seja, o cliente em atendimento não é afetado, porém o próximo a ser atendido será sempre o de maior prioridade.

\subsubsection{Parâmetros de Desempenho em Redes de Filas}

Segundo Kleinrock (Kleinrock, 76), dois fatores formam a essência da teoria das filas: o padrão de chegada dos clientes (taxa em que os clientes chegam a uma fila) e o padrão de serviço nos centros (taxa de serviço em um servidor). Tais parâmetros influenciam o comportamento do desempenho de um determinado sistema de filas. É possível, através desses fatores, por exemplo, avaliar a utilização (percentual que um servidor permanece ocupado), tempo de residência (tempo médio gasto por um cliente em um centro de serviço, tanto na fila quanto no servidor) e comprimento da fila (número médio de clientes em um centro de serviço, tanto esperando quanto recebendo serviço) (Lazowska et. al., 84). Essas medidas de desempenho, para um único servidor, podem ser obtidas através da resolução de algumas equações, denominadas leis fundamentais.

\subsubsection{Leis Fundamentais}

Suponha-se que se tenha:

$$
\begin{aligned}
N(t) & =\text { Número de clientes no sistema em um tempo } t \\
\alpha(t) & =\text { Numero de clientes que chegam no intervalo [0,t] } \\
T_{i} & =\text { Tempo gasto no sistema pelo i-ésimo cliente (fila e servidor) } \\
B_{i} & =\text { Tempo em que o i-ésimo cliente utiliza o servidor (recurso) } \\
\lambda & =\text { Taxa de chegada dos clientes no intervalo }[0, t], \text { definida por } \lambda_{1}=\alpha(t) / t
\end{aligned}
$$

Através das quantidades acima (denominadas quantidades básicas (Lazowska et. al., 84)), pode-se derivar algumas medidas relativas ao desempenho de um sistema. Uma delas é a utilização, que é dada através da seguinte equação:

$$
\mathrm{U}=\mathrm{B}_{\mathbf{i}} / \mathbf{T}_{\mathbf{i}}
$$

A equação da utilização de um recurso fornece o percentual que ele permaneceu ocupado num determinado intervalo de tempo. Por exemplo, para um tempo de ocupação de um recurso $\left(B_{i}\right)$ igual a 10 segundos, e um tempo de sistema $\left(T_{\mathfrak{i}}\right)$ igual a 20 segundos, a utilização desse recurso é de $10 / 20$ (ou 50\%). Outra equação bastante utilizada, conhecida como Teorema de Little (Bertsekas \& Gallager, 92), relaciona o número de clientes no sistema em um determinado tempo $t(\mathrm{~N})$, com o tempo de sistema gasto por esses clientes $(\mathrm{T})$, conforme abaixo.

$$
\mathbf{N}=\lambda \mathbf{T}
$$

O teorema de Little expressa uma idéia bastante natural: sistemas "cheios" (grande valor de $\mathrm{N}$ ) estão associados a longos atrasos de clientes (grande valor de $\mathrm{T}$ ), e vice-versa. Por exemplo, em um dia de chuva, o tráfego de automóveis (na hora do rush) se move de maneira mais lenta que a média de um dia normal (grande valor de $\mathrm{T}$ ), enquanto que as ruas estão mais cheias (grande valor de $\mathrm{N}$ ). Similarmente, um restaurante fast-food (pequeno valor de $\mathrm{T}$ ) 
necessita de uma sala de espera menor (pequeno valor de $\mathrm{N}$ ) que um restaurante regular, para a mesma taxa de chegada de clientes. O teorema de Little possui uma vasta utilização pelo fato de sua idéia, apesar de simples, ser aplicável em várias situações.

\subsubsection{Aplicações de Redes de Filas em Redes de Dados}

Esta seção discute a aplicação da teoria de filas como metodologia de análise para medir atrasos em redes. No contexto de redes de dados ${ }^{2}$, clientes representam pacotes destinados à transmissão em uma certa linha de comunicação.

Em uma rede de dados, uma das medidas que mais influenciam o desempenho é o atraso médio requerido para que um pacote vá desde sua origem até o seu destino. Esse tipo de atraso pode influenciar sobremaneira a escolha e o desempenho de alguns algoritmos de redes, como os de roteamento ou de controle de fluxo (Bertsekas \& Gallager, 92).

Em uma linha de comunicação, o atraso total de pacotes está basicamente relacionado a quatro componentes (Bertsekas \& Gallager, 92):

- O atraso de processamento entre o tempo em que o pacote é corretamente recebido em um nó origem da linha e o tempo em que o pacote é designado para uma fila de linha de saída para a transmissão.

- O atraso de fila entre o tempo em que o pacote é designado a uma fila para transmissão e o tempo que ele começa a ser transmitido. Durante esse tempo, o pacote espera enquanto outros pacotes na fila são transmitidos.

- O atraso de transmissão entre os tempos em que o primeiro e último bits do pacote são transmitidos.

- O atraso de propagação entre o tempo em que o último bit é transmitido no nó origem da linha e o tempo do último bit é recebido no nó destino. Esse atraso é proporcional à distância física entre transmissor e receptor, fato que pode ser relativamente substancial, particularmente para uma linha de satélite ou uma linha de altíssima velocidade.

Para exemplificar a aplicação do Teorema de Little em um estudo analítico de atraso de pacotes em redes de dados, pode-se supor que um pacote em uma linha de transmissão chegue a cada $K$ segundos, e o primeiro pacote tenha chegado no tempo 0 . Todos os pacotes têm o mesmo tamanho e requerem $\alpha K$ segundos para transmissão $(\alpha<1)$. $O$ atraso de processamento mais o de propagação por pacote é de $P$ segundos. A taxa de chegada aqui é $1 / \mathrm{K}$. Pelo fato dos pacotes chegarem em uma taxa regular (tempo entre chegadas igual), não há atraso de fila. Os pacotes gastam um tempo $T$ no sistema (incluindo o atraso de propagação). Esse tempo $T$ é dado por $T=$ $\alpha K+P$. De acordo com o Teorema de Little, tem-se:

$$
N=\lambda T=\alpha+P / K
$$

A equação acima mostra que o tempo gasto no sistema pelo i-ésimo cliente (T) é diretamente proporcional ao atraso (P) ao qual esse cliente está submetido.

\footnotetext{
${ }^{2}$ Rede de dados é uma designação geral dada às redes de computadores que permitem o tráfego de dados, independente de topologias, protocolos, etc. (Bertsekas \& Gallager, 92).
} 
A intenção aqui é mostrar a possibilidade da solução analítica para problemas de desempenho, através da aplicação de algumas equações relativamente simples. É óbvio também que, para problemas mais complexos, possivelmente as referidas equações não seriam aplicáveis (conforme exposto na seção 3.4, capítulo 3). Também, tem-se a intençāo de demonstrar formas diferentes de se expor a mesma situação. As figuras 4.2 e 4.3 ilustram o mesmo fato, ou seja, chegadas e partidas de pacotes em um determinado sistema. Na figura 4.2, a metodologia utilizada é a demonstração matemática da situação, através do gráfico de $\mathrm{N}$ (número de pacotes no sistema em um determinado tempo $t$ ) em fưção do tempo de chegadas dos pacotes ( $t$ ). Já a figura 4.3 mostra um modelo de redes de filas de mais alto nível, para representar a mesma situação. Logicamente (exceto talvez para os matemáticos), o poder de clareza e concisão do modelo é mais explícito.

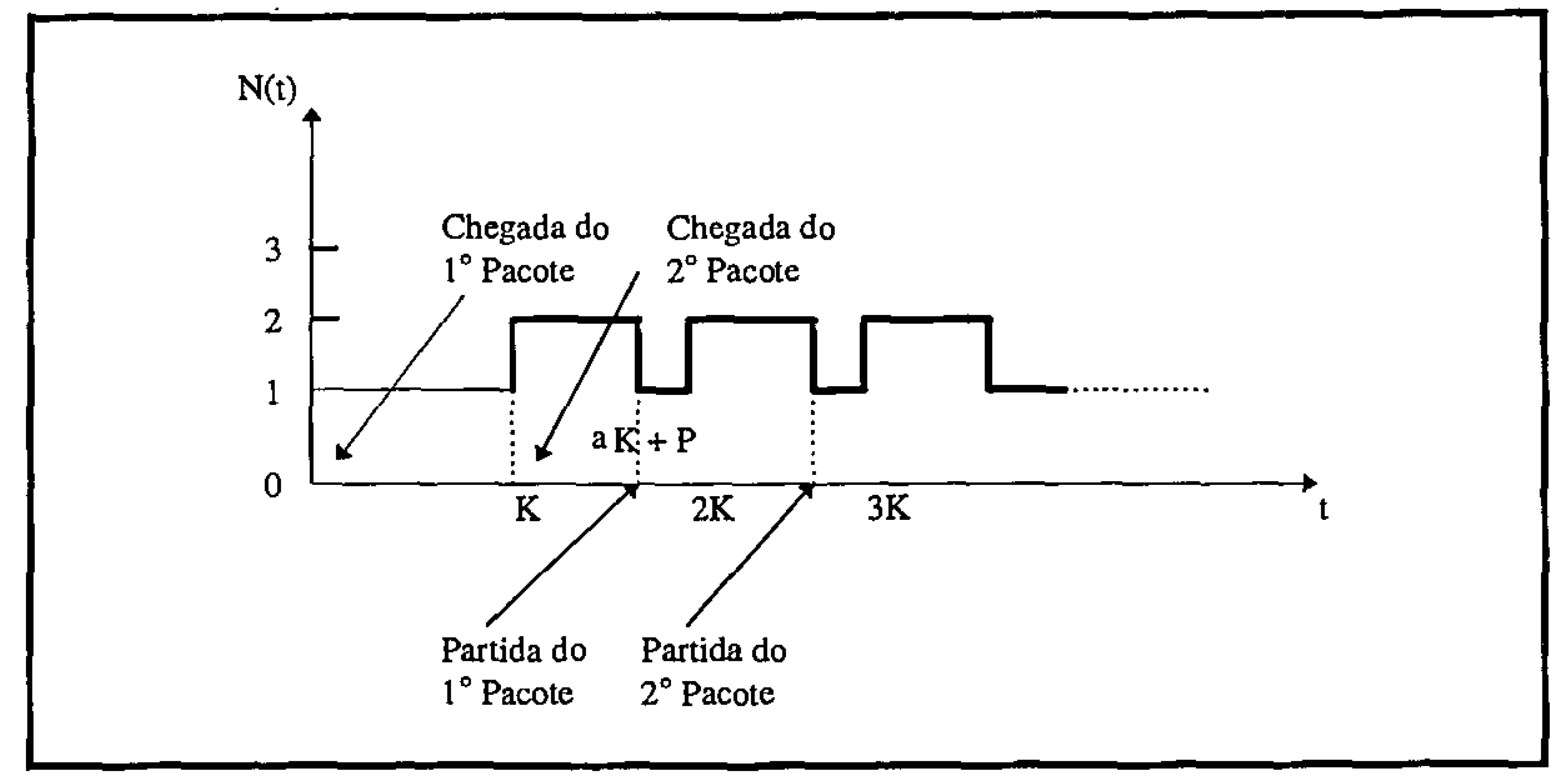

Figura 4.2. Chegadas e Partidas de Pacotes em uma Linha de Comunicação.

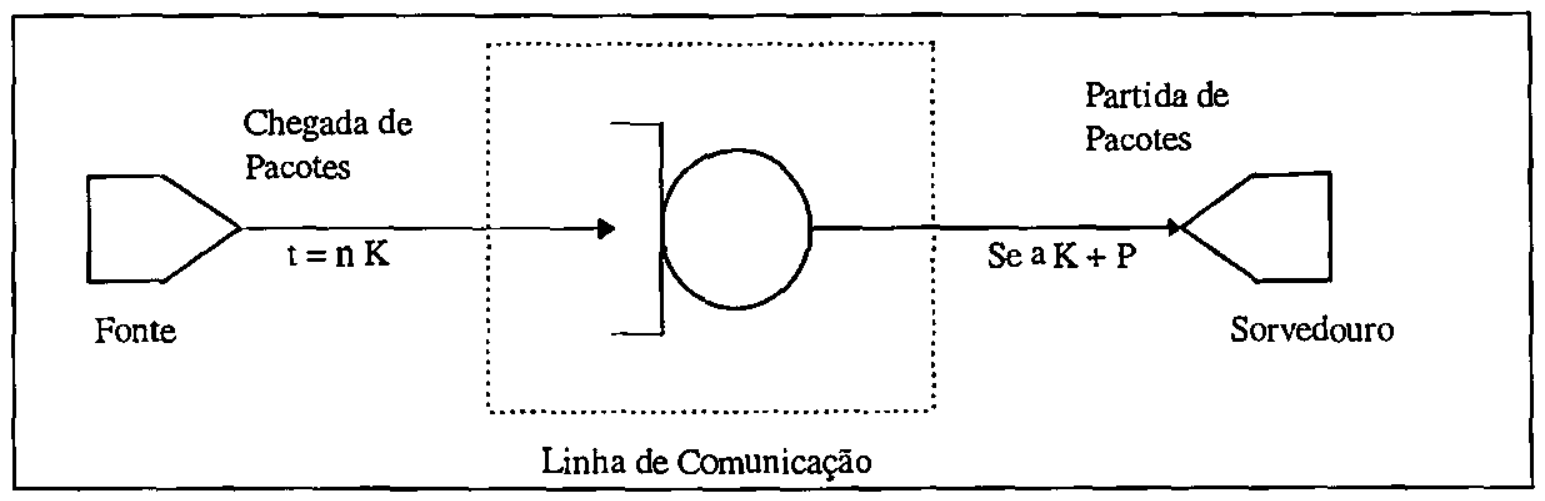

Figura 4.3. Modelo de Rede de Fila Representando Chegadas/Partidas de Pacotes.

A figura 4.3 adiciona algumas novas representações aos modelos básicos de redes de filas. Fontes, sorvedouros, expressões para tomada de decisão e submodelos são alguns desses novos símbolos, introduzidos no diagrama visando proporcionar um maior poder de 
representação aos modelos de redes de filas. A estrutura de uma extensão às redes de filas denominada RESQ (Research Queueing Package) será apresentada na seção 4.2.7.

\subsubsection{Redes de Filas Estendidas do RESQ}

A estrutura oferecida pelas redes filas básicas não satisfaz toda a necessidade de representação que um sistema complexo pode requerer. Com o objetivo de suprir essa deficiência, foi elaborado um conjunto pequeno de símbolos adicionais, que visa fornecer maior poder de representação aos diagramas originais. Essa extensão às redes de filas é denominada RESQ (Research Queueing Package). Nesta seção, são apresentados alguns dos conceitos adicionais do RESQ (Soares, 92).

Em RESQ, assim como no modelo básico, os clientes não são representados explicitamente. O.que fica explícito é rota descrita por eles. Em RESQ, os lugares visitados pelos clientes são chamados de nós.

Pode haver determinados clientes que precisem ser divididos em partes e, essas partes, posteriormente, precisem ser novamente agrupadas (como por exemplo, quebra de um mensagern em pacotes para a transmissão). Para possibilitar a representação desse tipo de situação, foram criados nós especiais denominados Split e Fusion. A figura 4.4 (Soares, 92) mostra os dois nós através de seus respectivos símbolos.

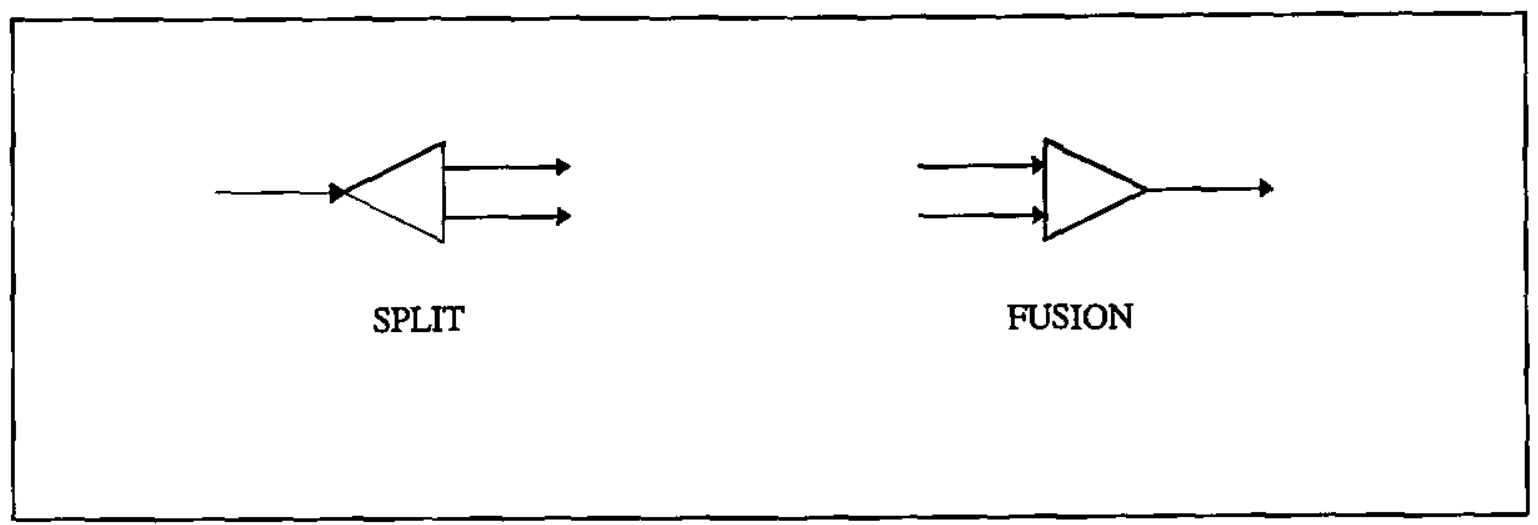

Figura 4.4. Nós Split e Fusion.

O nó que divide um determinado cliente em um certo número de partes é chamado de Split. O nó que, posteriormente, reagrupa essas partes é denominado Fusion. A aplicação dessa extensão é bastante interessante, por exemplo, na representação de algum tipo de multiplexação, onde seja necessário dividir um canal de transmissão de acordo com um determinado critério (como por exemplo, o tempo).

Outro tipo de nó importante definido em RESQ é aquele que representa a fonte ou o destino dos clientes, quando eles entram ou saem do sistema. O nó fonte representa um lugar no qual os clientes são gerados. O nó destino (ou sorvedouro) representa um lugar para o qual os clientes se dirigem quando deixam o sistema. A figura 4.5 (Soares, 92) apresenta os dois nós extremos de um sistema. 


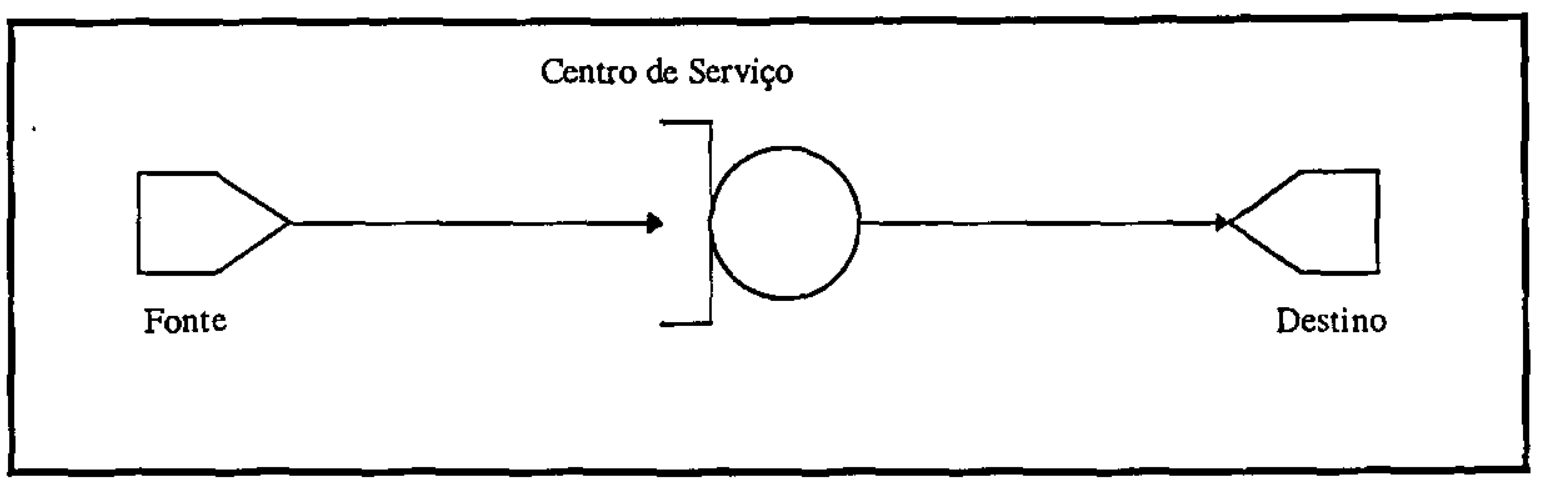

Figura 4.5. Nós Fonte e Destino.

Entretanto, uma das maiores contribuições de RESQ é a possibilidade de expressar tomadas de decisões. Essas decisōes podem se destinar a abranger todos os clientes do sistema (como as variáveis globais) ou apenas uma parte dos clientes. O nó que define valores às variáveis é denominado nó de atribuição. A partir da atribuição, pode-se determinar rotas definidas para os clientes. Também é possível em RESQ estabelecer a idéia de hierarquia, através da criação de submodelos, que são um subconjunto dos recursos de um modelo que precisam ser separados dos recursos restantes, ou para uma melhor estruturação e clareza, ou para a resolução (análise do submodelo) em separado. A figura 4.6 apresenta um conjunto de linhas definido como submodelo "linhas de comunicação", que é melhor especificado em uma representação à parte.

A figura 4.7 ilustra o roteamento de mensagens a hosts do mesmo domínio IP (Comer, 96). Nesse exemplo específico, as mensagens vêm de fontes externas ao domínio $\mathbb{P}$ (por exemplo, uma comunicação entre duas universidades de países diferentes). As mensagens são geradas em uma fonte externa ao sistema e, para que possam ingressar no sistema devem obedecer à condição imposta pelo domínio IP (143.107.231). Satisfeita essa condição, é definido no nó de atribuição que serão acrescidos mais dois dígitos, referentes à especificação do host desejado (143.107.231.XX). Após isso, a mensagem segue o roteamento de acordo com o destino desejado (143.107.231.1, 143.107.231.15, etc.), onde será devidamente processada. Se, porém, mesmo a mensagem estando no domínio 143.107.231, não existir o host destino (no caso do exemplo, XX acima de 191), a mensagem sai imediatamente do sistema. 


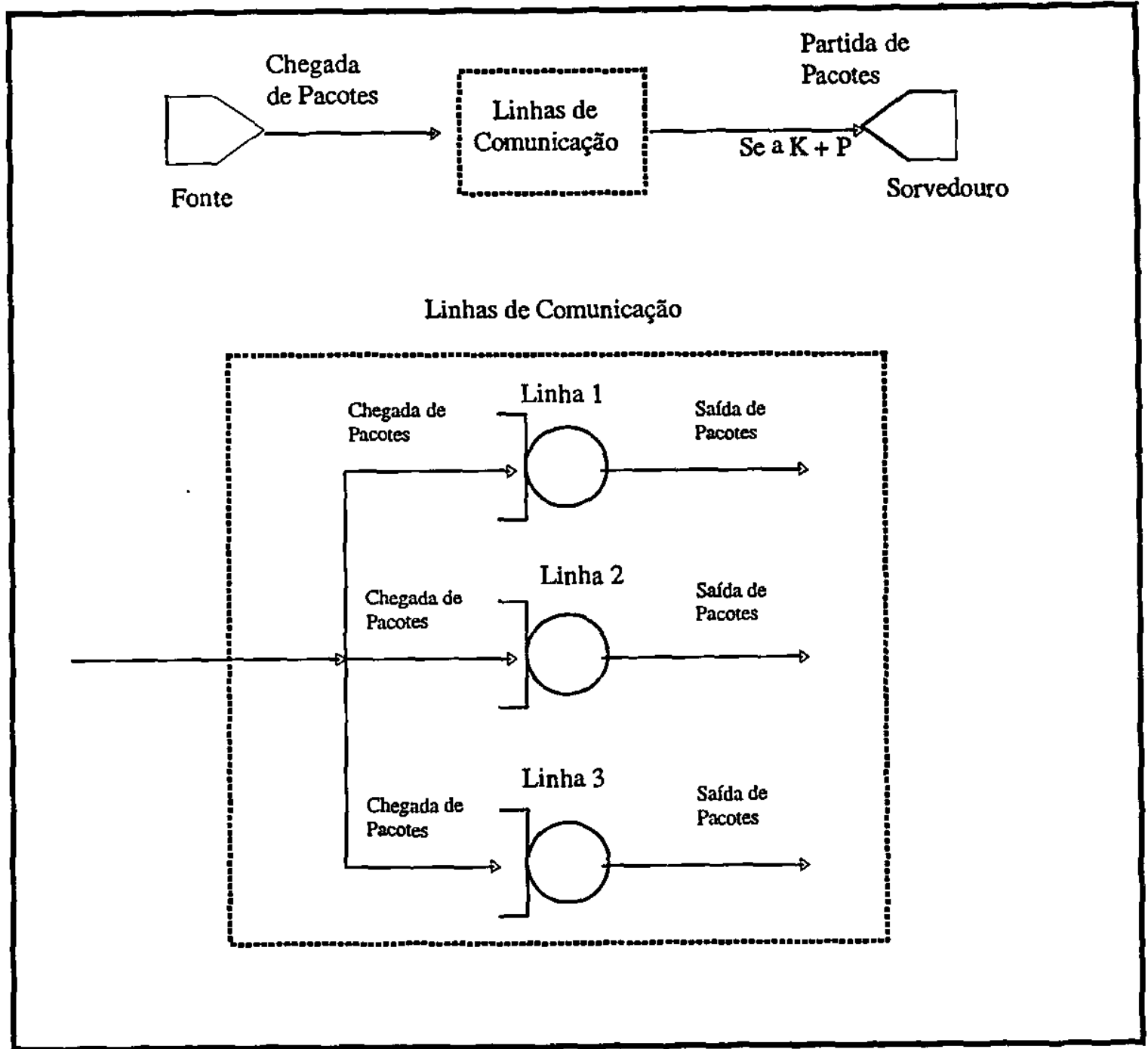

Figura 4.6. Submodelo Linhas de Comunicação. 


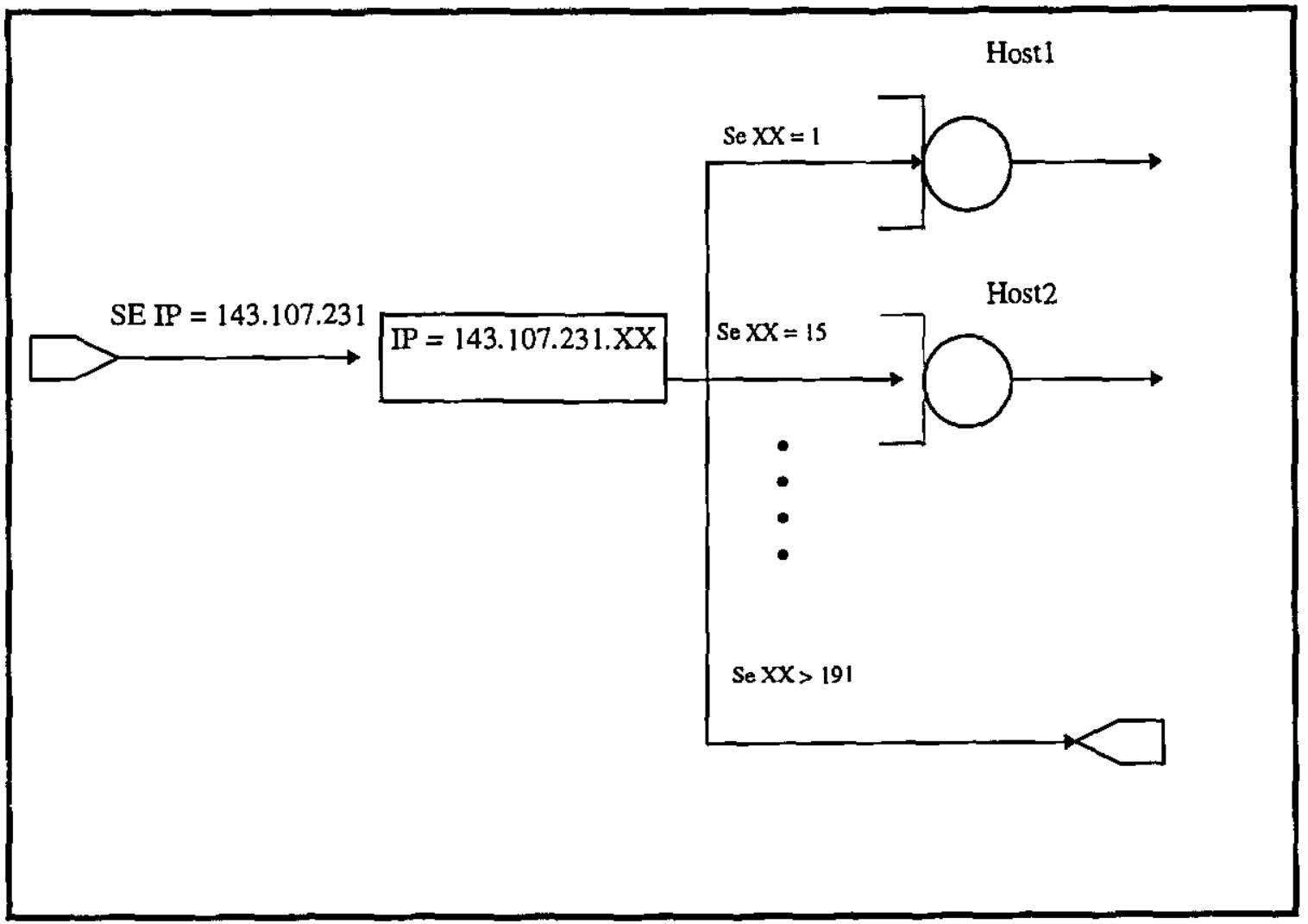

Figura 4.7. Roteamento de Mensagens através do Endereço IP dos Hosts.

Apenas uma parte das adições contidas na extensão RESQ foi mostrada acima, objetivando possibilitar uma representação mais clara e compreensível de um modelo através de um diagrama RESQ e sua simbologia. Essa extensão é amplamente discutida em (Nair \& Sauer, 85).

\subsubsection{Restrições às Soluções Analíticas em Redes de Filas}

A discussão iniciada no capítulo 3 (seção 3.4) sobre a melhor maneira de resolver um modelo volta à pauta, só que desta vez a discussão se concentra no modelo de redes de filas. Nesta seção são enfocadas algumas restrições impostas à solução analítica, quando se utilizam redes de filas. Vale enfatizar que não se deseja fazer uma apologia à simulação, pois já foi mostrado que, quando possível, a solução analítica possui uma aplicação até mais natural (por exemplo, a aplicação do Teorema de Little, vista na seção 4.2.6). A intenção é mostrar que certas simplificações impostas à resolução analítica, podem comprometer o seu poder de análise. Algumas das principais restrições que se aplicam às redes de filas são (Soares, 92):

- A distribuição do tempo entre chegadas em todas as fontes deve ser do tipo exponencial. Apesar dessa distribuição representar uma grande parte dos fenômenos, ela não pode ser considerada como regra. Nada impede que se pretenda resolver um modelo que possua uma distribuição geral $(\mathrm{G})$ do tempo entre chegadas dos clientes. 
- A posse simultânea de recursos não é permitida. Na realidade, entretanto, há vários casos em que se deseja que um determinado cliente usufrua de mais de um recurso ao mesmo tempo. Essa restrição inviabilizaria, por exemplo, a transmissão de uma mesma mensagem, simultaneamente, através de duas linhas de comunicação.

- Disciplinas de filas com prioridades não são permitidas. Essa restrição, por exemplo, impossibilitaria a resolução de um modelo de um sistema operacional como UNIX, que possui esquema de prioridades.

- Todas as filas são consideradas de capacidade infinita. Filas de espera finitas não são permitidas, o que nem sempre condiz com a realidade de um sistema computacional.

Essas restrições são algumas de um conjunto de restrições impostas à solução analítica de um modelo baseado em redes de filas. Como, muitas vezes, tais restrições são violadas em sistemas reais, a solução analítica tem o seu campo de atuação diminuído.

\subsection{Redes de Petri}

Rede de Petri é uma técnica de modelagem que permite a representação de sistemas, utilizando como alicerce uma forte base matemática (Maciel et. al., 96). Essa técnica possui a particularidade de permitir modelar sistemas paralelos, concorrentes, assíncronos e nãodeterminíticos (Valette \& Courvoisier, 80).

A representação gráfica de uma rede de Petri básica é formada por dois componentes: um ativo chamado de transição (barra) e outro passivo denominado lugar (círculo). Os lugares equivalem às variáveis de estado e as transições correspondem às ações realizadas pelo sistema (Maciel et. al., 96). Esses dois componentes são ligados entre si através de arcos dirigidos. Os arcos podem ser únicos ou múltiplos. A figura 4.8 mostra os elementos básicos de um grafo associado às redes de Petri.

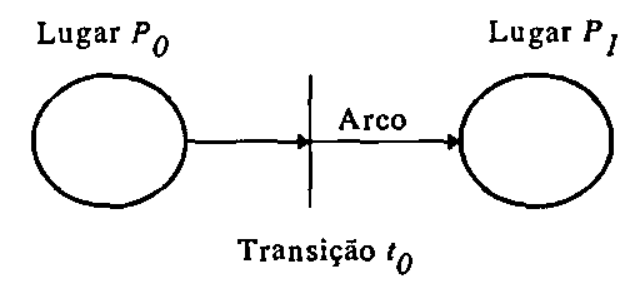

Figura 4.8. Grafo e seus Elementos Básicos.

\subsubsection{Definições}

As redes de Petri podem ser enfocadas através de três fundamentações diferentes. A primeira utiliza a teoria bag como suporte. A segunda usa os conceitos da álgebra matricial. A última se fundamenta na estrutura definida por relações. A seguir șão apresentadas as definições formais de cada uma dessas fundamentações. 


\subsubsection{Fundamentações para Redes de Petri}

- Definição 1: uma rede de Petri $R$ é uma quíntupla $R=(P, T, I, O, K)$, onde $P=\left\{p_{1}, p_{2}, \ldots, p_{n}\right\}$ é um conjunto finito não-vazio de lugares, $T=\left\{t_{1}, t_{2}, \ldots, t_{m}\right\}$ é um conjunto finito não-vazio de transições. I : $\mathrm{T} \rightarrow \mathrm{P}$ é um conjunto de bags ${ }^{3}$ que representa o mapeamento de transições para lugares de entrada. $\mathrm{O}: \mathrm{T} \rightarrow \mathrm{P}$ é um conjunto de bags que representa o mapeamento de transições para lugares de saída. $\mathrm{K}: \mathrm{P} \rightarrow \mathrm{N}$ é o conjunto da capacidades associadas a cada lugar, podendo assumir um valor infinito (Peterson, 81 ).

Para exemplificar a definição 1, supõe-se que se deseje representar um ano letivo de uma Universidade. $O$ ano letivo começa com o primeiro período (semestre) letivo, seguido das primeiras férias (de julho), logo após, tem-se o segundo período letivo, e finalmente as férias de final de ano. Assim, o ano letivo poderia ser representado conforme a figura 4.9.

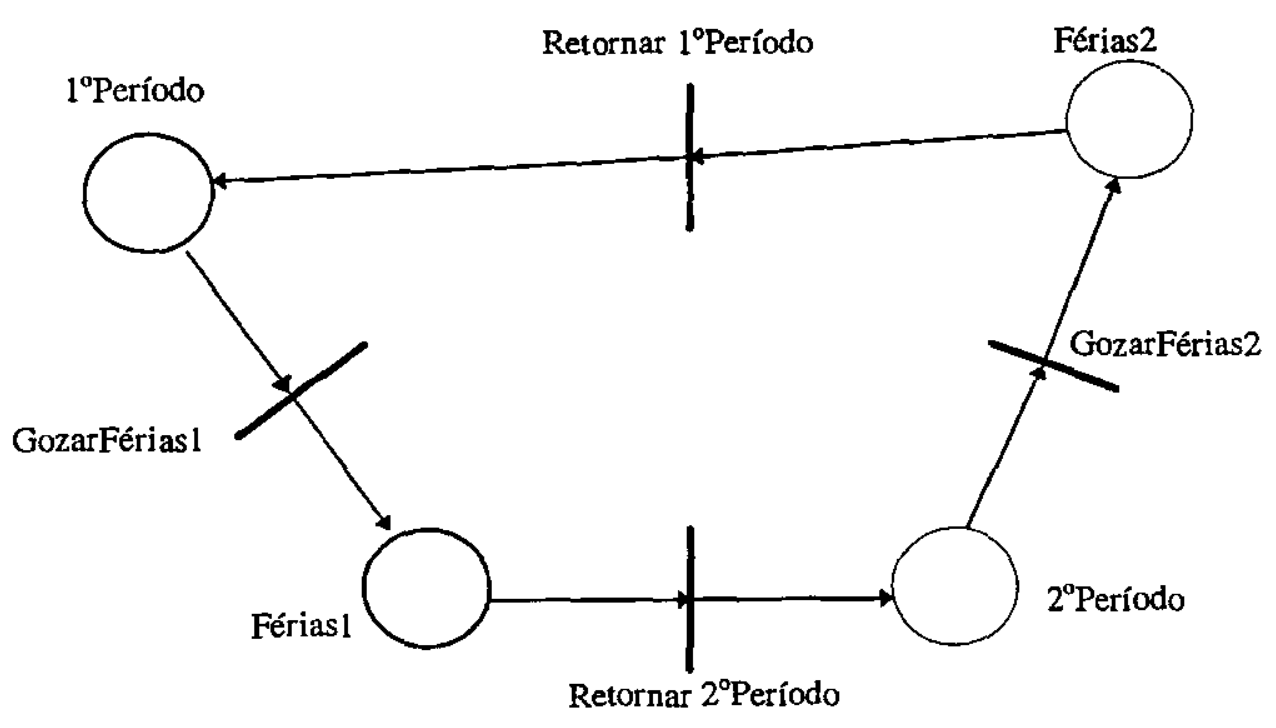

Figura 4.9. Ano Letivo Representado Graficamente em Redes de Petri. A figura 4.9 pode ser descrita da seguinte forma, utilizando-se a definição 1 :

$\mathrm{R}_{\text {Ano_Letivo }}=(\mathrm{P}, \mathrm{T}, \mathrm{I}, \mathrm{O}, \mathrm{K})$, onde

o conjunto de lugares $P$ é

$\mathrm{P}=\left\{1^{\circ}\right.$ Período, Férias $1,2^{\circ}$ Período, Férias 2$\} ;$

o conjunto de transições $T$ é

$\mathrm{T}=\left\{\right.$ GozarFérias 1, Retornar $2^{\circ}$ Período, GozarFérias 2, Retornar $1^{\circ}$ Período $\}$;

${ }^{3}$ Bag é uma generalizaçāo do conceito de conjunto que admite a repetição de elementos. Na notação de bags, utiliza-se [ ]. enquanto que para denotar conjuntos, utiliza-se \{\} (Maciel et. al., 96). 
o conjunto de bags de entrada Ié

$I=\left\{I(\right.$ GozarFérias 1$)=\left[1^{\circ}\right.$ Período $], I\left(\right.$ Retornar $2^{\circ}$ Período $)=[$ Férias 1$\}$, $\mathrm{I}($ GozarFérias 2$)=\left[2^{\circ}\right.$ Período $], I\left(\right.$ Retornar $1^{\circ}$ Período $)=[$ Férias 2$\left.]\right\}$;

o conjunto de bags de saída $\mathrm{O}$ é

$\mathrm{O}=\left\{\mathrm{O}(\right.$ GozarFérias 1$)=[$ Férias 1$], \mathrm{O}\left(\right.$ Retornar $2^{\circ}$ Período $)=\left[2^{\circ}\right.$ Período $]$,

$\mathrm{O}($ GozarFérias 2$)=[$ Férias 2$], \mathrm{O}\left(\right.$ Retornar $1^{\circ}$ Período $)=\left[1^{\circ}\right.$ Período $\left.]\right\}$;

e o conjunto de capacidades dos lugares é

$\mathrm{K}=\left\{\mathrm{K}_{1 \mathrm{oPer} \text { odo }}=1, \mathrm{~K}_{\mathrm{Ferrias} 1}=1, \mathrm{~K}_{2 \mathrm{oPeriodo}}=1, \mathrm{~K}_{\text {Férias } 2}=1\right\}$.

- Definição 2: a estrutura de uma rede de Petri, segundo o ponto de vista matricial, é uma quíntupla $\mathrm{R}=(\mathrm{P}, \mathrm{T}, \mathrm{I}, \mathrm{O}, \mathrm{K})$, onde $\mathrm{P}$ é um conjunto finito de lugares. $\mathrm{T}$ é um conjunto finito de transições, I : P x T $\rightarrow$ N é a matriz de pré-condições. $\mathrm{O}: \mathrm{P} \times \mathrm{T} \rightarrow \mathrm{N}$ é a matriz de póscondições. $\mathrm{K}$ é o vetor das capacidades associados aos lugares $(\mathrm{K}: \mathrm{P} \rightarrow \mathrm{N})$ (Peterson, 81).

Tomando-se como base novamente a figura 4.9, tem-se:

Os conjuntos de lugares e transições são idênticos àqueles vistos para a definiçãol.

A matriz I (pré-condições) é

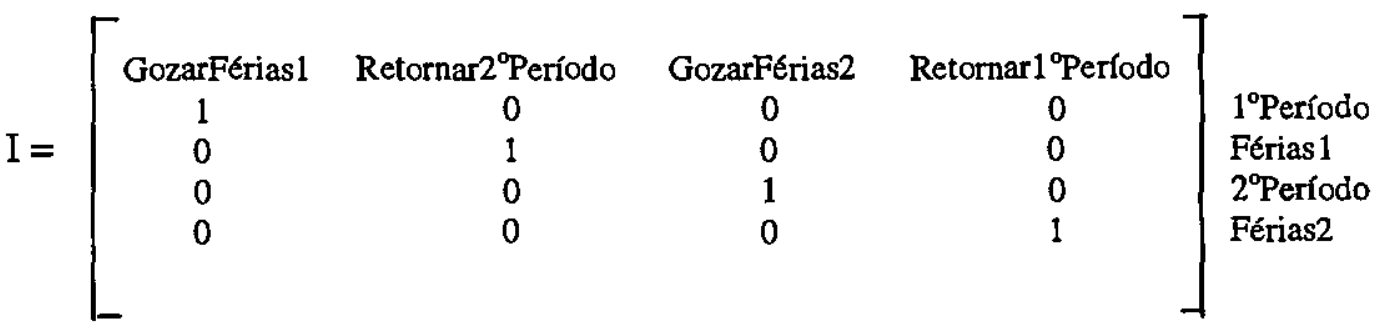

A matriz $\mathrm{O}$ (pós-condições) é:

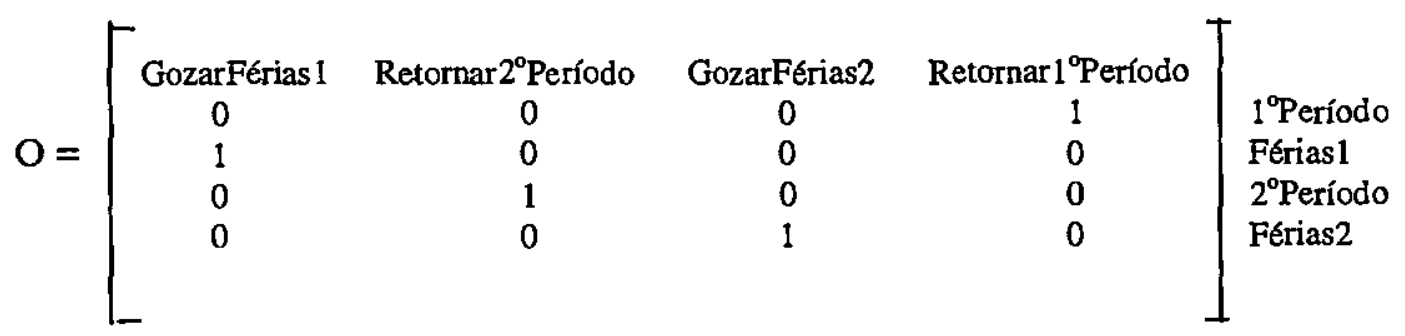

É importante ressaltar que as matrizes I e $\mathrm{O}$ representam as pré e pós-condições, respectivamente, de todas as transições da rede.

- Definição 3: a estrutura de redes de Petri, usando-se relações, é formada por uma quíntupla $R$ $=(\mathrm{P}, \mathrm{T}, \mathrm{A}, \mathrm{V}, \mathrm{K})$, onde $\mathrm{P}$ é o conjunto de lugares, $\mathrm{T}$ o de transiçōes, $\mathrm{A}$ o conjunto dos arcos $\mathrm{e}$ $\mathrm{V}$ corresponde ao conjunto de valorações desses arcos. Os elementos de A são arcos que 
conectam transições a lugares ou lugares a transições $(A \subseteq(P \times T) \cup(T \times P))$. Assim, os elementos de $\mathrm{A}$ podem ser agrupados em dois subconjuntos - o conjunto das entradas às transiçōes e o de saída às transições, $I=\left\{\left(\mathrm{p}_{\mathrm{i}}, \mathrm{t}_{\mathrm{j}}\right)\right\}$ e $\mathrm{O}=\left\{\left(\mathrm{t}_{\mathrm{j}}, \mathrm{p}_{\mathrm{i}}\right)\right\}$, respectivamente (Murata, 89).

Tomando-se ainda como referência a figura 4.9, tem-se que os conjuntos de lugares (P), de transições $(\mathrm{T})$ e de capacidades $(\mathrm{K})$ permanecem inalterados. Entretanto, na notação que utiliza relações, há o surgimento de dois novos conjuntos: o conjunto de $\operatorname{arcos}(\mathrm{A})$ e o conjunto de valores para esses arcos (V).

o conjunto de arcos A é

$A=\left\{\left(1^{\circ}\right.\right.$ Período, GozarFérias 1$),($ GozarFérias 1, Férias 1$)$, (Férias 1 , Retornar $2{ }^{\circ}$ Período), (Retornar $2^{\circ}$ Período, $2^{\circ}$ Período), ( $2^{\circ}$ Perfodo, GozarFérias 2$)$,

(GozarFérias2, Férias2), (Férias2, Retornar $1^{\circ}$ Período),

- (Retornar $1^{\circ}$ Período, $1^{\circ}$ Período) \}

o conjunto de valores dos arcos $\mathrm{V}$ é

$V=\{1,1,1,1,1,1,1,1\}$

\subsubsection{Redes de Petri Marcadas}

Marcas (tokens) são informações atribuídas aos lugares, para representar a situação (estado) da rede em um determinado momento. Define-se uma rede de Petri marcada pela dupla $R M=\left(R, M_{0}\right)$, onde $R$ é a estrutura da rede e $M_{0}$ a marcação inicial (Maciel et. al., 96). Assim, para simular o comportamento dinâmico dos sistemas, a marcação da rede de Petri é modificada a cada ação realizada (transição disparada). A figura 4.10 (Maciel et. al., 96) ilustra uma rede marcada.

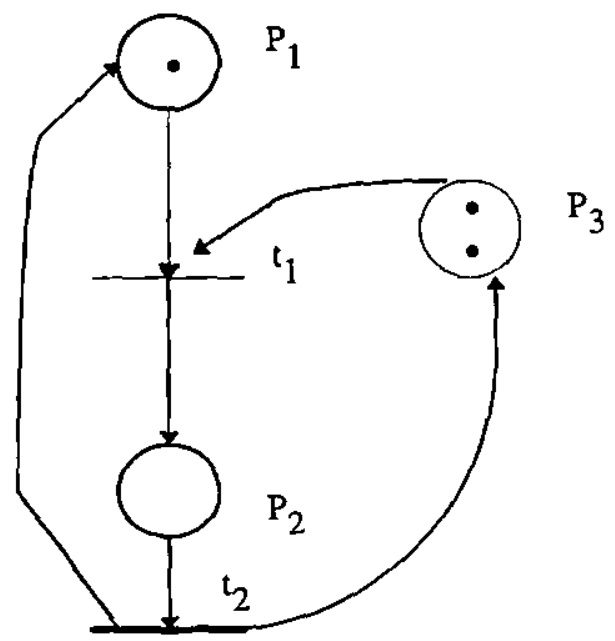

Figura 4.10. Rede Marcada. 


\subsubsection{Notações Particulares}

Em alguns casos, deseja-se representar a diferença entre transiçōes, visando melhorar a clareza do modelo. Além disso, em muitas situaçōes, pretende-se representar a execução de uma condição externa ao sistema modelado. Para representar tótulos de transiçōes, utiliza-se um alfabeto qualquer associado à rede (por exemplo, o alfabeto a,b,c,...,z). Para representar as condições externas, usa-se o mesmo esquema utilizado para rotular transições, entretanto, os símbolos vêm entre parênteses (conforme ilustra a figura 4.11).

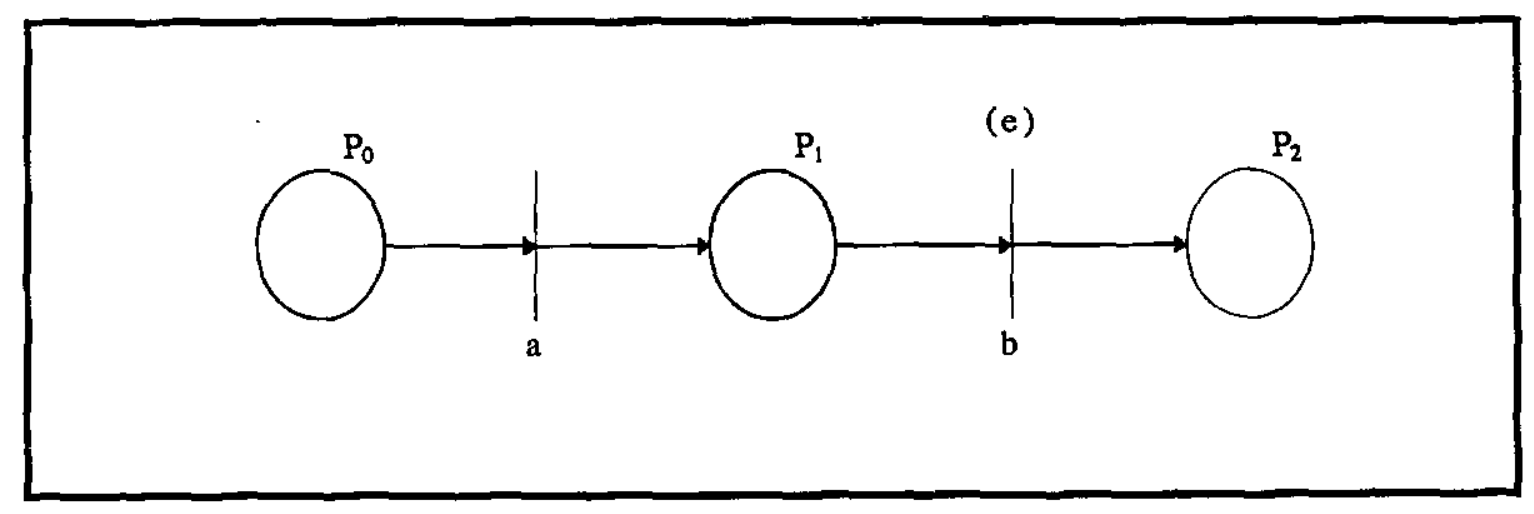

Figura 4.11. Rótulos e Condições Externas às Transições.

\subsubsection{Classes das Redes de Petri}

Podem-se agrupar as redes de Petri em duas grandes classes: as Ordinárias e NãoOrdinárias (de Alto nível) (Maciel et. al., 96). As redes ordinárias se caracterizam pelo tipo de suas marcas, ou seja, suas marcas são do tipo inteiro e não negativo, enquanto que as de alto nível possuem marcas de tipos particulares. As redes ordinárias se subdividem em:

- Rede Binária: é a rede mais elementar dentre todas. Essa rede só permite no máximo um token em cada lugar, e todos os arcos possuem valor unitário.

- Rede Place-Transition: é o tipo de rede que permite o acúmulo de marcas no mesmo lugar, assim como valores não unitários para os arcos.

As redes de alto nível são caracterizadas pelos tipos de suas marcas, que não são mais elementos do tipo inteiro positivo. Esse tipo de rede permite a individualização de uma marca (pertencente a um grupo) em um mesmo lugar. Essa individualização pode ser realizada através de vários artifícios, como por exemplo, cor da marca ou objetos representando os tokens. Redes não-ordinárias não aumentam o poder de representação de um modelo. Entretanto, elas permitem uma maior clareza e um maior (ou menor) nível de abstração ao modelo. 


\subsubsection{Redes Elementares}

Nesta seção, são apresentadas algumas redes que, a partir delas, derivam muitas outras redes mais complexas. São discutidas as redes representativas de sequienciamento, distribuição, junção, escolha não-determinística e atribuição.

- Sequienciamento: é a rede que representa a execução de uma ação, desde que uma determinada condição seja satisfeita. Após a execução dessa ação, pode-se ter outra ação, desde que satisfeita outra determinada condição (figura 4.12).

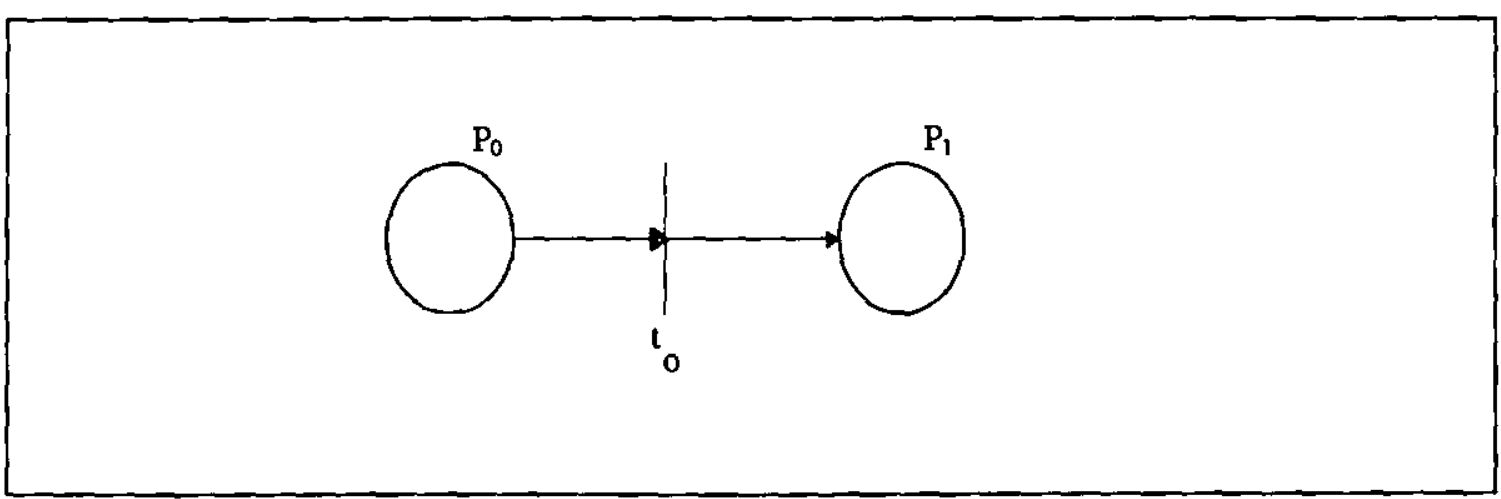

Figura 4.12. Seqủenciamento.

- Distribuição: é a rede elementar utilizada na criação de processos paralelos a partir de um processo pai. Os processos filhos são criados através da distribuição dos tokens encontrados no processo (lugar) pai. A distribuição é mostrada na figura 4.13.

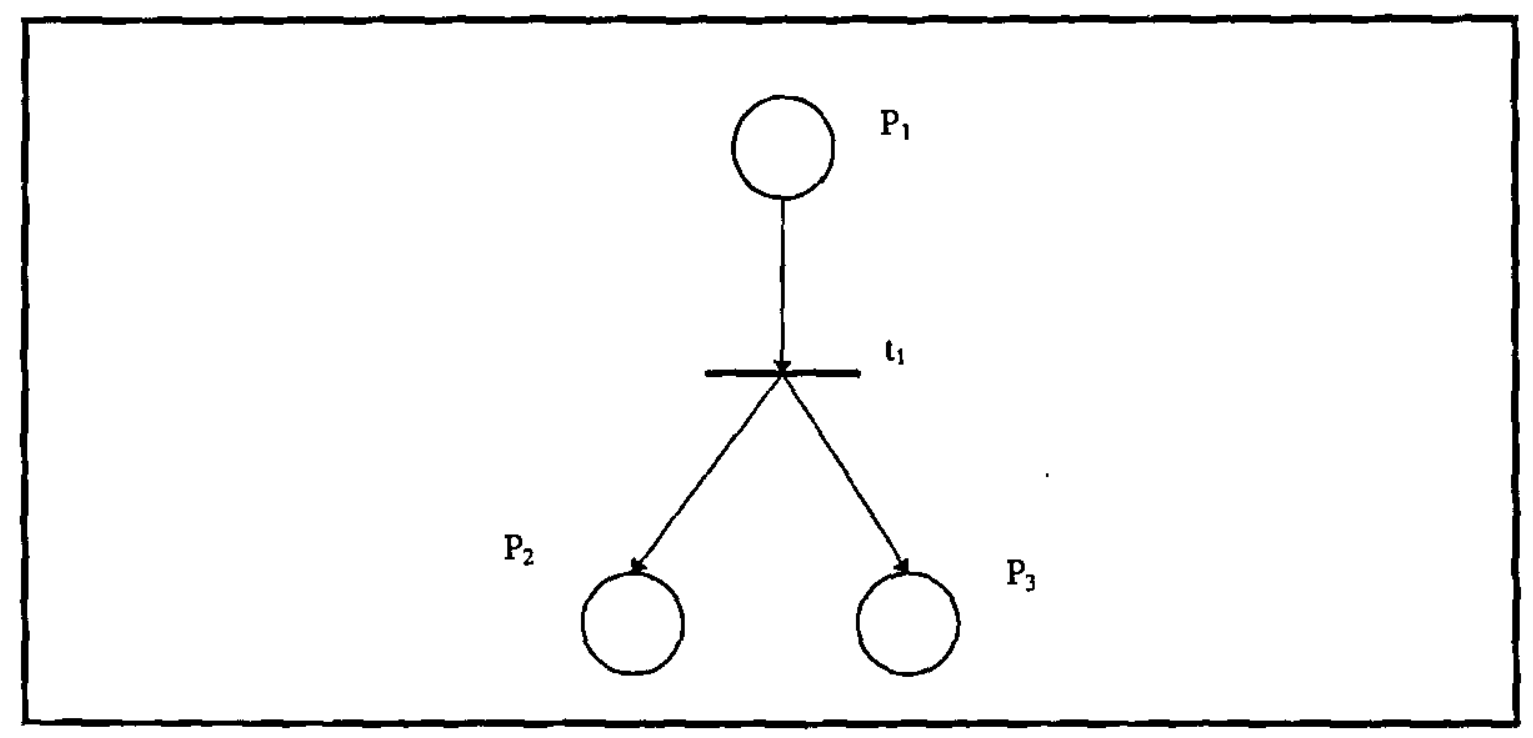

Figura 4.13. Distribuição.

- Junção: é a rede que modela a sincronização entre atividades concorrentes. No exemplo da figura 4.14 , a transição $t_{1}$ só dispara quando existirem fichas tanto em $\mathrm{P}_{1}$, quanto em $\mathrm{P}_{2}$, estabelecendo, assim, o sincronismo. 


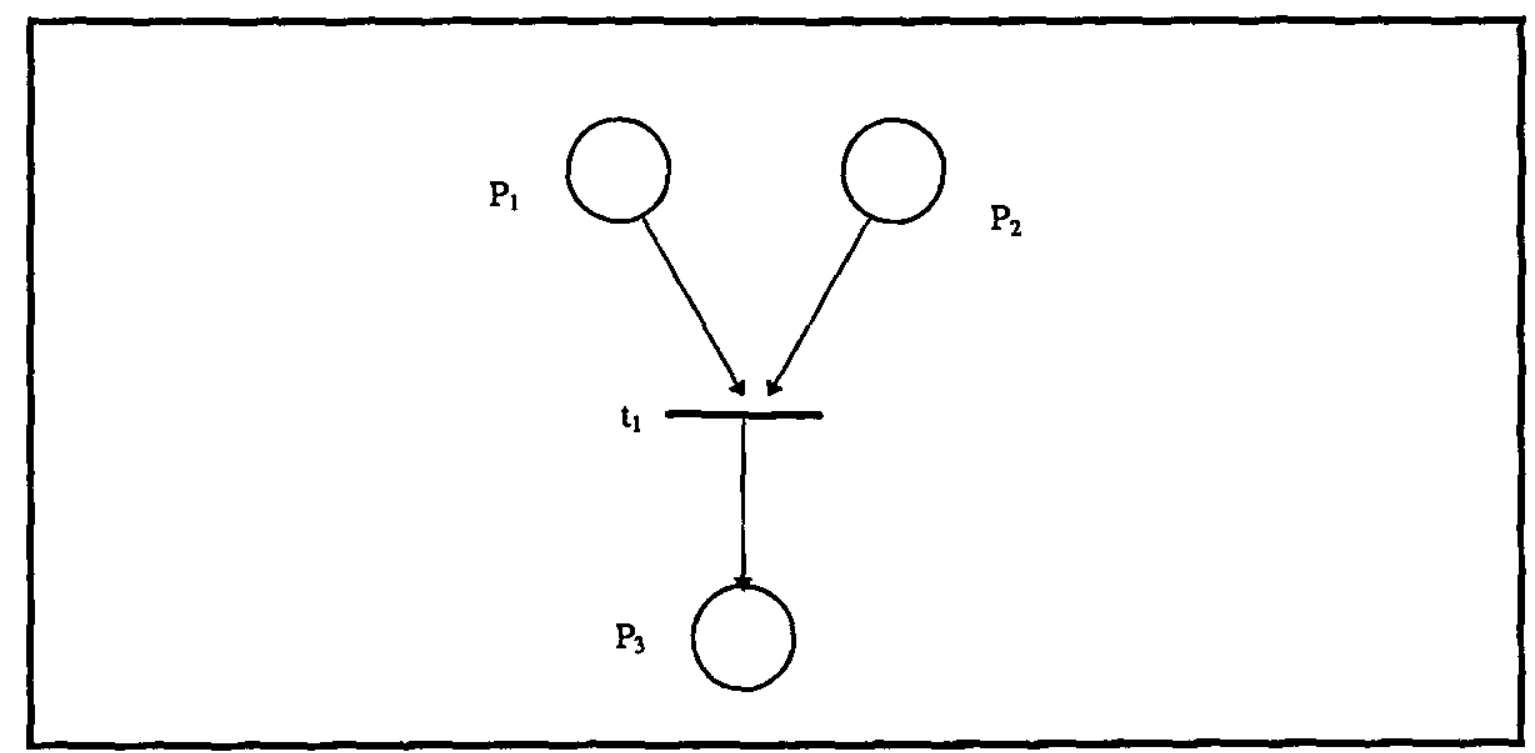

Figura 4. 14. Junção.

- Escolha Não-Determinística: é uma rede que ao se disparar uma transição, inabilita-se a outra. Entretanto, não existe possibilidade de escolha (conforme figura 4.15). $O$ fator nãodeterminístico dessa rede gera uma situação chamada de conflito (Maciel et. al., 96). O conflito pode ser classificado como estrutural ou efetivo. Ambos os conflitos estão associados ao fato de duas transições possuírem o mesmo lugar como entrada. Porém, se a rede não possuir tokens, o conflito é dito estrutural. Contudo, se há uma única marca no lugar comum às transições, diz-se que o conflito é efetivo. A figura 4.16 (Maciel et. al., 96) ilustra os dois tipos de conflito.

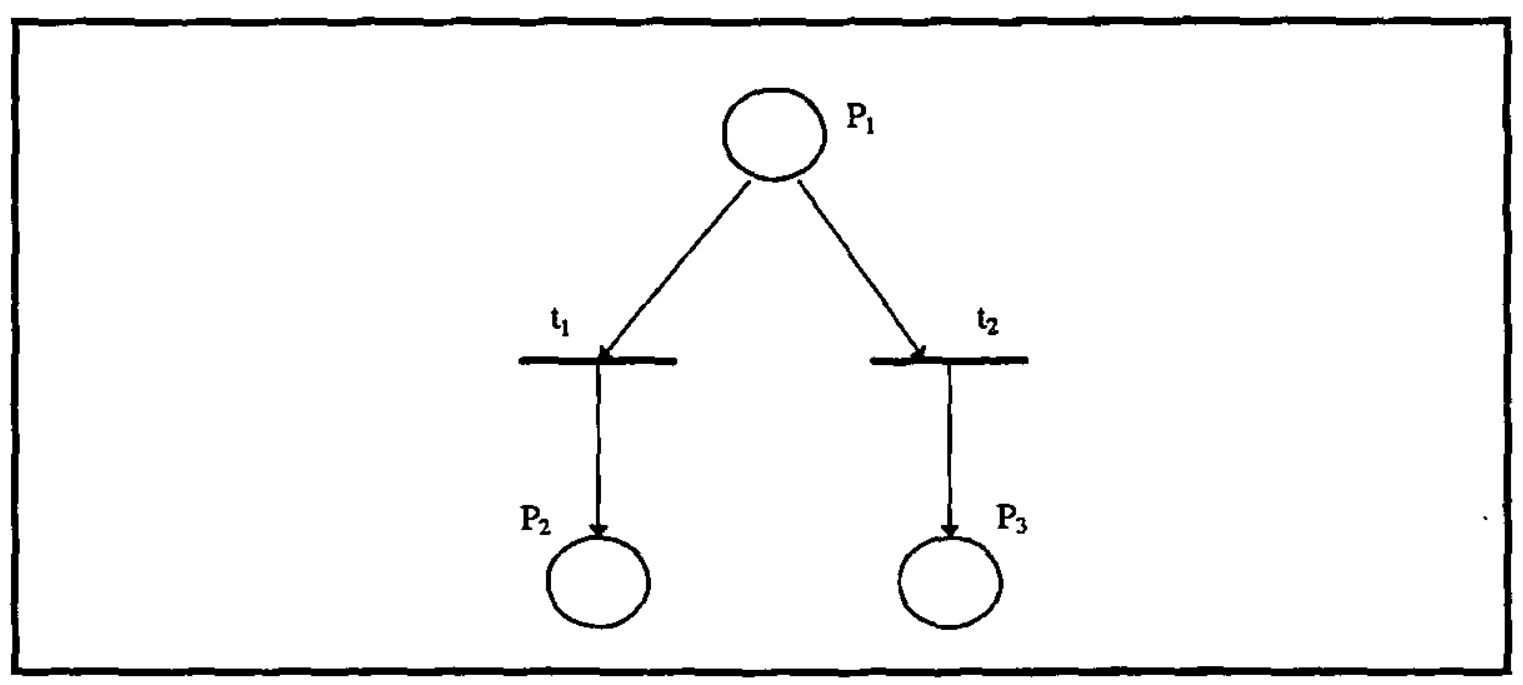

Figura 4.15. Escolha Não-Determinística. 


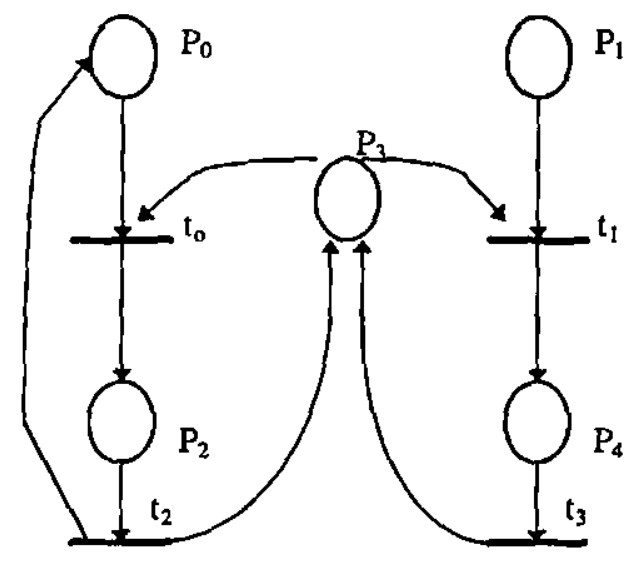

(a)

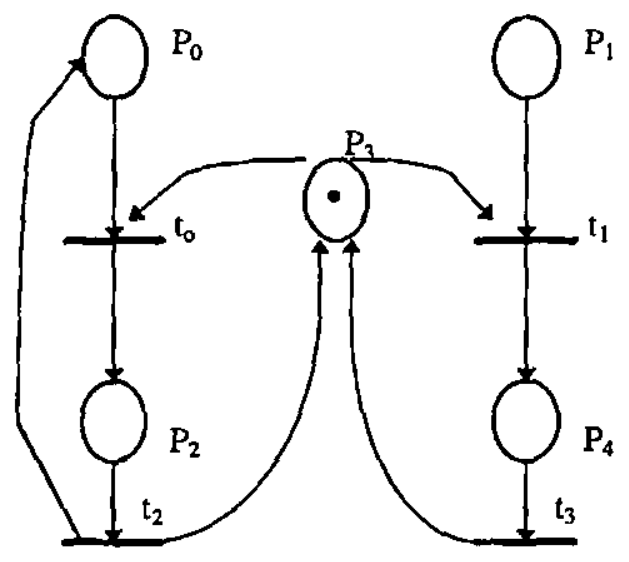

(b)

Figura 4.16. (a) Conflito Estrutural e (b) Conflito Efetivo.

A escolha determinística da transição a ser disparada não é um recurso abordado nas redes elementares. Porém, essa deficiência das redes de Petri originais são resolvidas em algumas extensões propostas, abordadas na seção 4.3.7.

\subsubsection{Redes de Petri em Protocolos de Comunicação}

Uma das áreas mais interessantes para aplicação de modelagem (especialmente redes de Petri) é a área da representação de protocolos de comunicação. Em protocolos, geralmente, as transições são bem nítidas (por exemplo, a transmissão ou recepção de uma mensagem). Muitas situações que são mutuamente exclusivas se fazem presentes (como a escolha entre um receptor dentre vários). A figura 4.17 (Maciel et. al., 96) mostra o comportamento de um protocolo bastante simples. Apesar de simples, o modelo apresenta situações interessantes para discussão.

O funcionamento do protocolo da figura 4.17 se fundamenta basicamente na decisão de qual receptor (1 ou 2) deve aceitar a mensagem. Nesse exemplo específico, a escolha é nãodeterminística, isto é, não se pode decidir qual o arco que o token deve seguir. Além disso, a escolha é mutuamente exclusiva, ou seja, apenas uma das transições será habilitada $\left(\mathrm{t}_{2}\right.$ ou $\left.\mathrm{t}_{4}\right)$. A escolha citada se processa quando o token, que vem de $t_{0}$, chega ao lugar $\mathrm{P}_{6}$. Nesse ponto, o token ou parte para o Receptor1 (habilitando a transição $t_{2}$ ), ou para o Receptor2 (habilitando a transição $\left.t_{4}\right)$. A partir daí, após a escolha do receptor, o token segue para um buffer $\left(\mathrm{P}_{3}\right.$ no Receptor 1, ou $\mathrm{P}_{4}$ no Receptor 2), para ser reconhecido pelo disparo da transição t $t_{3}$ (Receptor 1) ou $t_{5}$ (Receptor 2). 


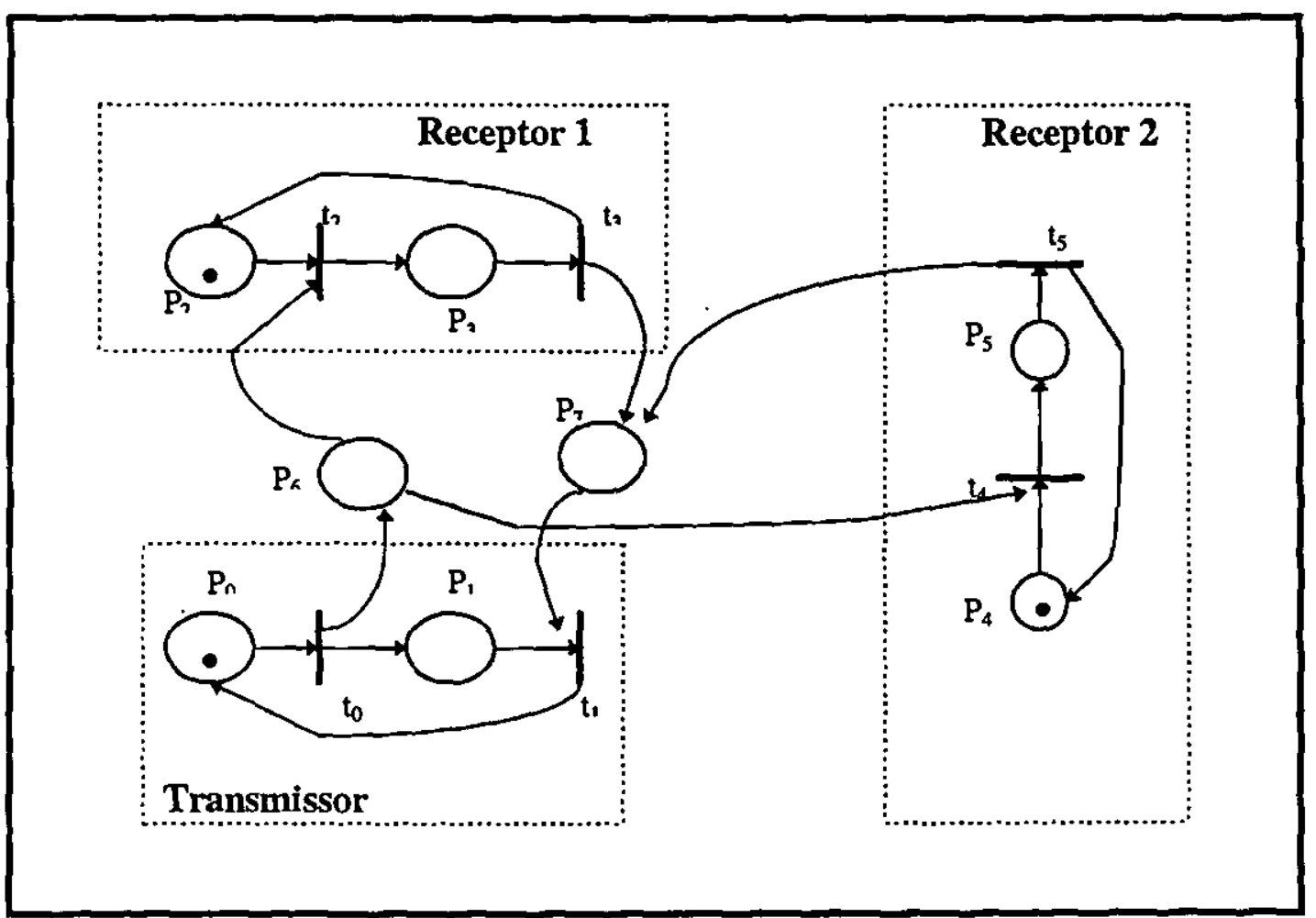

Figura 4.17. Protocolo de Comunicação.

O modelo é interessante para representar um protocolo que trabalhe de maneira aleatória. Entretanto, nem sempre é interessante se valer dessa situação (a eventualidade). Para os casos em que se deseja estipular o destino que o token deve seguir, ou seja, trabalhar de forma determinística, foram propostas algumas extensões às redes de Petri originais. Essas extensões são discutidas na próxima seção.

\subsubsection{Extensões às Redes de Petri}

Nesta seção são vistas algumas extensões propostas com a finalidade de aumentar a aplicação das redes de Petri. São discutidas as redes de Petri coloridas, hierárquica e temporizadas determinísticas.

\subsubsection{Redes de Petri Coloridas}

As redes de Petri coloridas têm por objetivo reduzir o tamanho do modelo, permitindo que os tokens sejam individualizados, através de cores atribuídas a eles; assim, diferentes processos ou recursos podem ser representados em uma mesma rede. As cores não significam apenas cores ou padrões. Elas podem representar tipos de dados complexos, usando a nomenclatura de colorida apenas para referenciar a possibilidade de distinção entre os tokens (Jensen et. al., 90). A figura 4.18 apresenta uma rede colorida, possuindo a representação original, onde são realmente utilizadas cores para os tokens. Nessa figura, os arcos são rotulados com cores $(a, b, c)$. 
No exemplo da figura 4.18, utiliza-se o modo mais elementar de redes coloridas, no qual se associa ao arco uma determinada cor, assim, o token se destinará ao arco cuja cor for idêntica a da marca. Observando-se essa figura, pode-se perceber que os tokens de $\mathrm{P}_{0}$ não habilitarão a transição $t_{0}$, pois o arco que liga $\mathrm{P}_{0}$ a $t_{0}$ só aceita cores do tipo "a", e o lugar $\mathrm{P}_{0}$ só possui marcas do tipo "d". Em contrapartida, $P_{1}$ possui marcas do tipo "a", podendo habilitar a transição $t_{1}$.

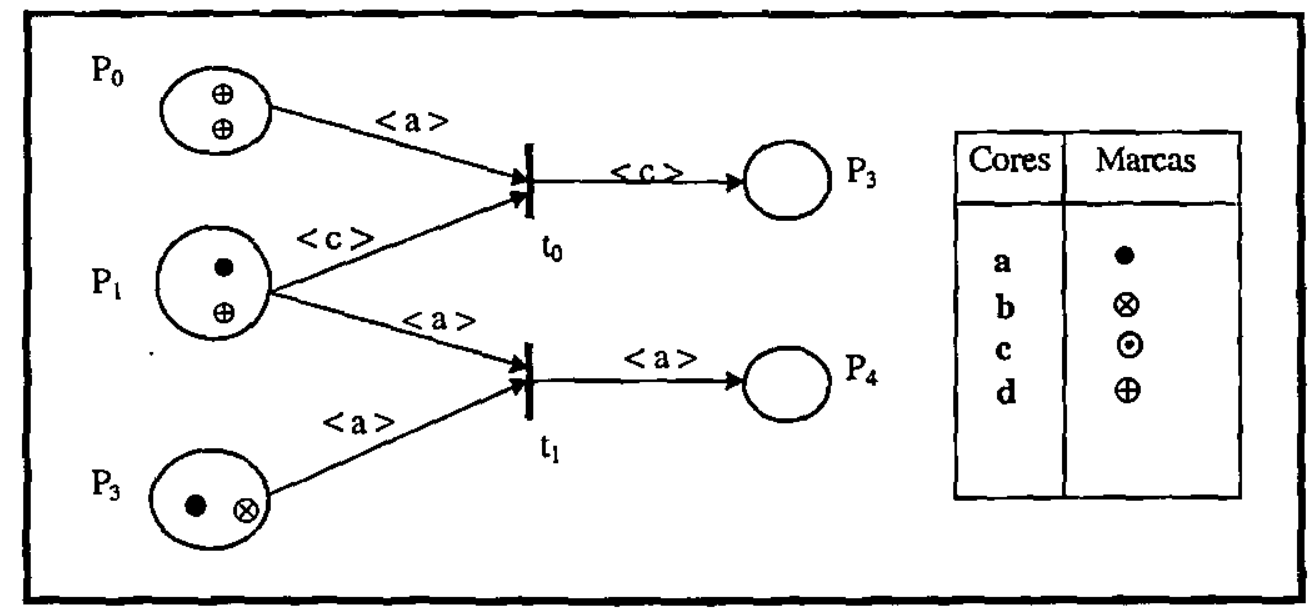

Figura 4.18. Rede de Petri Colorida.

Ainda que um tanto quanto rudimentar, a rede colorida original provê mecanismos que possibilitam efetuar uma escolha determinística. Esse poder de escolha já significa um grande avanço em direção a uma representação mais clara de um modelo, porém modificações (acréscimos) posteriores vieram dar maior adequação às redes coloridas, com relação à representação das escolhas não-determinísticas. A seguir, processa-se uma discussão a respeito de algumas melhorias adicionadas às redes coloridas, tornando-as mais poderosas. Para facilitar o uso da nomenclatura, faz-se referência às redes coloridas com as melhorias adicionais, chamando-as somente por redes de Petri coloridas.

As redes de Petri coloridas são compostas por três diferentes partes (Maciel et. al., 96):

- estrutura,

- declarações,

- inscrições.

Estrutura é um grafo dirigido com dois tipos de vértices (lugares e transições). Os lugares são representados graficamente por círculos (ou por elipses) e as transições por retângulos. Essa representação herda a propriedade das redes coloridas originais de poder armazenar em cada lugar marcas de tipos diferentes, além de poder representar valores associados a tipos de dados mais complexos. Declarações compreendem a especificação dos conjuntos de cores e declarações de variáveis. As inscrições variam de acordo com o componente da rede. Os lugares possuem três tipos de inscrições: nomes, conjunto de cores e expressão de inicialização (marcação inicial). As transições têm dois tipos de inscrições: nomes e expressões guarda, e os arcos apenas um tipo de inscrição dado pela expressão. Como formas para distinguir as inscrições, nomes são escritos com letras normais, cores em itálico, expressões de inicialização sublinhadas e as expressões guarda são colocadas entre colchetes. 
Nomes, quando associados a lugares, não têm significado formal, apenas facilitam a identificação. As expressões guarda associadas às transiçōes são expressões booleanas que devem ser atendidas para que seja possível o disparo das transições (Maciel et. al., 96).

Para ilustrar a aplicação de redes de Petri coloridas, será mostrada uma situação clássica de geração de impasse: o jantar dos filósofos (Tanenbaum, 95). Essa situação consiste de três filósofos que podem estar em três estados diferentes: comendo, pensando ou com fome. Os filósofos estão à volta de uma mesa, sendo que cada um deles tem à sua frente um garfo e um prato de comida. São, no entanto, necessários dois garfos para que um filósofo possa comer, ou seja, um filósofo precisa do seu garfo e do de seu vizinho. O impasse ocorrerá quando todos os filósofos pegarem o garfo da direita e aguardarem a liberação do garfo da esquerda. A figura 4.19(Maciel et. al., 96) apresenta o jantar dos filósofos modelado em rede de Petri colorida.

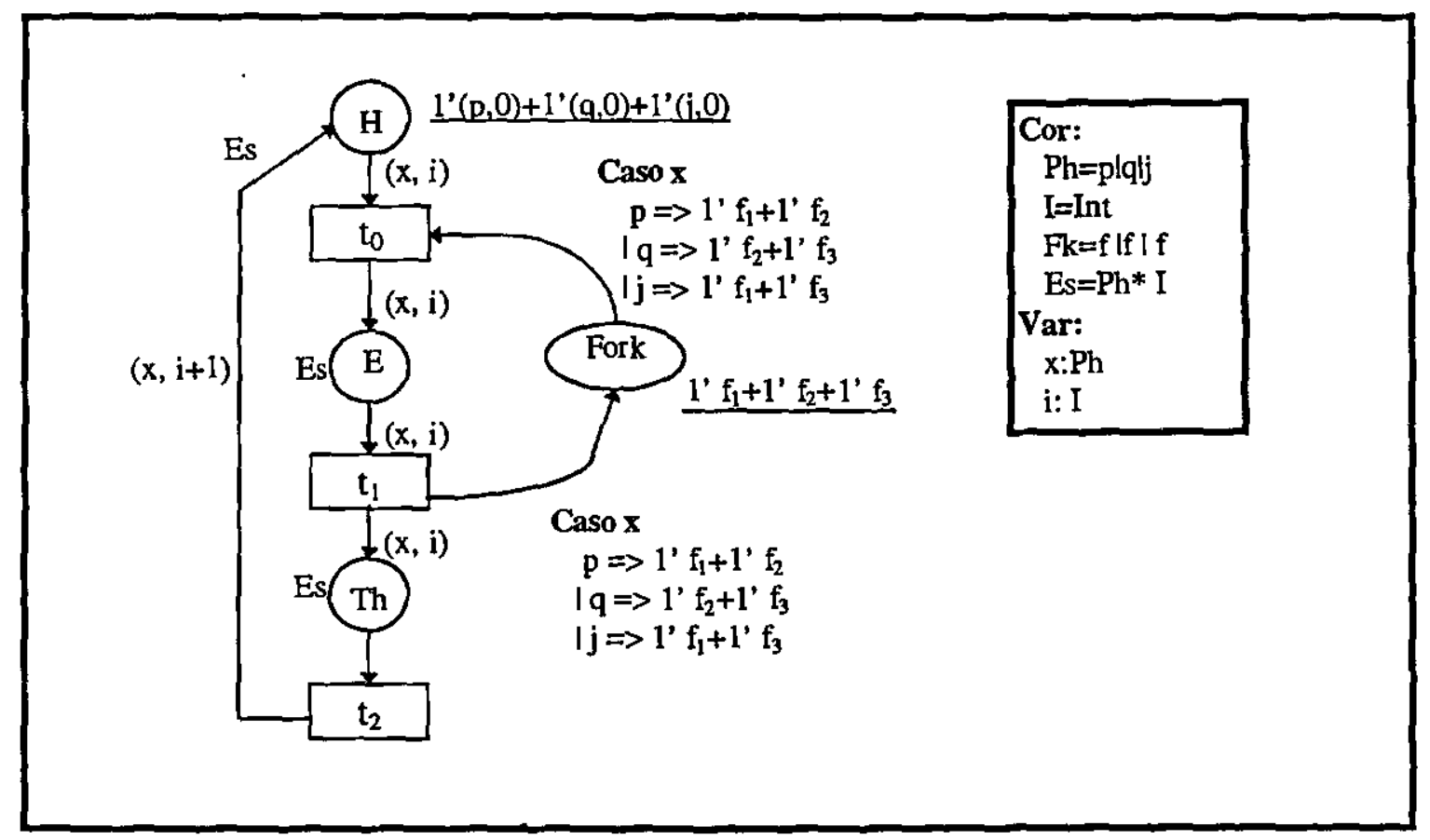

Figura 4.19. Jantar dos Filósofos Modelado em Redes Coloridas.

$\mathrm{Na}$ figura 4.19, os lugares representam os estados possíveis para os filósofos ( $\mathrm{H}$ para "com fome", E para "comendo" e Th para "pensando") e os recursos do sistema (no caso, os garfos representados por Fork). A variável $\mathrm{x}$ indica o filósofo que irá passar para $\mathrm{o}$ estado "comendo" (E) e a variável i indica o número de iteraçōes que já ocorreram. Na primeira iteração, o lugar $\mathrm{H}$ possui três marcas (marcação inicial) que estão sublinhadas. Dependendo da atribuição dada à variável $x$, uma das três expressões é avaliada no arco que liga o lugar Fork à transição to. Assim, se, por exemplo, $x=p$, então a expressão $1^{\prime} f_{1}+l^{\prime} f_{2}$ é avaliada e apenas a marcação $l^{\prime}(p, 0)$ do lugar $H$ irá à transição $t_{0}$, significando que apenas o filósofo $p$ irá passar para o estado "comendo". Desta forma, para cada atribuição de $x(p, q$ ou j) haverá uma situação diferente, ou seja, uma marca diferente no lugar $\mathrm{E}$ (estado "comendo"). A modelagem colorida, além de evitar o impasse (o que também poderia ser obtido através de uma rede nãodeterminística), ainda possibilita uma representação mais clara e concisa ao modelo.

Apenas para efeito de comparação, apresenta-se também a figura 4.20 , ilustrando o mesmo problema da figura 4.19, o jantar dos filosofos. Só que na 4.20 (Maciel et. al., 96), a representação utilizada segue a metodologia das redes de Petri ordinárias. A comparação 
evidencia o poder de concisão e clareza que as redes coloridas proporcionam. Como é usada apenas para efeito ilustrativo, a rede ordinária não será explicada. Essa comparação é plenamente discutida em (Maciel et. al., 96).

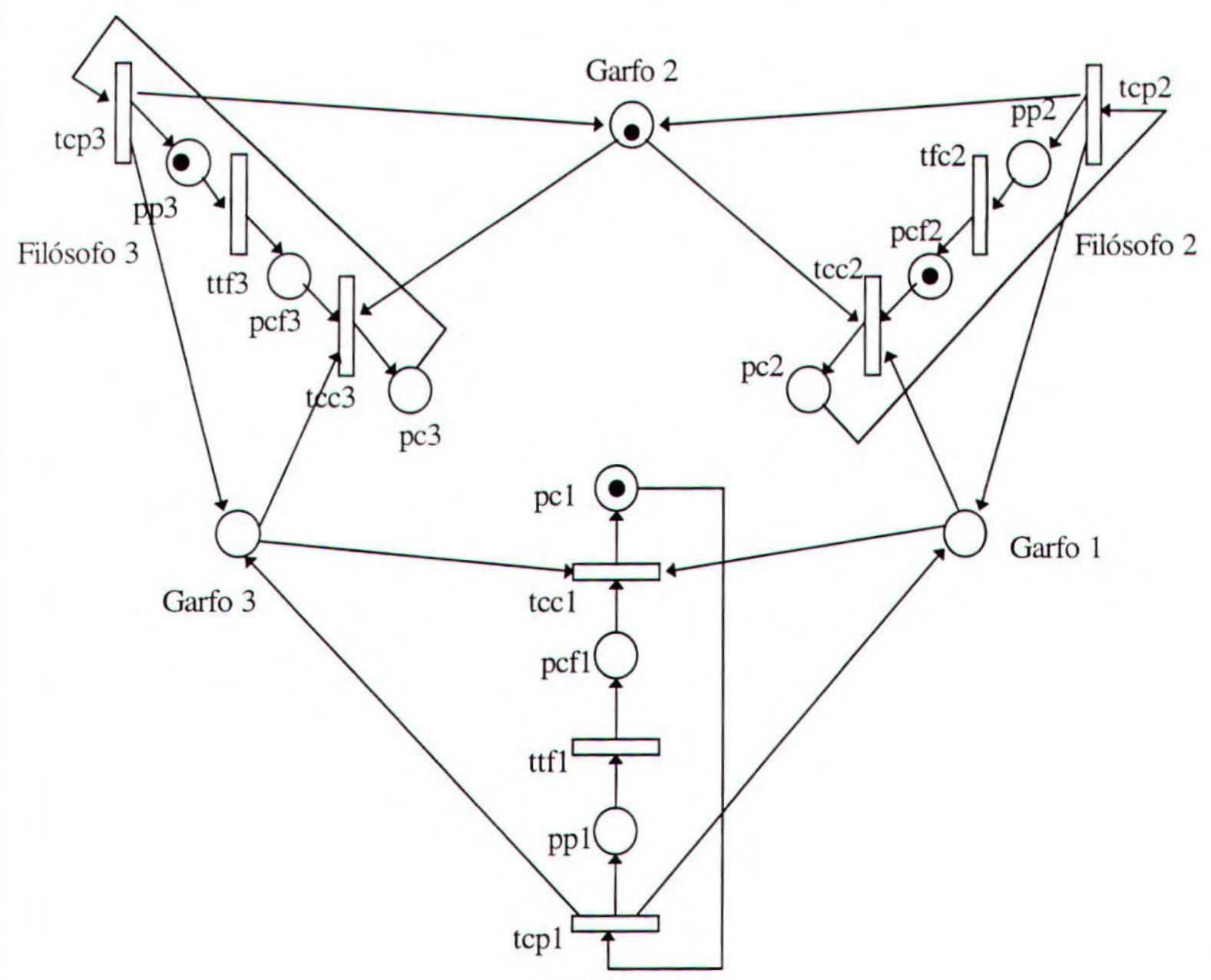

Filósofo 1

Figura 4.20. Jantar dos Filósofos em Rede Ordinária.

\subsubsection{Redes Hierárquicas}

Um dos problemas apresentados nas redes de Petri originais é o fato que, à medida que o tamanho do sistema cresce, vai se tornando cada vez mais difícil manter a clareza do modelo. Esse fato se deve, em grande parte, à falta de hierarquização dos modelos originais. Para amenizar essa limitação, foram criados mecanismos que possibilitam o agrupamento ou o refinamento de partes do modelo. Um dos problemas dessa abordagem é manter a consistência com os elementos vizinhos àqueles que sofrem um agrupamento. $\mathrm{Na}$ abordagem hierárquica, mostrada nesta seção, lugares e transições podem ser apresentados sob uma ótica de mais alto nível. 
Na representação hierárquica, dois componentes são fundamentais para viabilizar uma representação em mais alto nível: a superpágina e a subpágina (Dittrich, 95). A primeira representa um agrupamento de componentes (transições, lugares e arcos), visando gerar um modelo mais compacto e inteligível, como se fosse uma "caixa preta". Já as subpáginas são o detalhamento de uma superpágina, de forma a esclarecer alguns detalhes omitidos na representação em alto nível. A figura 4.21 apresenta uma representação em alto nível para o exemplo do protocolo de comunicação visto na figura 4.17. O exemplo mostra a representação do transmissor e dos receptores 1 e 2 em forma de superpáginas.

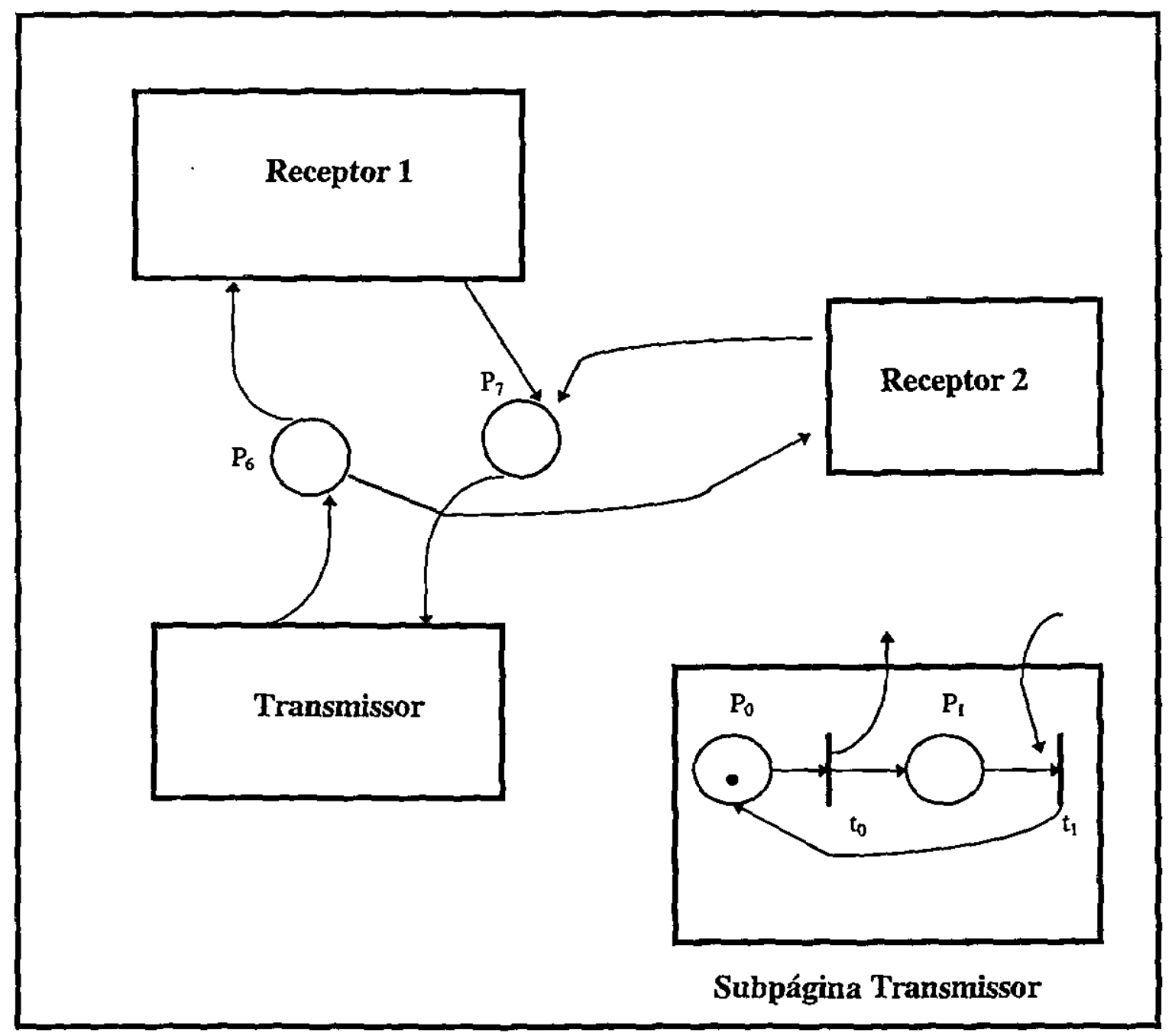

Figura 4.21. Hierarquia Utilizando Superpáginas.

\subsubsection{Rede de Petri Temporizada Determinística}

Para suprir a necessidade de escolha deterministica (assim como nas redes coloridas), foram desenvolvidas as redes de Petri temporizadas. Essas redes possibilitam a representação do comportamento dinâmico de sistemas que possuam atividades concorrentes, assíncronas e nãodeterminísticas, através da adição do conceito de tempo no modelo (Coolahan \& Roussopoulos, 83). O tempo também pode ser usado de maneira probabilística, ou seja, o disparo de transições está associado a distribuiçōes de probabilidade (seção 4.2.3). Essas redes são denominadas redes de Petri estocásticas, pois seus comportamentos podem ser descritos por processos estocásticos. 
A associação do tempo a componentes da rede pode se realizar de várias maneiras. As principais são (Maciel et. al., 96):

- O tempo associado aos lugares. Assim, os tokens (após o disparo de uma transição) só estarão disponíveis para disparar uma nova transição após um determinado tempo que está associado ao lugar.

- O tempo associado às marcas. Nesse caso o tempo indica quando a marca estará disponível para disparar uma transição.

- O tempo associado às transições. O objetivo desta seção é enfocar as redes de Petri temporizadas determinísticas com tempos associados às transiçōes. Por uma questão prática, quando se fizer referência à rede de Petri temporizada, estará subentendido que está-se referindo às redes de Petri temporizadas determinísticas com tempos associados às transições.

Um exemplo de rede de Petri temporizada determinística é apresentado na figura 4.22. Nela, as transições $t_{1}$ e $t_{2}$ possuem tempos associados diferentes, o que significa que uma transição será disparada antes da outra. Supondo-se que $\mathrm{d}_{1}<\mathrm{d}_{2}$, então o token chegará primeiro ao lugar $P_{1}$. Assim, de maneira determinística, pode-se estabelecer a ordem em que os eventos devem ocorrer.

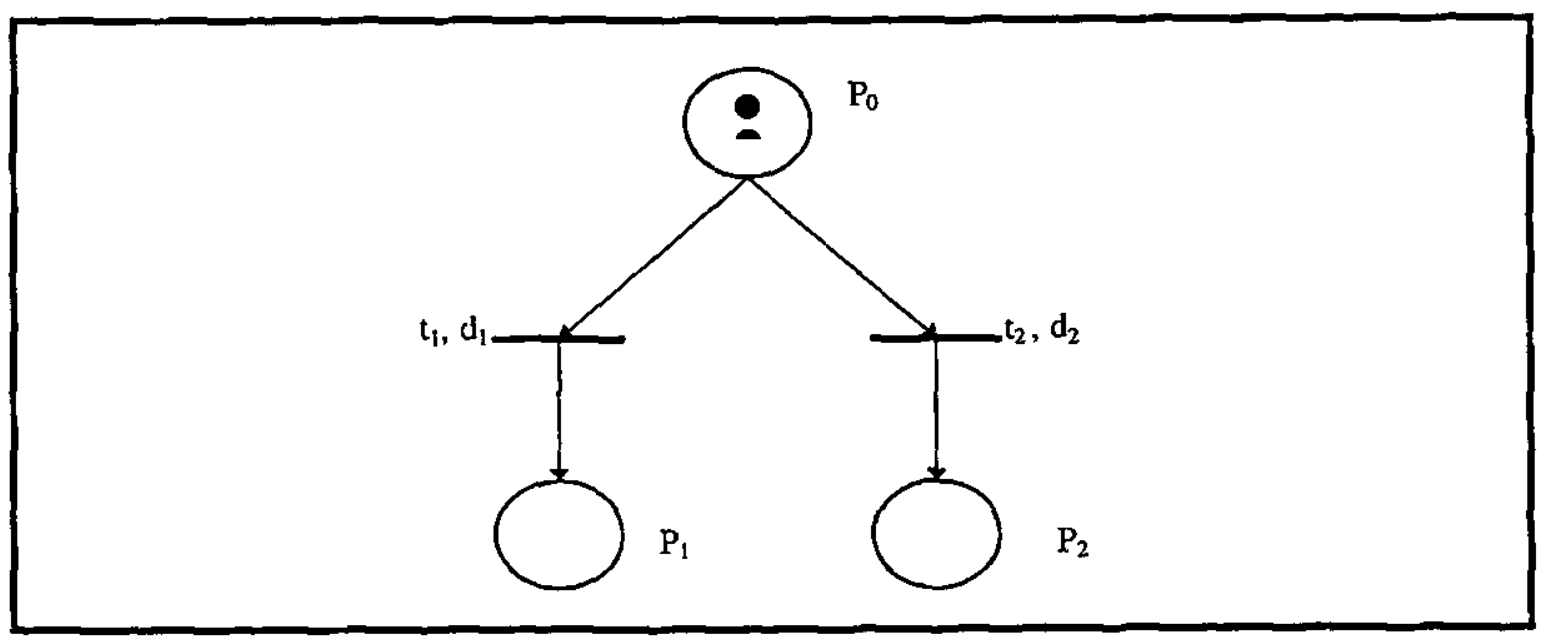

Figura 4.22. Rede de Petri Temporizada Determinística.

\subsubsection{Análise das Redes de Petri}

Há três grupos de métodos para se analisar as redes de Petri: análise baseada na árvore de cobertura, métodos baseados na equação fundamental das redes de Petri e as técnicas de redução (Murata, 89). Esta seção enfoca a análise baseada na equação fundamental das redes de Petri (EFRP). 


\subsubsection{Análise da EFRP}

A equação fundamental, ou equação de estados, possibilita a análise da acessibilidade das marcações, bem como o número de vezes que cada transição deve ser disparada para que se obtenha a referida marcação (Murata, 77).

A Equação Fundamental das Redes de Petri é:

$$
M^{\prime}(p)=M_{0}(p)+C . s, \forall p \in P
$$

Onde $s$ é o vetor característico cujos componentes $s_{i}$ são naturais e representam o número de vezes que cada transição $t_{i}$ foi disparada para obter-se a marcação $M^{\prime}(p)$ a partir de $M_{0}(p)$, e $C$ é a matriz de incidência, dada pela diferença entre as matrizes de pós e pré-condiçōes $(\mathrm{C}=\mathrm{O}-\mathrm{I})$. Assim, pode-se determinar se uma marcação $\mathrm{M}_{\mathrm{k}}$ é acessívei a partir de $\mathrm{M}_{0}$.

Observando-se a figura 4.23 (Maciel et. al., 96), pode-se analisar a acessibilidade da marcação $M^{\prime}=(0,0,0,1,1,0,1)$ a partir da marcação inicial apresentada.

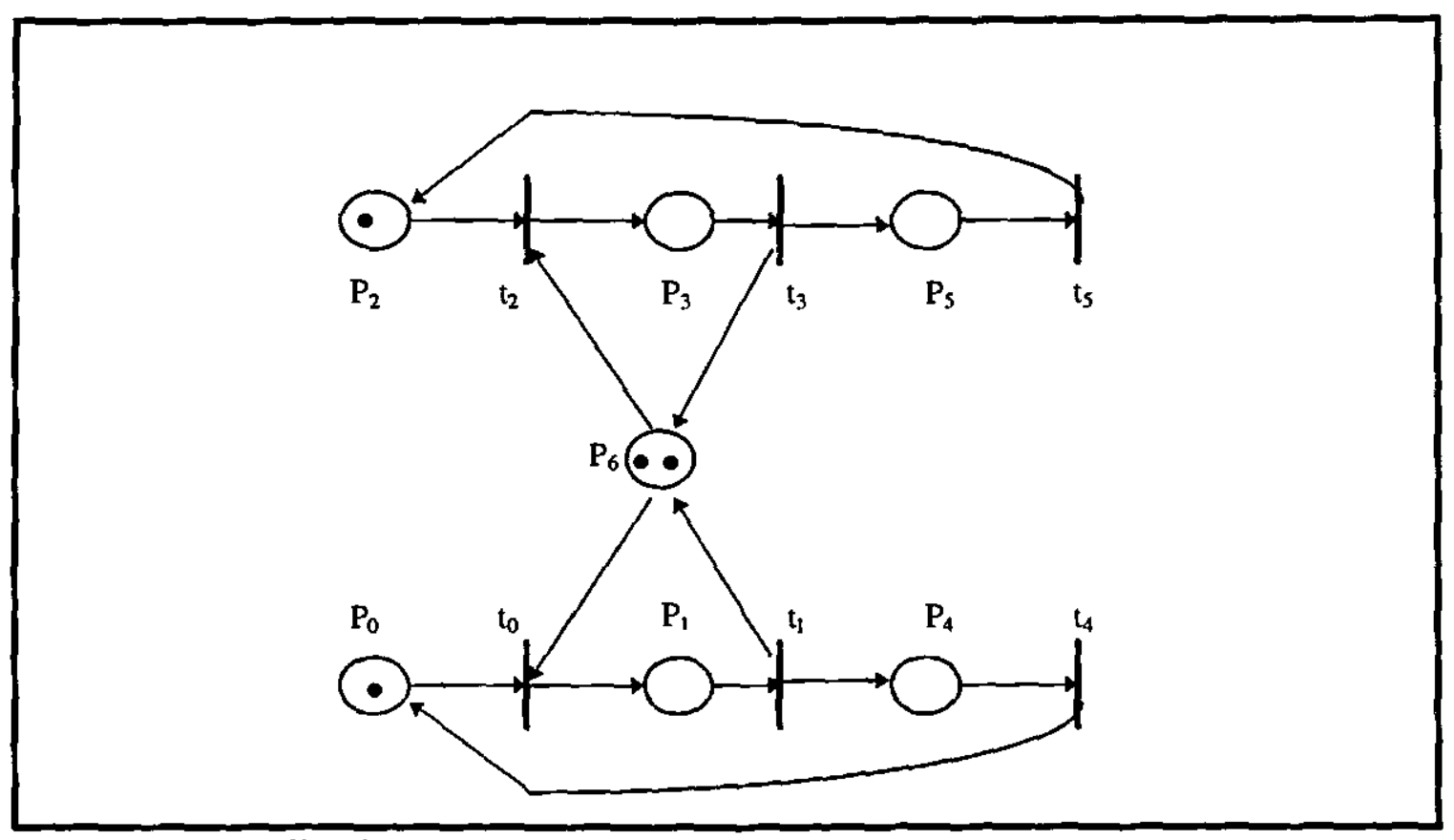

Figura 4.23. Acessibilidade de uma Marcação.

A partir da EFRP, tem-se o seguinte sistema matriciai: 


$$
\begin{gathered}
M^{\prime}(\mathrm{p}) \quad \mathrm{M}_{0}(\mathrm{p}) \\
{\left[\begin{array}{l}
0 \\
0 \\
0 \\
1 \\
1 \\
0 \\
1
\end{array}\right]-\left[\begin{array}{l}
1 \\
0 \\
1 \\
0 \\
0 \\
0 \\
2
\end{array}\right]=\left[\begin{array}{cccccc}
-1 & 0 & 0 & 0 & 1 & 0 \\
1 & -1 & 0 & 0 & 0 & 0 \\
0 & 0 & -1 & 0 & 0 & 1 \\
0 & 0 & 1 & -1 & 0 & 0 \\
0 & 1 & 0 & 0 & -1 & 0 \\
0 & 0 & 0 & 1 & 0 & -1 \\
-1 & 1 & -1 & 1 & 0 & 0 \\
- & & &
\end{array}\right] \times\left[\begin{array}{l}
\mathrm{s}_{0} \\
\mathrm{~s}_{1} \\
\mathrm{~s}_{2} \\
\mathrm{~s}_{3} \\
\mathrm{~s}_{4} \\
\mathrm{~s}_{5}
\end{array}\right]}
\end{gathered}
$$

A partir da solução do sistema matricial, podem-se determinar as relações entre os números de disparos de das transições. Por exemplo, tem-se que $s_{0}=s_{4}+1$, isto é, o número de disparos de $t_{0}$ é uma unidade maior que o número de disparos da transição $t_{4}, \mathrm{e} \mathrm{s}_{0}=\mathrm{s}_{1}$, indicando que o número de disparos de $t_{0}$ deve ser igual ao número de disparos de $t_{1}$. Assim, a partir dos elementos de $s$, podem-se obter as segu intes relações:

$$
\mathrm{s}_{0}=\mathrm{s}_{4}+1, \mathrm{~s}_{1}=\mathrm{s}_{0}, \mathrm{~s}_{2}=\mathrm{s}_{5}+1, \mathrm{~s}_{3}=\mathrm{s}_{2}-1, \mathrm{~s}_{4}=\mathrm{s}_{1}-1, \mathrm{~s}_{5}=\mathrm{s}_{3}
$$

Se considerar-se $s_{0}=1$ e $s_{3}=0$, tem-se como solução do problema $s=(1,1,1,0,0,0)$. Significando que com os disparos das transições $t_{0}, t_{1}$ e $t_{2}$, obtém-se a marcação $M^{\prime}$, a partir de $\mathrm{M}_{0}$, isto é, $\mathrm{M}^{\prime}$ é alcançável a partir de $\mathrm{M}_{0}$. Vale observar que a marcação $\mathrm{M}^{\prime}$ pode ser alcançada em outras relações de disparo de transições.

\subsection{Statecharts}

Statecharts, assim como redes de Petri, são uma técnica de representação de sistemas através da visão de seus estados, e a modificação deles diante da ocorrência de uma determinada ação. Nesta seção, são apresentados conceitos, notações e exemplos de modelos utilizando a referida técnica.

\subsubsection{Definição e Notação Básica}

A definição básica de statecharts é alicerçada em conjuntos de estados, transições, eventos primitivos, condições primitivas e variáveis, a partir dos quais o modelador pode especificar os valores das variáveis do sistema em um certo instante. A idéia central do statechart é suprir a deficiência dos diagramas de estado em representar sistemas complexos (Harel, 87). Sistemas complexos requerem uma estrutura de representação hierárquica (com agrupamento e refinamento de estados) e de concorrência; de maneira que seja facilmente visível o movimento através dos estados do sistema no decorrer do tempo.

A técnica statechart é uma extensão às máquinas de estado finito, que possibilita a representação de hierarquia, concorrência e comunicação entre os diversos estados de um determinado sistema (Harel, 87). Os statecharts têm, preferencialmente, a finalidade de 
especificar sistemas reativos, ou seja, sistemas que devem reagir a estímulos externos e internos, normalmente sob condições críticas em relação ao tempo.

Esquematicamente, tem-se(Harel,87):

Statecharts $=$ Diagrama de Estados + Hierarquia + Concorrência + Mecanismos de Comunicaçāo.

Os estados de um statechart (que representam os valores das variáveis do sistema em um determinado instante) podem ser classificados em dois grupos: básicos e não-básicos. Os estados básicos são aqueles que nāo possuem subestados. Já os não-básicos são decompostos em subestados. Essa decomposição pode ser de dois tipos: OR ou AND. Se a decomposição é do tipo OR, então o sistema sempre estará em um único subestado em um certo instante. Entretanto, se a decomposição é do tipo AND, o estado poderá estar em mais de um subestado, simultaneamente. A figura 4.24 mostra os elementos básicos de estados na notação statechart.

A figura 4.24 apresenta as formas de representação de estados em statecharts. A esquerda, um estado $X$ do tipo $O R$ e seus subestados $\left(X_{1}, X_{2}, X_{3}\right)$, indicando que o sistema não estará em mais de um subestado ao mesmo tempo (subestados disjuntos). À direita, um estado $\mathrm{Y}$ do tipo AND e seus subestados $\left(\mathrm{Y}_{1}, \mathrm{Y}_{2}, \mathrm{Y}_{3}\right)$, indicando que o sistema pode estar em mais de um subestado simultaneamente. A concorrência de estados (ou subestados) é representada através de linhas tracejadas. Além da concorrência, a figura em questão ainda introduz a idéia de hierarquia entre os estados, ou seja, os subestados estão contidos em um estado denominado estado-pai (no exemplo, X e Y). Reciprocamente, um estado-pai contém estados-filho (subestados) dentro de si.

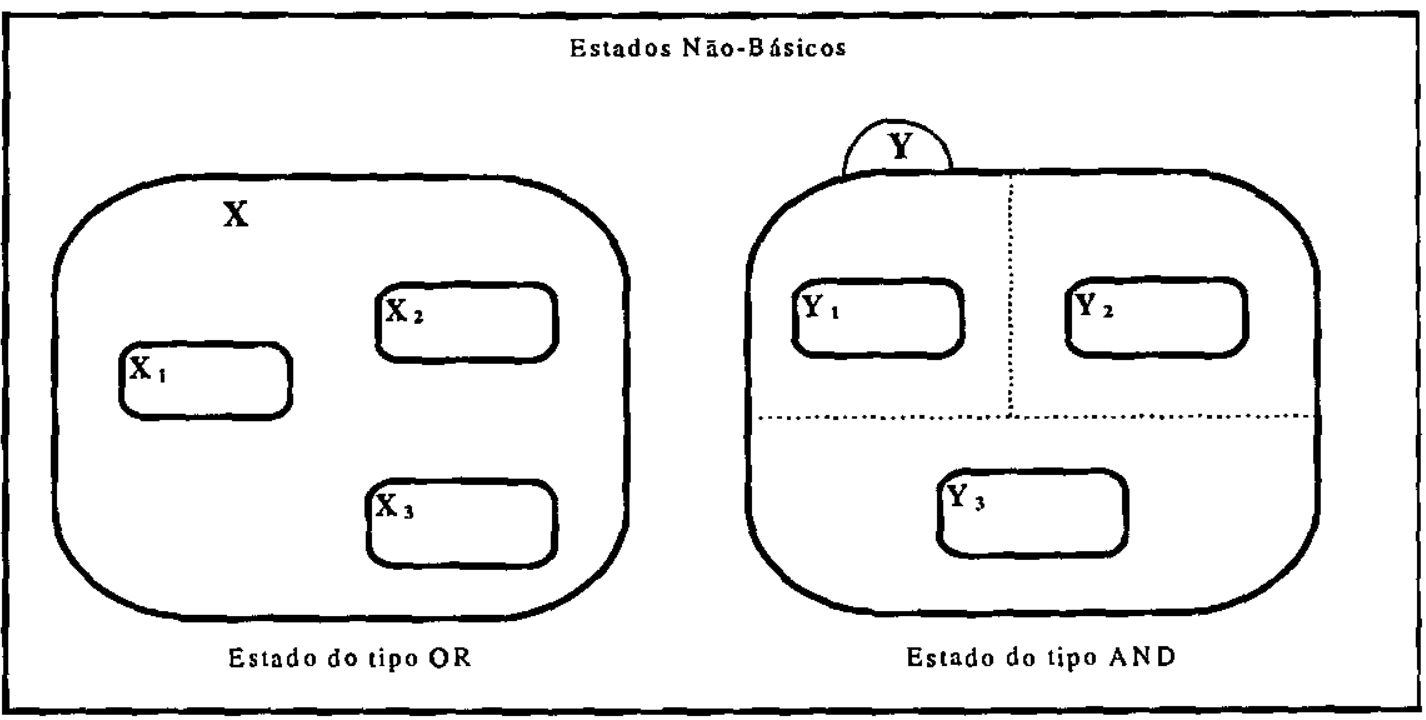

Figura 4.24. Representação de Estados em Statecharts.

Eventos (letras minúsculas) disparam transições, as quais são representadas por setas que unem estados. Os eventos podem ocorrer obedecendo a certas condições. Essas condiçōes são representadas por letras minúsculas entre parênteses (Boaventura, 92). Além disso, um superestado pode ter um estado inicial default, ou seja, toda vez que o sistema entrar nesse superestado, sempre será através do estado default. A figura 4.25 ilustra esses conceitos. 


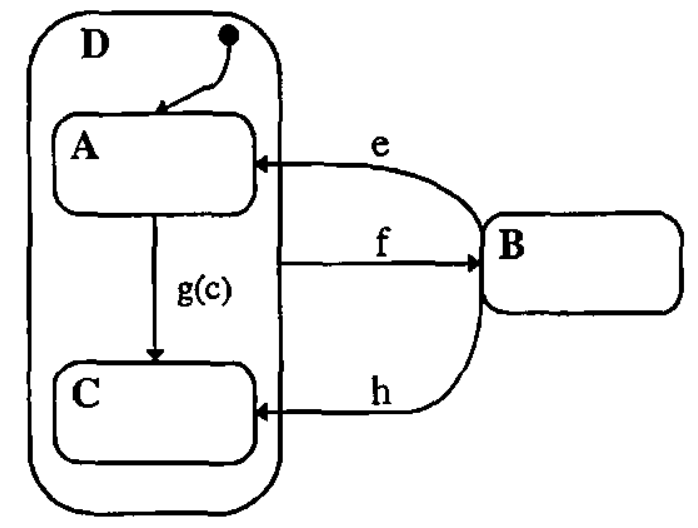

Figura 4.25. Estados, Eventos e Transiçס̃es.

Na figura, A, B, C e D são estados. O sistema passa de um estado para o outro quando a ocorrência de um evento $(e, f, g(c), h)$ dispara uma transição (setas). O evento $g(c)$ está controlado por uma condição (no caso, condição c). O estado default de D (superestado) é o estado A, representado pela seta característica do diagrama. Esse fato significa que o estado D sempre começa pelo seu subestado A.

\subsubsection{Sintaxe do Statechart}

\section{- Estados}

O conjunto de estados, $S$, é função da hierarquia, do tipo, da história e do estado default. A função hierárquica define o número de subestados de um estado, ou seja, é uma função do tipo $S \rightarrow 2^{n}(\mathrm{n} \in \mathrm{N}$ ). A função tipo define qual o tipo do estado (AND ou OR), isto é, é uma função do tipo $S \rightarrow\{$ AND, OR $\}$. A função história representa a capacidade de "lembrar" uma visita anteriormente feita a um estado, ou seja, é do tipo $\boldsymbol{H} \rightarrow \boldsymbol{S}$, onde $\boldsymbol{H}$ é um subconjunto do conjunto de estados. A função default define, para cada superestado, o seu estado inicial.

\section{- Transições}

Uma transição é definida por $t=(X, l, Y)$, onde $X$ é um conjunto origem, $Y$ é um conjunto destino, e $l$ é um rótulo (Boaventura, 92). Informalmente, se $l=e / a$, o sistema está em $X$ e $e$ ocorre, então $t$ está habilitada e pode ser tomada. Se $t$ é tomada, $a$ é executado e o sistema transiciona então para $\mathrm{X}$.

\subsubsection{Semântica do Statechart}

A semântica de execução dos statecharts é baseada em um modelo discreto de tempo, segundo o qual os estados de um sistema são duráveis, enquanto que as transiçōes são instantâneas. $O$ termo passo de execução ou de simulação tem origem nesse modelo de tempo. 
Diz-se, então, que em passo de execução, o statechart assume uma configuração de estados, a qual corresponde ao conjunto de estados básicos ativos naquele passo. Dessa forma, a cada passo, obtém-se uma nova configuração do statechart, a qual pode ou não ser igual à configuração anterior, dependendo de quais transições disparem. A figura 4.26 ilustra a configuração inicial de um statechart, a partir de seus estados default.

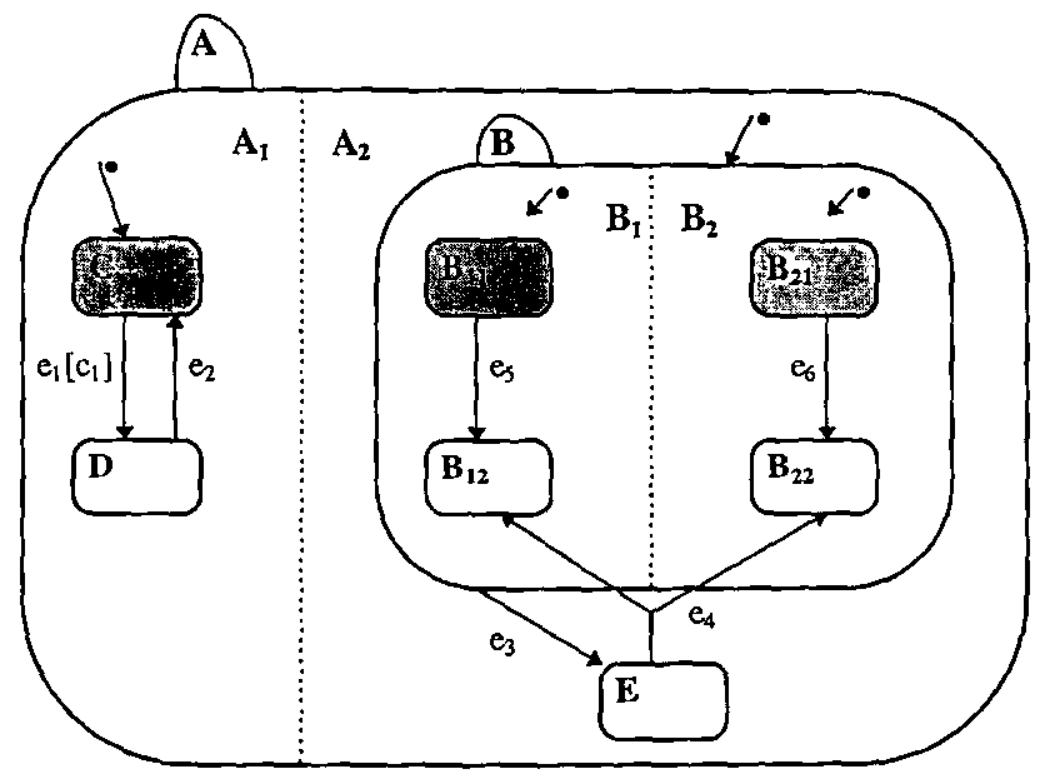

Figura 4.26. Configuração Inicial de um Statechart.

Caso os eventos $e_{1}\left[c_{1}\right]$ e $e_{5}$ ocorram, a nova configuração do statechart será igual à ilustrada na figura 4.27. Nota-se que, como os estados $A_{1}$ e $A_{2}$ são paralelos (ortogonais), os eventos $e_{1}\left[c_{1}\right]$ e $e_{5}$ acontecem simultaneamente. 


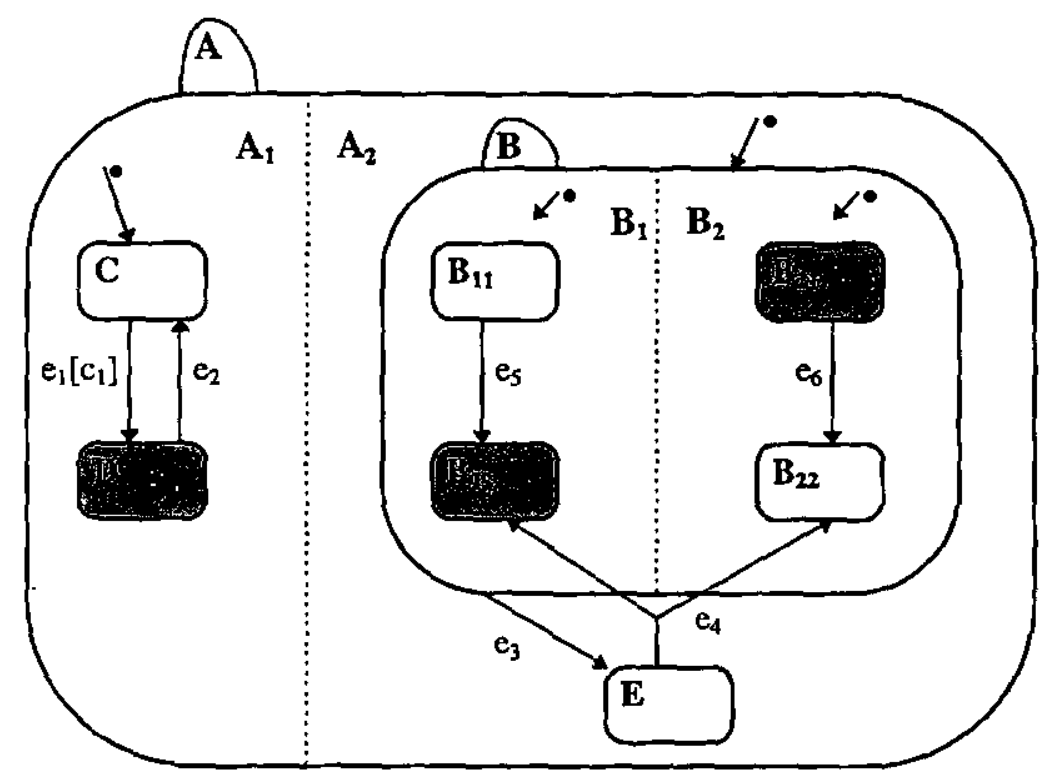

Figura 4.27. Configuração do Statechart após a Ocorrência de $\mathrm{e}_{1}\left[\mathrm{c}_{1}\right]$ e $\mathrm{e}_{5}$.

\subsubsection{Statecharts Temporais}

Os statecharts foram estendidos para uma versão voltada à especificação de sistemas de tempo real, dando origem aos "Timed Statecharts" (Pnuelli \& Kensten, 92). Nessa extensão, as expressões de eventos são acrescidas de um intervalo $[1, \mathrm{u}]$ que determina as fronteiras temporais mínima e máxima do disparo da transição. Os parâmetros temporais associados à transição determinam o tempo durante o qual o sistema permanecerá no conjunto de estados de origem, bem como o atraso permitido para que a transição dispare após a fronteira mínima ter sido alcançada.

Informalmente, pode-se dizer que a regra de disparo de uma transição temporal é a seguinte: uma transição temporal com uma expressão de evento " $t:[l, u][c] / a$ " associada, irá disparar se a condição $c$ resultar em true. Além disso, a transição só dispara depois de decorridas $l$ unidades de tempo, podendo levar $u-l$ unidades de tempo para que isso ocorra. Quando a transição finalmente disparar, a ação $a$ será executada e o sistema passará a estar no conjunto de estados destino da transição. A figura 4.28 ilustra um protocolo simples (anteriormente modelado em redes de Petri, figura 4.17), agora modelado em statecharts temporais. 


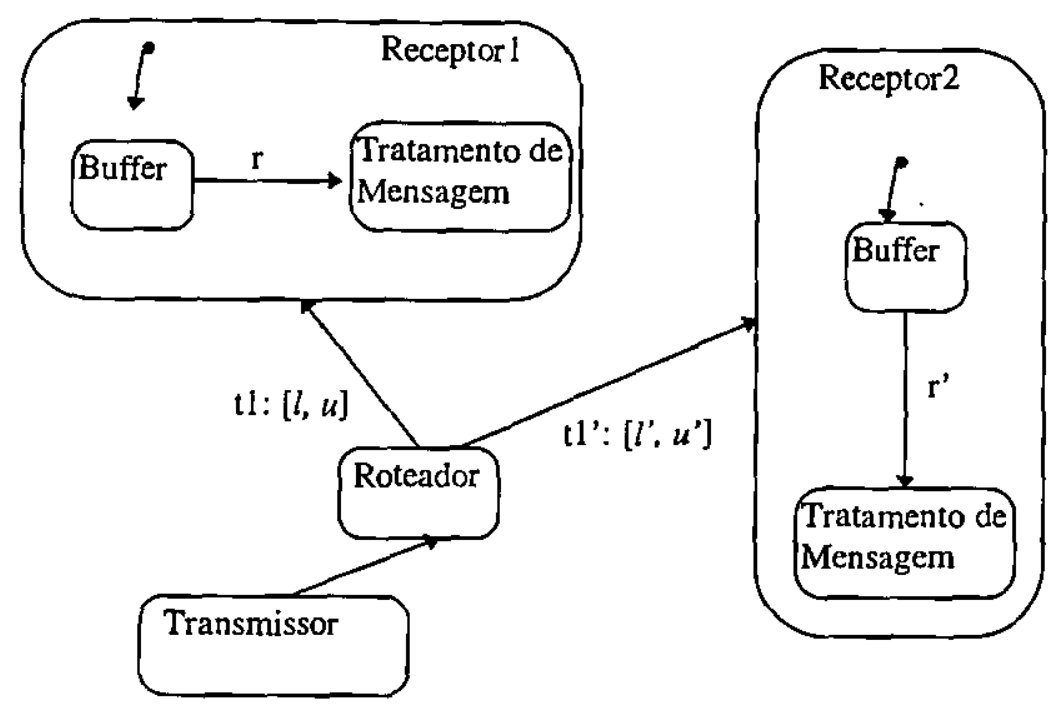

Figura 4.28. Statechart Temporal Representando um Protocolo Simples.

Na figura 4.28, a representação temporal evita a possibilidade de existência de escolha não-determinística no estado "Roteador", ou seja, a transição disparada será aquela que possuir menor valor de limite máximo ( $u$ ou u'). Assim a mensagem seguirá para o receptor que primeiro conseguir passar do estado "Roteador" para o estado Receptor (1 ou 2).

\subsection{Considerações Finais}

Modelos são técnicas de representação de um sistema computacional que proporcionam um estudo relativamente preciso (dependendo do método de resolução do modelo), sem que o sistema exista de fato. Essa flexibilidade tornam os modelos um objeto de estudo interessante em várias áreas da computação.

Várias técnicas de modelagem foram criadas para representar os sistemas (sejam eles computacionais ou não). Algumas delas são amplamente discutidas na literatura especializada e muito aplicadas na representação de sistemas computacionais. Neste capítulo, foram enfocadas três técnicas para modelagem de sistemas: as redes de filas, as redes de Petri e os statecharts.

Todas as técnicas, na sua notação original, possuem certas restrições para modelar alguns tipos de sistemas. As redes de filas, por exemplo, podem ser empregadas apenas em situações típicas de ocorrência de filas diante de recursos do sistema. Não representando, de forma mais abrangente, os estados e as transições às quais o sistema é submetido no decorrer do tempo. Redes de Petri e Statecharts, nesse aspecto, são equivalentes, ou seja, ambas as técnicas representam o sistema através de seus estados, e suas transições. Algumas das restrições das notações originais foram eliminadas, através da criação de extensões às técnicas. Fundamentalmente, tais extensões se preocupam em propiciar ao modelo a possibilidade de escolha determinística de um determinado trajeto e de uma representação hierárquica do sistema. Em redes de filas, a extensão RESQ provê essas características adicionais. Em redes de Petri, essas características são fornecidas, por exemplo, através das extensões coloridas ou 
temporizadas. Os statecharts também as provêem através de extensões como os statecharts temporais.

Como pode ser observado, os três métodos possuem uma forte base matemática. Essa base possibilita a prova analítica de algumas características do modelo. Um exemplo dessa possibilidade foi apresentado na seção 4.3.8.1, quando da apresentação da equação fundamental das redes de Petri (EFRP). Essa equação permite que, a partir de uma marcação inicial, determine-se se é possível alcançar uma certa marcação final. A prova através da resolução de um sistema matricial mostra um exemplo do fundamento matemático que está por trás dessa técnica.

Por fim, vale ressaltar que na impossibilidade da aplicação da solução analítica do modelo, a união do poder de representação dos modelos à flexibilidade dada pela simulação pode se constituir em uma saída bastante atraente. Há vários estudos realizados (e em andamento) que relacionam as proficuidades obtidas através da associação da modelagem com a simulação. $O$ grupo de Sistemas Distribuídos e Programação Concorrente do ICMSC/USP desenvolveu e está aprimorando o Ambiente de Simulação Automático (ASiA) (Santana et. al., 96a)(Santana et. al., 96b)(Spolon, 94a)(Spolon, 94b), que utiliza modelo de redes de filas associado à simulação orientada a evento. 


\section{Capítulo 5}

\section{Simulação}

\subsection{Considerações Iniciais}

Os modelos proporcionam a possibilidade de se antever características do comportamento de um sistema, mesmo antes que ele exista. Essa possibilidade adiciona uma série de benesses a um projetista de sistemas. Como foi abordado anteriormente (capítulo 3), a solução "ideal" do modelo está relacionada com algumas variantes do sistema real (por exemplo, número de informações que o sistema modelado vai manipular). Também frisou-se a capacidade limitada da solução do modelo através de métodos analíticos. A solução do modelo através de simulação tem-se mostrado mais aplicável para uma grande parte de sistemas que são alvos de modelagem.

No contexto da computação, a simulação refere-se ao emprego de um processo computacional para implementar um modelo que imita algum fenômeno ou sistema dinâmico (sistemas cujos estados se alteram com o tempo). A idéia de simulação é tão antiga quanto a própria computação. John von Neumann já vislumbrava a aplicação da computação na automação de dados estatísticos na modelagem de fenômenos (conhecida como processo Monte Carlo, onde o comportamento do sistema é descrito através de distribuição de probabilidade).

Nos dias atuais, a simulação transcende a fronteira do vislumbre, e passa a fazer parte de diversas áreas do conhecimento humano. Dentre os fatores que incentivaram o avanço da simulação, podem-se citar o desenvolvimento de hardware e das linguagens de programação, reduzindo de maneira considerável os esforços necessários para programar um modelo de simulação (Fishwick, 95).

Esta seção expõe características fundamentais da simulação. A abordagem se concentra apenas no aspecto seqüencial da simulação, não enfocando os conceitos da simulação distribuída. A simulação seqüencial aqui apresentada focaliza apenas o aspecto discreto. $O$ aspecto contínuo é posto em segundo plano, pelo fato de que a maioria dos fenômenos computacionais pode ser representada através de variáveis de estado que se alteram de maneira discreta.

\subsection{A Natureza dos Modelos}

A natureza de um sistema é avaliada de acordo com as mudanças (alterações) nas variáveis de estado do sistema. O tempo, na maioria das simulaçôes, é a principal variável independente. As outras variáveis incluídas na simulação são funções do tempo e, portanto, são variáveis dependentes. As mudanças podem ser discretas ou contínuas (dependendo do sistema a ser modelado), gerando duas técnicas básicas para modelagem de sistemas (Soares, 92):

Modelo de mudança discreta (ou modelo discreto) é aquele em que as variáveis dependentes variam discretamente em pontos especificos do tempo simulado, referidos como tempo de evento, conforme apresentado na figura 5.1. 


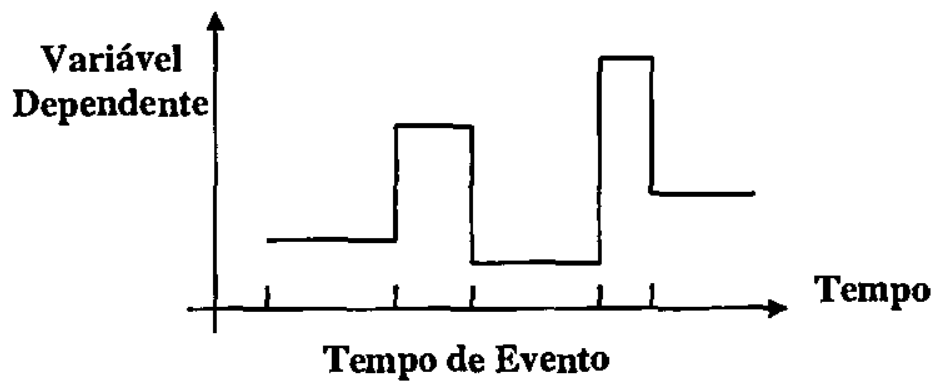

Figura 5.1. Variável Dependente em um Modelo Discreto.

Modelo de mudança contínuo (ou modelo contínuo) é aquele em que as variáveis dependentes podem variar continuamente ao longo do tempo simulado, conforme apresentado na figura 5.2.

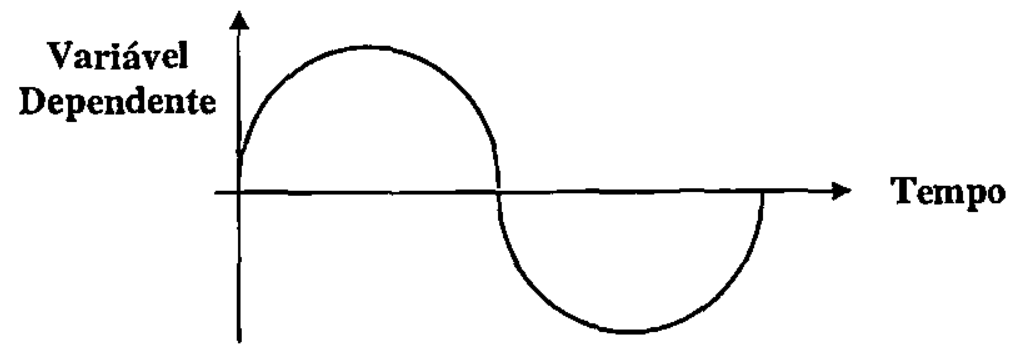

Figura 5.2. Variável Dependente em um Modelo Contínuo.

\subsection{Fases da Simulação}

Dentro de um processo de simulação, os seguintes estágios de desenvolvimento podem ser identificados (Soares, 92):

1. Estudo do Sistema e Definição dos Objetivos.

2. Construção do Modelo.

3. Determinação dos Dados de Entrada e Saída.

4. Tradução do Modelo.

5. Verificação.

6. Validação.

7. Experimentação.

8. Análise doß Resultados.

9. Documentação. 
O marco zero do processo de uma simulação é o estudo e entendimento do sistema considerado. O sistema deve ser definido com precisão e as metas pretendidas devem ser claras e objetivas (Pedgen, 91). Um mau entendimento dos objetivos do sistema e da simulação provavelmente poderá levar todo processo ao insucesso.

A segunda etapa do processo é a construção do modelo. Três técnicas para construção de modelos foram abordadas no capítulo 4: Redes de Filas, Redes de Petri e Statecharts. Essas técnicas, basicamente, possibilitam uma ampla abstração do sistema real, além de proporcionar uma maneira de solução do modelo. A grande complexidade dessa fase é fazer com que o modelo (sendo elaborado sob o ponto de vista do modelador) expresse realisticamente as características essenciais do sistema real.

Uma vez construído o modelo, deve-se gerar os dados de entrada que o alimentarão. Essa fase de formulação, via de regra, utiliza valores de entrada inicialmente hipotéticos ou baseados em alguma análise preliminar. Entretanto, nada impede que esses dados sejam modificados, tendo como base fatores considerados válidos pelo modelador. Porém, independente do juízo adotado para escolha dos dados de entrada, eles podem ser obedecer fundamentalmente a dois critérios: os dados podem ser vistos como Estocásticos (Probabilísticos) ou Determinísticos (sequiência de passos de trabalho).

Após a formulação dos dados de entrada, deve-se traduzir o modelo para uma forma aceitável pelo computador. Vários software de simulação estão disponíveis para realizar esse propósito. A gama vai de extensões funcionais de linguagens de programação convencionais, a linguagens específicas ou pacotes de simulação. A seção 5.4 mostra uma visão geral de software para simulação disponíveis atualmente.

As duas fases seguintes são, de certa maneira, complementares. A quinta etapa (de verificação) determina se o modelo traduzido para o computador executa como o esperado. A sexta fase (de validação) consiste em determinar se o modelo é uma representação razoável do sistema. Assim, as duas fases em questão exprimem se o modelo funciona e se ele realmente representa o sistema real.

As etapas de experimentação e de análise dos resultados são aquelas em que efetivamente há a exercitação do modelo e uma posterior interpretação das saídas. Nessas duas etapas, a simulação se faz mais clara, pois então se obtêm saídas que podem atestar a eficácia de todo o processo.

A etapa da documentação consiste na elaboração de documentos que retratem de maneira clara o desenvolvimento do processo de simulação, através de todas as suas etapas, especificando as características importantes de cada fase, assim como os resultados obtidos.

Apesar das fases da simulação terem sido apresentadas de uma maneira que subentendesse um aspecto seqüencial, nada impede que haja interações entre as diversas etapas do processo. Na realidade, a maioria das processos de simulação é feita de maneira nãoseqüencial.

\subsection{Orientações para Simulação}

Basicamente, há três entidades que podem proporcionar orientações distintas à simulação: atividades, eventos e processos. O importante é ressaltar que essas entidades não são disjuntas. $\mathrm{Na}$ verdade, umas são componentes das outras. O conjunto dessas entidades representa o 
comportamento e o desempenho do sistema. A figura 5.3 (Soares, 92) apresenta o interrelacionamento entre as três entidades.

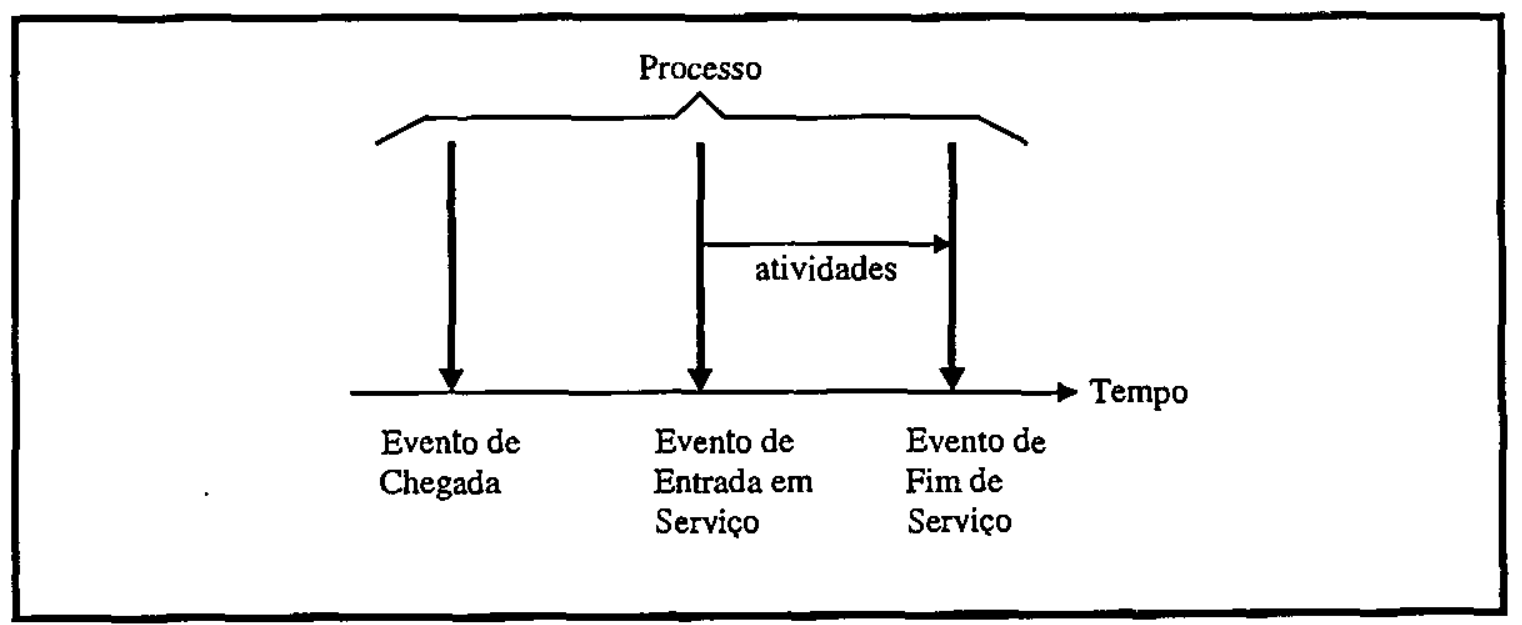

Figura 5.3. Relações entre Evento, Processo e Atividade.

Todas as entidades mostradas na figura 5.3 dependem do nível de detalhamento (visão particular) do sistema considerado. $O$ importante é perceber que o relacionamento entre elas ocorre da seguinte maneira: eventos ocorrem e mudam o estado do sistema. Os eventos são motivados por algum tipo de atividade. $\mathrm{E}$ o conjunto de eventos logicamente relacionados e suas atividades motivadoras constituem o processo (que é um superconjunto contendo eventos e atividades).

Para exemplificar o relacionamento entre as entidades, supõe-se que se queira representar uma situação já bastante explorada neste trabalho: processos (que aqui serão referenciados por jobs, para evitar ambigüidade) concorrendo por um processador. Um job chega à fila do processador (evento) e, após algum período de tempo, ele é atendido (evento), o processador o processa (atividade) e, após o processamento, o job abandona o processador (evento). Toda essa sequiência de eventos e atividades é chamada de processo.

Assim, a simulação discreta pode ser orientada de acordo com a entidade básica (atividades, eventos e processos) que direciona a ótica da simulação, resultando nas seguintes orientações (Soares, 92):

\subsubsection{Simulação Orientada a Evento}

Na simulação orientada a evento, um sistema é modelado através da definição das mudanças que ocorrem em cada evento (Soares, 92), ou seja, a visão do sistema é fornecida através da ocorrência de eventos e do impacto que eles causam nos estados do sistema.

Tomando-se ainda como base o exemplo de jobs para serem processados por um processador, tem-se que este (o processador) é o servidor (recurso) do sistema. Já os jobs são os clientes do servidor. Com um servidor único, o estado do sistema é completamente definido pelo estado do processador e pelo número de jobs à espera de processamento. Em suma, os eventos chegadas e saídas de jobs do processador definem os aspectos dinâmicos do sistema, daí, nesse exemplo, a orientação ser baseada em eventos. 


\subsubsection{Simulação Orientada ao Exame da Atividade}

Nesta orientação, descrevem-se as atividades relacionadas com cada entidade do sistema, definindo as condiçōes que causam o início e o fim de uma atividade, isto é, os eventos. Essa abordagem focaliza sua atenção na atividade, sendo que os eventos são usados apenas para delimitar o acontecimento de uma atividade.

Assim, no caso do exemplo visto para a orientação a eventos, a atividade do processamento dos jobs é o ponto central da simulação, e os eventos de chegadas e saídas de jobs servem apenas para delimitar a atividade de processamento. Para utilizar-se essa abordagem, é necessário que a duração da atividade seja indefinida, pois assim o estado do sistema estaria mais condicionado à atividade. No exemplo utilizado aqui, a atividade de processamento seria o aspecto mais importante da simulação, ou seja, as chegadas e saídas de jobs em uma fila possuem uma importância secundária em relação ao processamento deles.

\subsubsection{Simulação Orientada a Processo}

Em simulação orientada a processo, o sistema a ser simulado é visto como uma coleção de processos interativos, controlados e coordenados pela ocorrência de eventos (Soares, 92). Essa abordagem é bastante interessante quando se deseja representar processos ocorrendo de maneira concorrente em um sistema.

Tomando-se o exemplo utilizado nas duas abordagens anteriores, tem-se que há a possibilidade agora de representar vários servidores (processadores) trabalhando concorrentemente, cada um com sua fila de jobs separada. Assim, o sistema pode ser descrito como um conjunto de processos que operam de maneira concorrente durante a simulação.

\subsection{Software para Simulação}

De uma maneira geral, os software para implementar a simulação podem ser agrupados nas seguintes subclasses (Soares, 92):

- Linguagens de programação convencionais;

- Linguagens de simulação;

- Extensões funcionais;

- Pacotes de uso específico.

Linguagens de Programação Convencionais, apesar de não terem sido desenvolvidas com o objetivo de simular, podem impiementar simulações, logicamente, sujeitas a várias restrições inerentes às peculiaridades da própria linguagem. Entretanto, essas linguagens (como C, Pascal, etc.) possuem a vantagem de serem amplamente conhecidas e, conseqüientemente, haver mais pessoas habituadas com o estilo da linguagem.

Linguagens de Simulação já são projetadas com uma finalidade específica: a simulação de sistemas. Essas linguagens obedecem a uma das orientações vistas na seção 5.3 (ao exame da atividade, a evento ou a processo), conforme as necessidades que o modelo (ou o modelador) impōe. Em outras palavras, as linguagem de simulação podem ser orientadas ao exame da 
atividade, a evento ou a processo. Como exemplo de linguagem de simulação orientada ao exame da atividade tem-se CSL. Exemplos de linguagens orientadas a evento são SIMSCRIPT, GASP, SMPL, SLAM II (Morselli, 95). Alguns exemplos de linguagens de simulação orientada a processo são GPSS, Q-GERT (Soares, 92), SIMULA e RESQ (Soares, 92).

Extensões Funcionais são bibliotecas acrescentadas a linguagens de propósito geral (C, Pascal, Fortran, por exemplo), que são denominadas linguagens hospedeiras. A grande vantagem das extensões reside no fato de não se necessitar de aprendizagem de uma nova linguagem para realizar simulação, pois a linguagem utilizada é conhecida. $O$ único problema está no fato de que é necessário um prévio conhecimento da filosofia da simulação adotada. São exemplos de extensões SMPL (extensão da linguagem C orientada a evento) (MacDowgall, 87), e HPSIM (extensão da linguagem Modula 2 orientada a processo) (Sharma \& Lauwrence, 88).

Entretanto, existem software para simulação que são direcionados à avaliação de sistemas peculiares. Esses software são denominados pacotes de simulação e, para casos bastante específicos, realizam soluções de simulação satisfatórias. O problema dos pacotes de simulação está na inflexibilidade do software, isto é, pequenas mudanças no modelo simulado podem gerar uma extrapolação do escopo da ferramenta, inviabilizando a sua utilização. Em (Swain, 95), há um vasto estudo desse tipo de software para simulação, exemplificado na tabela 5.1.

\begin{tabular}{|c|c|c|c|c|c|}
\hline Software & ARENA & $\begin{array}{l}\text { OPNET } \\
\text { Modeler }\end{array}$ & QueGAUSS & PROVISA & $\begin{array}{c}\text { WorkFlow } \\
\text { Analyzer }\end{array}$ \\
\hline Proprietário & $\begin{array}{c}\text { Systems } \\
\text { Modeling } \\
\text { Corporation }\end{array}$ & MIL 3, Inc. & $\begin{array}{l}\text { Aptech } \\
\text { Systems, } \\
\text { Inc. }\end{array}$ & AT\&T & $\begin{array}{c}\text { Meta } \\
\text { Software } \\
\text { Corp. }\end{array}$ \\
\hline $\begin{array}{l}\text { Aplicações } \\
\text { Típicas }\end{array}$ & $\begin{array}{l}\text { Ferramenta de } \\
\text { Simulação } \\
\text { geral, molda- } \\
\text {-se a muitas } \\
\text { aplicações } \\
\text { diferentes. }\end{array}$ & $\begin{array}{l}\text { Modelagem } \\
\text { de protocolos } \\
\text { de } \\
\text { comunicação } \\
\text { de redes. }\end{array}$ & $\begin{array}{l}\text { Sistemas de } \\
\text { filas. }\end{array}$ & $\begin{array}{l}\text { Manufatura } \\
\text { com } \\
\text { capacidade } \\
\text { finita de } \\
\text { escalona- } \\
\text { mento }\end{array}$ & $\begin{array}{l}\text { Melhorias } \\
\text { de } \\
\text { processos } \\
\text { de negócios }\end{array}$ \\
\hline Plataformas & $\begin{array}{l}\text { PC's (DOS) e } \\
\text { Estações } \\
\text { (UNIX) }\end{array}$ & $\begin{array}{l}\text { DEC-Alpha, } \\
\text { HP-UX, } \\
\text { IBM, SUN }\end{array}$ & $\begin{array}{l}\text { IBM PC, } \\
\text { SUN, IBM } \\
\text { RISC. }\end{array}$ & $\begin{array}{l}\text { IBM PC, } \\
\text { SUN, HP. }\end{array}$ & $\begin{array}{l}\text { IBM, } \\
\text { MAC, } \\
\text { SUN. }\end{array}$ \\
\hline $\begin{array}{c}\text { Preço (U\$) } \\
\text { Versão } \\
\text { Padrão }\end{array}$ & $\begin{array}{l}\text { Contato com } \\
\text { o vendedor }\end{array}$ & 25.000 & 275 & $\begin{array}{c}\text { Contato } \\
\text { com o } \\
\text { vendedor }\end{array}$ & 10.000 \\
\hline
\end{tabular}

Tabela 5.1. Pacotes de Simulação.

\subsection{O Ambiente para Simulação Automático (ASiA)}

O ASiA foi desenvolvido e vem sendo aprimorado pelo grupo de Sistemas Distribuídos e Programação Concorrente do ICMSC-USP (Santana et. al., 96a)(Santana et. al., 96b)(Spolon, 94a)(Spolon, 94b). O ambiente consiste de quatro módulos básicos: um editor gráfico, um gerador de aplicações, um de análise de saída e um de visualização. A figura 5.4 (Santana et. al., 96a)(Santana et. al., 96b) ilustra o relacionamento entre os módulos básicos do ASiA. 


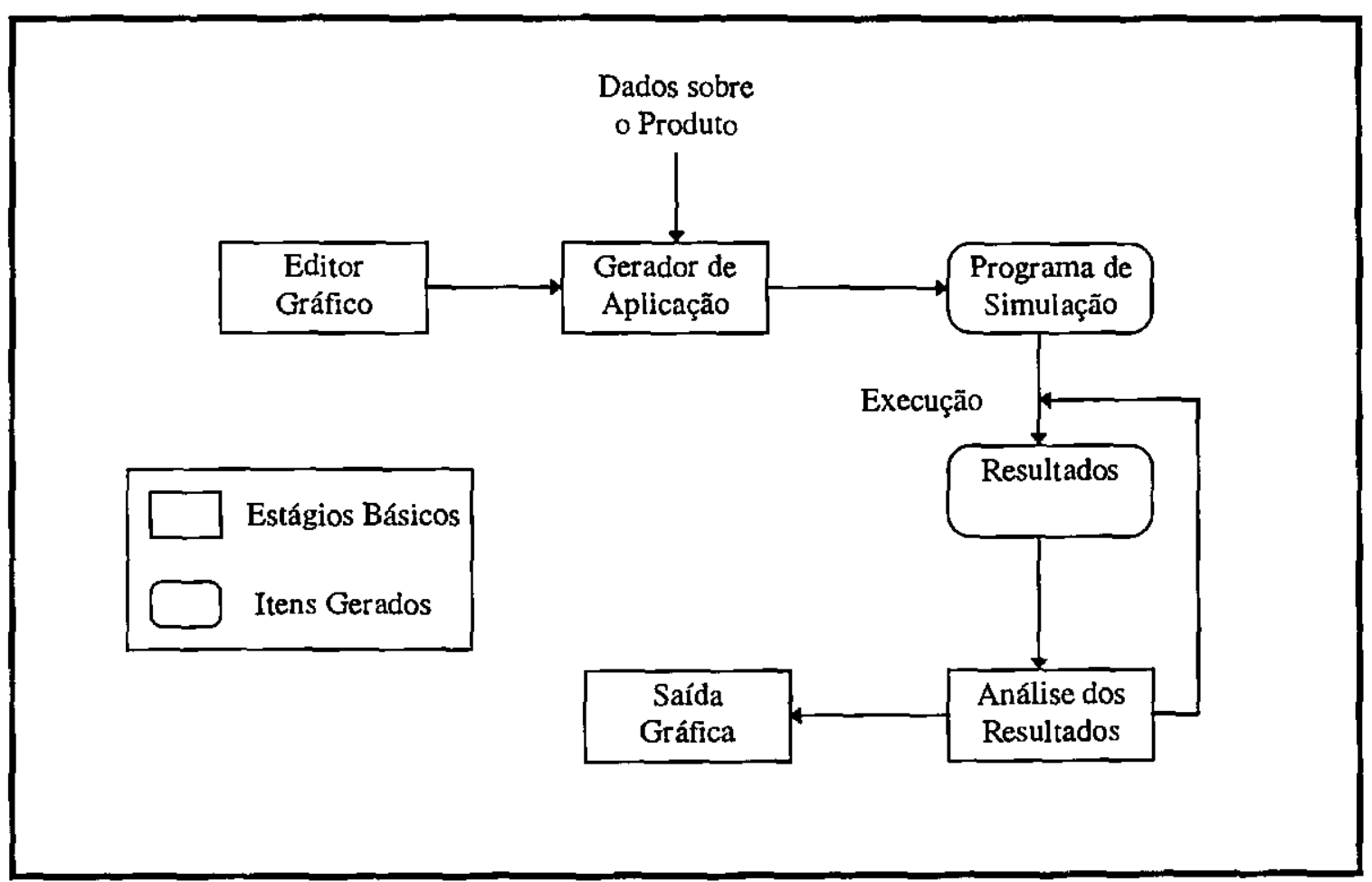

Figura 5.4. Estrutura Básica do ASiA.

O editor gráfico do ASiA (EdGraf) (Santana et. al., 96b) serve de interface entre o usuário e módulo gerador de aplicação. Esse editor foi implementado utilizando-se a linguagem $\mathrm{C}$ e programação para Windows, em plataformas Windows 3.1/1BM-PC compatíveis. O editor gráfico oferece ao usuário uma interface amigável, possibilitando que ele desenhe seu modelo na tela, apague elementos do modelo, grave arquivos, etc. O ASiA utiliza como método de modelagem as rede de filas.

O gerador de aplicaçāo (Santana et. al., 96a) foi desenvolvido utilizando-se a linguagem C (em IBM-PC) e SMPL, que é uma extensão funcional de C para simulação orientada a evento (MacDowgall, 87). Por conseguinte, o ASiA é um ambiente que provê simulação orientada a evento (conforme visto na seção 5.3.). Esse módulo tem como produto final o programa de simulação.

O programa de simulação será executado, e os resultados obtidos a partir dessa execução serão avaliados pelos outros dois módulos do ASiA. O módulo de visualização permite que os resultados alcançados na simulação sejam visualizados através de gráficos inteiramente definidos pelo usuário, que pode determinar tanto o tipo de gráfico a ser usado (barra, ponto, linha, etc.), quanto as informações constantes nos eixos. O módulo de análise de saída provê intervalos de confiança para garantir que a aleatoriedade da simulação não torne os resultados pouco confiáveis. Esses dois últimos módulos foram desenvolvidos no ambiente Windows, utilizando o compilador Borland $\mathrm{C}_{++} 4.02$. 


\subsection{Considerações Finais}

Uma exigência do atual estado da arte da computação é a criteriosa avaliação de um sistema computacional antes que ele efetivamente exista, para que então se decida pela implementação (ou desistência) do projeto do sistema. Essa exigência atual reforça o poder e a aceitação da simulação como técnica de avaliação do comportamento de um determinado sistema.

Graças ao avanço das ferramentas, hoje, a simulação está sendo utilizada em inúmeras áreas do conhecimento humano. A seção 5.4 apresentou um pequeno subconjunto do universo possível das aplicações. Foi também apresentada uma ferramenta de simulação denominada ASiA (seção 5.5.), desenvolvida pelo grupo de Sistemas Distribuídos e Programação Concorrente do ICMSC-USP. Esse grupo está empenhado em pesquisas referentes à modelagem e simulação para a observação do comportamento de sistemas computacionais (com ênfase para os sistemas distribuídos). Essas pesquisas incluem, entre os seus objetivos, o estudo de novos métodos de modelagem, como por exemplo redes de Petri. 


\section{CAPÍTULO 6}

\section{STOCHASTIC FEATURE CHARTS (SFC)}

\subsection{Considerações Iniciais}

Um fator relevante em uma avaliação de desempenho de um sistema computacional é a possibilidade de inserção de probabilidades no modelo, associadas às transições entre os possíveis estados que esse sistema possa vir a se encontrar. Das técnicas abordadas nesta dissertação, em sua concepção original, apenas as redes de filas já trazem a idéia de chegadas às filas e atendimento nos servidores obedecendo a uma função distribuição de probabilidade (por exemplo, a clássica exponencial M/M/1).

Entretanto, a necessidade de se representar mais que apenas o comportamento do sistema, fez com que fossem criadas extensões às técnicas formais, cuja finalidade primordial girava em torno da representação dos sistemas de maneira mais real, ou seja, também em termos probabilísticos. Dessa preocupação, surgiram algumas extensões para redes de Petri com esse propósito. Dentre elas, duas se tornaram notórias: Stochastic Petri Nets (Molloy, 82) e Generalized Stochastic Petri Nets (Chiola, 93). Em ambas, consta o intuito de se visualizar o sistema como um conjunto de processos estocásticos, onde, apesar de inter-relacionadas, as ocorrências de um determinado estado $S_{n+1}$ só depende, no máximo, da ocorrência do estado $S n$.

Apesar dessa latente necessidade, os Statecharts ainda não possuem uma extensão com esse propósito. O próprio idealizador dos Statecharts, David Harel (Harel, 87), já sugeria para trabalhos futuros a possibilidade da descrição de processos estocásticos, batizado à época de "Markov-Charts". Este capítulo propõe uma extensão aos Statecharts, denominada de Stochastic Feature Charts, que objetiva associar os Statecharts às cadeias de Markov, podendo-se assim determinar de maneira probabilística (e, portanto, mais realista) as mudanças de estados ocorridas em um sistema com o decorrer do tempo. Antes, porém, serão apresentados alguns conceitos que fundamentam a proposta desta dissertação. Vale ressaltar que, quando não for estritamente necessário, pretende-se "esconder" a complexidade matemática de algumas definições. 


\subsection{Processos Estocásticos e Cadeias de Markov}

Um Processo Estocástico é uma variável aleatória cujo valor varia com o tempo, ou seja, um processo estocástico é um modelo matemático utilizado para o estudo de fenômenos aleatórios que tem como resultados funções. Essas funções são chamadas trajetórias e estão definidas sobre um conjunto arbitrário $T$ (usualmente tomado como o intervalo real $[0,+\infty)$ ), também chamado de conjunto de parâmetros.

Formalmente, um processo estocástico consiste de um conjunto não vazio $\mathrm{T}$, chamado de espaço paramétrico, e na associação para cada $t \in \mathrm{T}$ de uma variável aleatória Xt: $\Omega \rightarrow \mathrm{S}$ (onde $\Omega$ e cada ponto do espaço amostral $\mathrm{W}$ ), todas elas definidas sobre o mesmo espaço de probabilidades (Kovacs, 96).

Usualmente, $\mathrm{T}$ é tomado como o conjunto $[0,+\infty)$ ou $\mathrm{N}=\{0,1,2,3, \ldots\}$. No primeiro caso, está-se referindo a um processo estocástico a parâmetro contínuo; e no segundo, está-se tratando de um processo estocástico a parâmetro discreto. $O$ âmbito desta pesquisa se restringe aos processos estocásticos a parâmetro discreto e o parâmetro aqui abordado sempre será o tempo.

Os processos estocásticos podem ser definidos de acordo com uma notação matricial, através de Matrizes Estocásticas.

Uma matriz quadrada $P=\left(p_{i j}\right)$ é chamada matriz estocástica, se cada uma de suas linhas é um vetor de probabilidade, isto é, se cada entrada de $P$ é não negativa e a soma das entradas em cada linha é 1. Formalmente, $p_{i j}, i, j \in \mathrm{N}$, tal que $p_{i j} \geq 0 \mathrm{e} \forall i \in \mathrm{N}, \sum p_{i j}=1$ (Meyer, 95). A matriz apresentada na figura 6.1 é uma matriz estocástica.

$$
\left[\begin{array}{ccc}
0 & 1 & 0 \\
1 / 2 & 1 / 6 & 1 / 3 \\
1 / 3 & 2 / 3 & 0
\end{array}\right]
$$

Figura 6.1. Exemplo de Matriz Estocástica. 
Um exemplo de um processo estocástico pode ser dado pelo número de pacotes em trânsito na sub-rede de comunicação de uma rede local. O número é função específica do instante em que são feitas as observações. Espera-se um número maior de pacotes imediatamente após a submissão de uma transferência de arquivos do que em outros instantes.

Se, entretanto, um processo estocástico do tipo $x_{1}, x_{2}, \ldots$, possui as propriedades de (Lipschultz, 94):

(i) Cada resultado pertence a um conjunto finito de resultados $\left(a_{1}, a_{2}, \ldots, a_{m}\right)$, chamado o espaço de estados do sistema; se o resultado da n-ésima tentativa é $a_{i}$, diz-se que o sistema se encontra no estado $a_{i}$ no instante n;

(ii) O resultado de qualquer ensaio (sinônimo de etapa, no contexto deste capítulo) depende no máximo do resultado imediatamente anterior e não de qualquer outro dos estados precedentes; a cada par de estados $\left(a_{i}, a_{j}\right)$ está associada a probabilidade $p_{i j}$ de que $a_{j}$ ocorre imediatamente após ter ocorrido $a_{i}$;

então esse processo estocástico é denominada Cadeia de Markov (finita) e, os números $p_{i j}$ são probabilidades de transição entre dois estados, sendo que cada linha da matriz denominada de matriz de transição (figura 6.2) apresenta os valores das probabilidades $p_{i j}$ de um estado origem transicionar para um estado destino (Lipschultz, 94).

Assim, a cada estado $a_{i}$ corresponde a i-ésima linha $\left(p_{i 1}, p_{i 2}, \ldots, p_{i m}\right)$ da matriz de transição $P$. Se o sistema está no estado $a_{i}$, então esse vetor-linha representa as probabilidades de todos os possíveis resultados do próximo ensaio, de forma que é um vetor de probabilidade. Consequentemente, a matriz de transição $P$ da cadeia de Markov é uma matriz estocástica.

$$
\left[\begin{array}{ll}
p_{11} & p_{12} \ldots \ldots p_{l m} \\
p_{21} & p_{22} \ldots . . . p_{2 m} \\
\ldots & \ldots . . . \\
p_{m 1} & p_{m 2} \ldots . . p_{m m}
\end{array}\right]
$$

Figura 6.2. Matriz de Transição. 
$\mathrm{Na}$ verdade, uma cadeia de Markov é um processo estocástico que possui uma propriedade especial denominada "Memoryless", ou seja, o futuro não depende da forma em que se chega a um estado $s_{n-1}$; depende só do fato que no tempo $t_{n-1}$ está-se no estado $s_{n-1}$ (Kovacs, 96). Partindo-se dessa propriedade, pode-se definir um Statechart através de uma analogia às cadeias de Markov, vendo esses Statecharts através de matrizes de transição e suas propriedades. Essa analogia é iniciada a seguir.

\subsection{Stochastic Feature Charts (SFC)}

Pode-se imaginar um Statechart como um conjunto de estados $S$, onde há uma probabilidade $p$ de se transicionar de um estado-origem $s_{n}$ para um estado-destino $s_{n+1}$ $\left(\forall s_{i} \in S\right)$, conforme figura 6.3 .

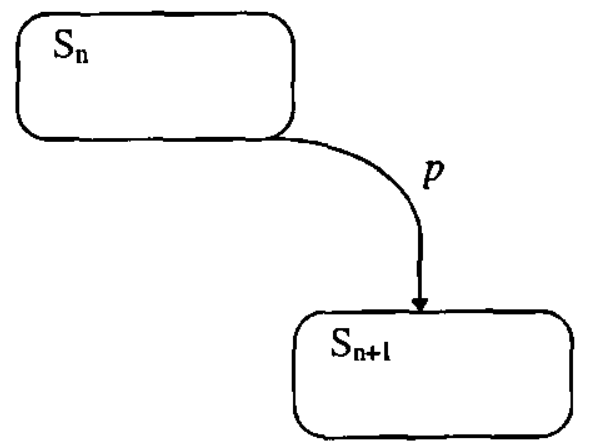

Figura 6.3. Estados e Probabilidade de Transição.

Apesar da definição dos statecharts ser baseada em conjuntos de estados, de transições, de eventos primitivos, de condições primitivas e de variáveis, em SFC será considerado apenas o conjunto de estados. Na verdade, esse conjunto será interpretado como bags, ou seja, conjuntos que admitem repetições em seu cerne. Essa nova interpretação se deve ao fato de que um estado pode ser estado-entrada de mais de um estado, aparecendo, assim, mais de uma vez no conjunto de estados-entrada. O conjunto de estados S do Statechart original, em SFC, é subdividido em 
bag de estados de entrada ${ }^{\circ} S$, e bag de estados de saída $S^{o}$. Além dessas duas bags, faz-se necessário definir mais uma bag $P$, que terá como elementos todas as probabilidades de se passar de um estado $s_{i}$ para um estado $s_{j}$.

Formalmente, Stochastic Feature Chart é definido como uma tripla:

$$
\mathrm{SFC}=<^{\circ} S, S^{\circ}, P>\text {, onde: }
$$

${ }^{o} S$ é a bag de estados de entrada;

$S^{\prime \prime}$ é a bag de estados de saída;

$P \quad$ é bag das probabilidades de um estado de entrada $s_{i}$ transicionar para um estado de saída $s_{j}$.

Deve-se observar que continua preservada a característica original dos statecharts, ou seja, SFC também tem apenas um conjunto de estados, porém agora decomposto em duas bags (estados de entrada e de saída).

\subsubsection{Notação SFC}

Algumas modificações são propostas com o intuito de cobrir certas especificações sugeridas aqui e que, logicamente, não poderiam ter sido abordadas no diagrama original.

O diagrama SFC possui basicamente três elementos, como segue (figura 6.4):

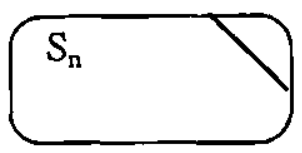

Denota os estados de um SFC

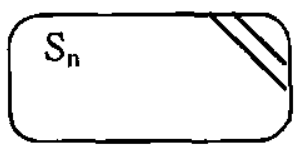

Denota os estados destino concorrentes de um SFC

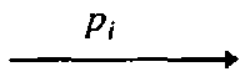

Seta direcionada que denota a transição entre os estados, cujos rótulos são probabilidades $p_{i}$, $\forall i \in \mathrm{N}$ 
Apropriadamente, SFC herda todos os elementos dos statecharts tradicionais, exceto o fato de que em qualquer seta direcionada todo rótulo se refere a valores probabilísticos.

\subsubsection{Estados Absorventes}

Formalmente, um estado $a_{i}$ de um SFC é dito absorvente se o sistema permanece no estado $a_{i}$, uma vez que este tenha sido visitado. Assim, um estado $a_{i}$ é chamado absorvente se somente se a i-ésima linha da matriz de transição $P$ tem 1 (um) na diagonal principal e 0 (zeros) nas outras posições. A matriz da figura 6.5 ilustra essa possibilidade.

$\mathrm{A}\left[\begin{array}{lll}\mathrm{A} & \mathrm{B} & \mathrm{C} \\ \mathrm{B} & p_{1} & p_{2} \\ 0 & 1 & 0 \\ 0 & 0 & 1\end{array}\right]$

Com $p_{1}+p_{2}=1, \mathrm{~B}$ e C são estado absorventes.

Figura 6.5. Matriz de Transição com Estados Absorventes.

Pode-se supor que, por exemplo, um processo ao abandonar o processador deve seguir ou para uma impressora ou para um monitor de vídeo. O estado A representa o processador de um computador, e B e C representam os dispositivos de entrada/saída monitor de vídeo e impressora, respectivamente. Assim, para a situação do SFC abaixo, a matriz de transição da figura 6.5 seria adequada, pois B e C são estados absorventes, ou seja, ao serem visitados, o sistema permanece neles. A figura 6.6 ilustra a mesma situação num gráfico SFC. 


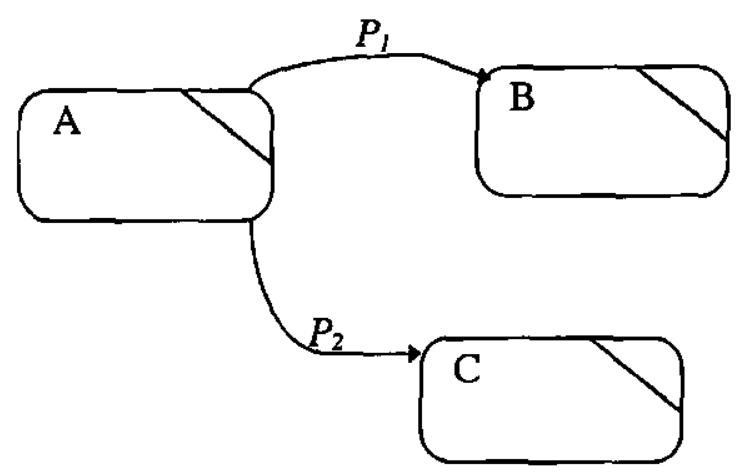

Figura 6.6. SFC com Estados B e C Absorventes.

Intuitivamente, pode-se inferir que para que um SFC possua estado(s) absorvente(s), deve haver estado(s) que não possua(m) estados de saída, a não ser eles próprios.

\subsubsection{Matrizes Regulares, Vetores Fixos e SFC Regulares}

Uma matriz estocástica $P$ é considerada regular se somente se todas as entradas de alguma de suas potências $P^{2}, P^{3}, \ldots P^{n}$ têm seus valores positivos (Meyer, 95). As matrizes estocásticas regulares possuem a propriedade importante de haver um único vetor fixo $t$ de probabilidade, cujas componentes de $t$ são todas positivas. Supondo-se que, por exemplo, $t=$ $(x, 1-x)$ seja o vetor fixo da matriz regular $P$, então o produto de $t$ e $P$ resultará nos valores dos componentes do vetor fixo. A figura 6.7 ilustra essa afirmativa.

Analogamente para qualquer matriz regular, pode-se obter os valores das componentes do vetor através da resolução do sistema gerado pela multiplicação do vetor $t$ pela matriz $P$, e através da igualdade, encontrar valores para componentes de $t$ (x e 1-x, no exemplo da figura $6.7)$.

À medida que se realiza a seqüência de suas n potências (etapas), e observado que a matriz de transição $P$ obtida é uma matriz regular, então $P$ converge a uma matriz $T$, cujas linhas tendem ao único vetor fixo $t$, isto é, com o aumento do valor de n (potências de $P$ ), $P$ converge para $T$. 


$$
\begin{aligned}
& (x, 1-x)\left[\begin{array}{cc}
p & 1-p \\
q & 1-q
\end{array}\right]=(x, 1-x) \\
& (p x+q(1-x),(1-p) x+(1-q)(1-x))=(x, 1-x) \\
& p x+q(1-x)=x \\
& x-p x+q x=q \\
& x(1-p+q)=q \\
& x=q /(1-p+q) \quad(1-p) x+(1-q)(1-x)=1-x \\
& \operatorname{logo,~o~vetor~} t=(q /(1-p+q), 1-(q /(1-p+q))) \\
& \begin{array}{c}
\downarrow \\
\downarrow
\end{array}
\end{aligned}
$$

Figura 6.7. Vetor Fixo de uma Matriz Estocástica Regular.

Baseando-se na teoria de Markov, pode-se estender o conceito de matriz estocástica regular aos SFC. Assim, um SFC é considerado regular se há uma potência de sua matriz de transição $P$ que tem todas as suas entradas positivas. A utilização dessa propriedade será apresentada posteriormente. Por hora, far-se-á apenas a exemplificação de um SFC regular.

Considerando-se um exemplo de uma transmissão de pacotes em um meio de comunicação. Supondo-se que o sistema possua os estados A (Fila de pacotes), estado B (canal livre) e estado C (canal ocupado), tepresentados pelo SFC da figura 6.8 .

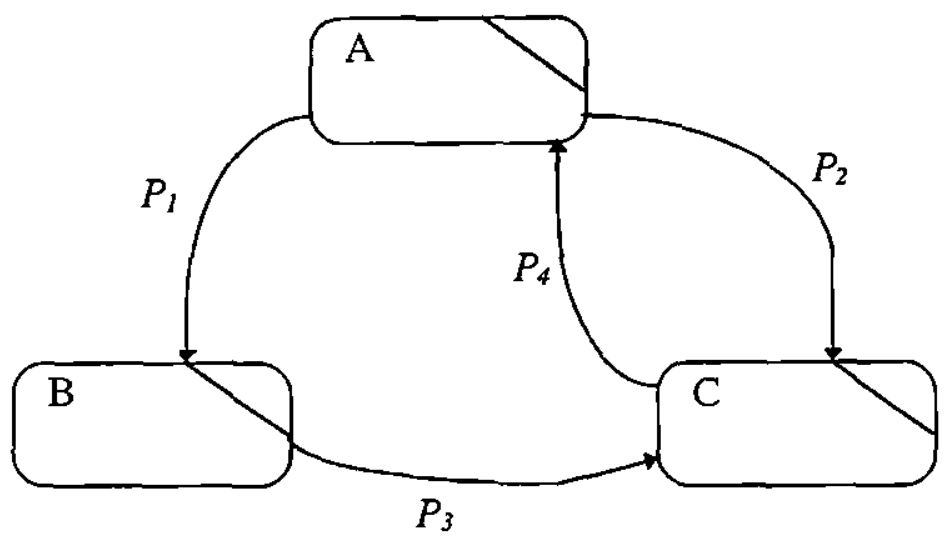

Figura 6.8. SFC de uma Linha de Comunicação. 
E também se tenha a seguinte matriz de transição (figura 6.9).

$\mathrm{A}$
$\mathrm{A}$
$\mathrm{B}\left[\begin{array}{lll}0 & \mathrm{~B} & \mathrm{C} \\ 0 & 0 & p_{1} \\ p_{4} & 0 & 0\end{array}\right]$

Figura 6.9. Matriz de Transição do SFC da Figura 6.8.

A semântica da matriz de transição (e do próprio SFC) é a seguinte: um pacote sai da fila de pacotes (estado A) ou para encontrar o canal livre (estado B, com probabilidade $p_{l}$ ) ou ocupado (estado $\mathrm{C}$, com probabilidade $p_{2}$ ). Na primeira hipótese (transição para o estado B), haverá apenas uma probabilidade $p_{3}$ de transicionar de $\mathrm{B}$ para $\mathrm{C}$, significando que após a transmissão, o canal passa de livre para ocupado. Uma última situação a ser abordada é a tentativa de transmissão em um canal ocupado (estado C) e o retorno do pacote à fila (estado $\mathrm{A}$, com probabilidade $p_{4}$ ).

Empiricamente, observa-se que a quinta potência de $P\left(P^{5}\right)$ é a primeira potência de $P$ que possui todas entradas positivas (figura 6.11), logo $P$ é uma matriz regular. Entretanto, essa conclusão não é intuitiva, pois deve-se observar o seguinte fator determinante: se há algum elemento $p_{i j}=1$ na diagonal principal, tanto na matriz $P$ original, quanto em uma de suas potências $P^{m}$, então a matriz $P$ não é regular, logo o SFC também não o é. A figura 6.10 apresenta as potências $P^{3}$ e $P^{4}$ que antecedem a potência que possui todas as entradas positivas. A seguir, a potência $P^{2}$ da matriz de transição original.

$$
P^{2}=\frac{\mathrm{A}}{\mathrm{B}}\left[\begin{array}{ccc}
p_{2} p_{4} & 0 & p_{1} p_{3} \\
p_{3} p_{4} & 0 & 0 \\
p_{1}{ }^{2} p_{4}{ }^{3} & p_{1} p_{4} & p_{2} p_{4}
\end{array}\right]
$$




$$
\begin{aligned}
P^{3}= & \mathrm{B}\left[\begin{array}{ccc}
\mathrm{A} & \mathrm{B} & \mathrm{C} \\
p_{1} p_{3} p_{4} & p_{1} p_{2} p_{4} & p_{2}{ }^{2} p_{4} \\
0 & p_{1} p_{3} p_{4} & p_{2} p_{3} p_{4} \\
p_{2} p_{4}{ }^{2} & 0 & p_{1} p_{3} p_{4}
\end{array}\right] \\
P^{4}= & \mathrm{A}\left[\begin{array}{ccc}
p_{2}{ }^{2} p_{4}{ }^{2} & p_{1}{ }^{2} p_{3} p_{4} & 2 p_{1} p_{2} p_{3} p_{4} \\
p_{2} p_{3} p_{4}{ }^{2} & 0 & p_{1} p_{3}{ }^{2} p_{4} \\
p_{1} p_{3} p_{4}{ }^{2} & p_{1} p_{2} p_{4}{ }^{2} & p_{2}{ }^{2} p_{4}{ }^{2}
\end{array}\right]
\end{aligned}
$$

Figura 6.10. Potências $P^{3}$ e $P^{4}$ que Ainda Possuem Entradas Nulas.

A

$$
\begin{aligned}
& P^{5}= \text { В }\left[\begin{array}{c}
2 p_{1} p_{2} p_{3} p_{4}^{2} \\
p_{1} p_{3}^{2} p_{4}^{2} \\
p_{1}^{2} p_{4}^{3}
\end{array}\right. \\
& \forall 0<p_{1}, p_{2}, p_{3}, p_{4-}<1
\end{aligned}
$$

B

C

Figura 6.11. Quinta Potência da Matriz de Transição $P$.

Agora, far-se-á uma pequena modificação no exemplo apresentado para uma linha de comunicação, conforme ilustra o SFC a seguir (figura 6.11).

A semântica do SFC é semelhante àquela da figura 6.8, exceto pelo fato de caso o canal esteja ocupado (estado C), o pacote retorna à fila. Aqui, o sistema permanece em C, o que provavelmente gere um comportamento de colisão (como acontece nos protocolos de acesso ao meio não-determinísticos, como o CSMA e CSMA/CD). O SFC da figura 6.12 não é regular, pois o estado $\mathrm{C}$ é absorvente (só possui estados de entrada). As implicações dessa característica são apresentadas a seguir. 


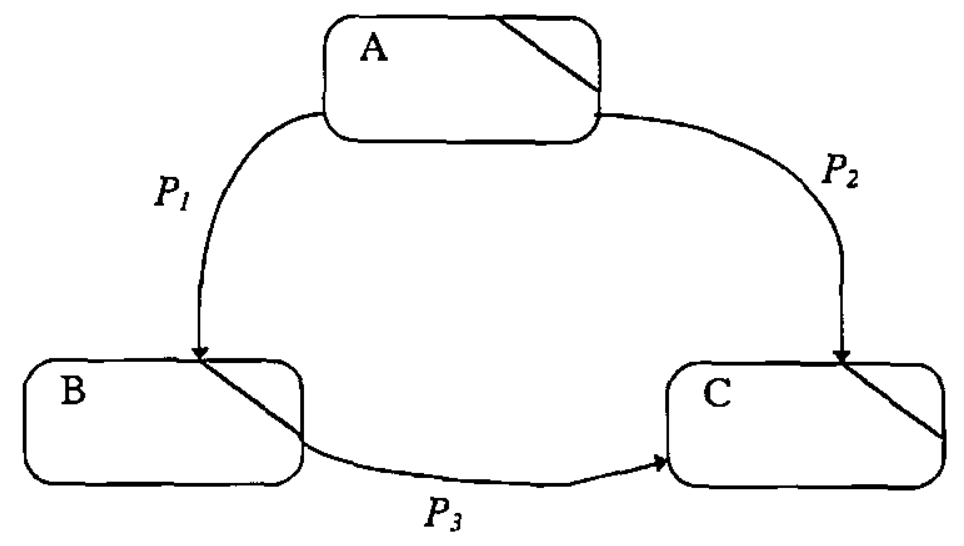

Figura 6.12. SFC de um Canal de Comunicação com Colisão.

\subsubsection{Probabilidade de Transição em Várias Etapas}

Pode-se ainda supor que, em algum instante arbitrário, a probabilidade de que o sistema esteja no estado $a_{i}$ seja $p_{i}$. Essa probabilidade é representada pelo vetor $\mathrm{p}=\left(p_{1}, p_{2}, \ldots, p_{m}\right)$ que é chamado distribuição de probabilidade do sistema naquele instante. Em particular, as distribuições de probabilidades inicial e na n-ésima etapa, respectivamente, são:

$$
p^{(0)}=\left(p_{1}{ }^{(0)}, p_{2}{ }^{(0)}, \ldots, p_{m}{ }^{(0)}\right) \text { e } p^{(n)}=\left(p_{1}{ }^{(n)}, p_{2}{ }^{(n)}, \ldots, p_{m}{ }^{(n)}\right)
$$

O teorema da transição em várias etapas especifica que: seja $\mathrm{P}$ a matriz de transição de uma cadeia de Markov. Se $\mathrm{p}=\left(p_{i}\right)$ é a distribuição de probabilidades do sistema em algum instante arbitrário, então $p P$ é a distribuição de probabilidades do sistema na etapa seguinte e $p P^{n}$ é a distribuição de probabilidades do sistema após as n etapas seguintes (Lipschultz, 94). Em particular:

$$
p^{(1)}=p^{(0)} P, \ldots, p^{(n)}=p^{(0)} P^{n}
$$

Assim, pode-se imaginar um sistema qualquer, no qual possam ocorrer várias iterações, como aquele ilustrado no SFC da figura 6.11. Supondo-se, ainda, que há mais de uma iteração, 
ou seja, há mais de uma transmissão de pacotes. A partir dessa situação, pode-se pretender determinar qual seria a probabilidade do sistema alcançar o estado A após, por exemplo, três iterações. Pode-se ainda supor que a distribuição de probabilidade inicial é $p=(0,1 / 2,1 / 2)$, isto é, a probabilidade de $\mathrm{A}$ permanecer em $\mathrm{A}$ é nula, e que $\mathrm{A}$ pode transicionar para $\mathrm{B}$ ou $\mathrm{C}$ com a mesma probabilidade. Pelo teorema anterior, tem-se (figura 6.13):

$$
p^{(3)}=p^{(0)} P^{3},
$$

ou ainda

$$
\begin{aligned}
& p^{(3)}=(0,1 / 2,1 / 2)\left[\begin{array}{lll}
0 & 0 & 1 \\
0 & 0 & 1 \\
0 & 0 & 1
\end{array}\right] \\
& p^{(3)}=(0,0,1)
\end{aligned}
$$

Figura 6.13. Vetor Distribuição de Probabilidades após Três Etapas.

A conclusão é de certa forma óbvia: após exatamente três etapas, a probabilidade do sistema se encontrar no estado A ou B é nula, pois C é um estado absorvente e o sistema, após alcançar $\mathrm{C}$ pela primeira vez, permanecerá nele indefinidamente.

Agora, pode-se supor que um SFC seja regular, por exemplo, como aquele apresentado na figura 6.8. Se o SFC é regular, então a sua matriz de transição $P$ também o é. Para essa situação, o teorema da distribuição estacionária de uma cadeia de Markov regular pode ser estendido naturalmente aos SFC.

O teorema da distribuição estacionária de uma cadeia de Markov regular especifica que: supondo-se que uma matriz de transição $P$, de uma cadeia de Markov, seja regular. Então para $n$ suficientemente grande, a probabilidade de que qualquer estado $a_{j}$ ocorra é aproximadamente igual à correspondente $t_{j}$ do único vetor fixo de probabilidade, $t$, de $P$, para todo $j$ (Lipschultz, 94).

Assim, o que se observa em um SFC regular é que o efeito do estado inicial ou da distribuição inicial do sistema desaparece conforme o número de etapas aumenta. Além disso, 
toda seqüência de distribuição de probabilidade converge para o vetor fixo de probabilidade, $t$, de $P$, chamado distribuição estacionária de um SFC.

Retomando-se o exemplo da figura 6.8, o SFC é regular, pois sua matriz de transição também o é. Então, após n etapas do SFC, a probabilidade de, por exemplo, o sistema se encontrar no estado $\mathrm{B}$ em um determinado instante tende à sua correspondente no vetor fixo $t$, de sua matriz de transição $P$. Assim, considerando que a distribuição de probabilidade inicial do SFC é $p^{(0)}=(0,1 / 2,1 / 2)$, pode-se observar que, para um número $n$ suficientemente grande de etapas, a influência da distribuição inicial desaparece (figura 6.14). Deve-se entender por "desaparecimento da influência da distribuição inicial" o fato de que, apesar do vetor fixo $t$ ter sido obtido a partir da distribuição de probabilidade inicial, $t$, muito provavelmente, apresentará valores distintos de $p^{(0)}$. Não se deve, contudo, interpretar que, para qualquer distribuição de probabilidade inicial, obter-se-á o mesmo vetor $t$.

$$
\begin{gathered}
(x, y, 1-x-y)\left[\begin{array}{ccc}
0 & 1 / 2 & 1 / 2 \\
0 & 0 & 1 \\
1 & 0 & 0
\end{array}\right]=(x, y, 1-x-y) \\
(1-x-y, x / 2, x / 2+y)=(x, y, 1-x-y) \\
1-x-y=x ; \quad x / 2=y \quad ; \quad x / 2+y=1-x-y \\
1-2 y-y=2 y \\
5 y=1 \\
y=1 / 5
\end{gathered}
$$

$$
(x, y, 1-x-y)=\left(\begin{array}{ccc}
A & B & C \\
(2 / 5,1 / 5,2 / 5)
\end{array}\right.
$$

Figura 6. 14. Distribuição Estacionária de um SFC.

Assim, observa-se que a probabilidade do sistema se encontrar, por exemplo, no estado $\mathrm{B}$, isto é, canal livre, após $n$ etapas, é de $1 / 5$, independentemente (e diferente) do valor $1 / 2$ da distribuição de probabilidades inicial. 


\subsubsection{Estados AND em um SFC}

Estados são considerados concorrentes (do tipo AND) se estando em um estado, o sistema deve estar em todos os seus componentes AND simultaneamente (Harel, 87). A figura 6.15 apresenta um Statechart com estados AND.

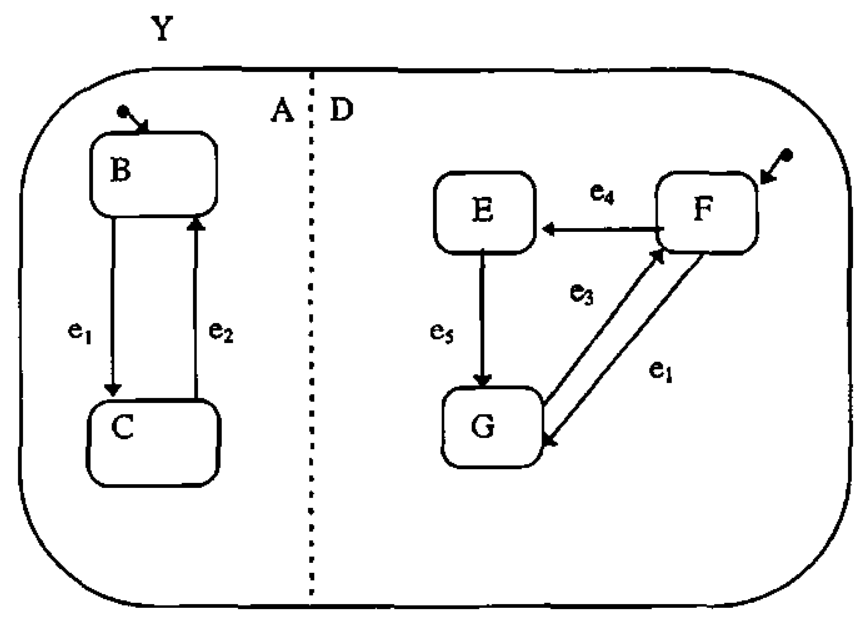

Figura 6.15. Statechart com Estados Concorrentes.

A semântica do Statechart acima especifica que os estados A e D são concorrentes, isto é, A e D ocorrem simultaneamente (chamado de produto ortogonal entre A e D). Os subestados de $\mathrm{A}$ e $\mathrm{D}$ obedecem às mesmas regras de transições dos estados $\mathrm{OR}$, exceto pelo fato de que o mesmo evento pode ocorrer em ambos os estados. No exemplo da figura 6.15 , há uma ocorrência dessa situação: o evento $e_{I}$ tanto transiciona o Statechart do estado $\mathrm{B}$ para o $\mathrm{C}$ (superestado $\mathrm{A}$ ), quanto do estado $F$ para $G$ (superestado $D$ ).

Em SFC, a semântica original é mantida, mudando-se apenas a notação utilizada. A intenção é adequar a notação básica às características probabilísticas necessárias. Para gerar essa adequação pretendida, convencionou-se sinalizar os estados destino de estados concorrentes que são disparados pela ocorrência do mesmo evento (assim como ilustrado pelo evento $e_{l}$ da figura anterior). Além disso, estados concorrentes que transicionam graças à ocorrência do mesmo evento possuem a mesma probabilidade associada. A figura 6.16 apresenta o Statechart anterior em notação SFC. 


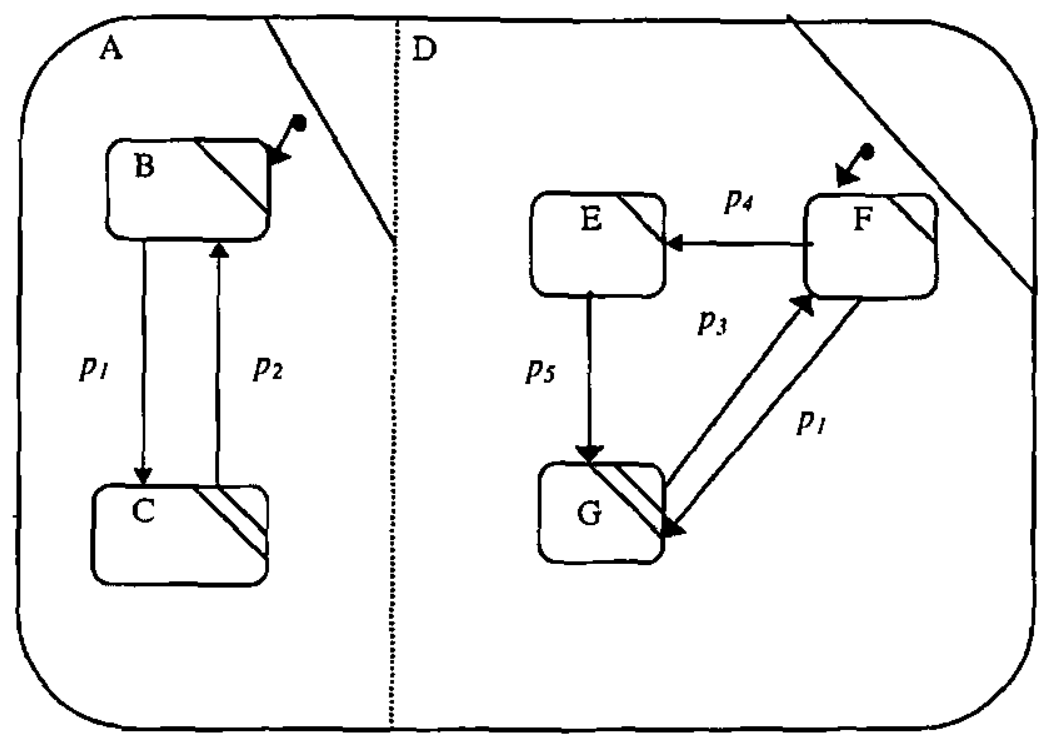

Figura 6.16. SFC com Estados Concorrentes.

Da mesma forma, os estados A e D são concorrentes (estados do tipo AND). Entretanto, em SFC há duas adequaçōes a serem feitas: os estados destino que são transicionados pela ocorrência de um mesmo evento recebem duas linhas diagonais no canto superior direito (estados $\mathrm{C}$ e $\mathrm{G}$, no diagrama acima); e na seta que conduz a esse estado deve constar a probabilidade comum ao evento (probabilidade $p_{\text {, }}$, entre B e C, e F e G).

Portanto, pretende-se, dessa forma, dividir estados AND em seus estados OR correspondentes, podendo-se elaborar uma matriz de transição para cada estado OR, simplificando, assim, a análise. Porém, deve-se sempre atentar para o fato de que estados que são transicionados pelo mesmo evento, devem possuir a mesma probabilidade de transição.

Para o Statechart da figura 6.16, podem-se criar uma matriz de transição para o estado A e uma para o estado D, e interpretá-las separadamente, como dois estados OR independentes, mantendo apenas a propriedade de conservar a mesma probabilidade para estados que transicionam graças à ocorrência do mesmo evento. A figura 6.17 apresenta as matrizes dos dois estados (do tipo OR) A e D do SFC anterior. 
Estado OR A

$\mathrm{A}\left[\begin{array}{lll}\mathrm{A} & \mathrm{B} & \mathrm{C} \\ \mathrm{B} & 1 & 0 \\ 0 & 0 & p_{l} \\ 0 & p_{2} & 0\end{array}\right] \mathrm{C}\left[\begin{array}{cccc}0 & 0 & 1 & 0 \\ 0 & 0 & 0 & p_{5} \\ 0 & p_{4} & 0 & p_{1} \\ 0 & 0 & p_{3} & 0\end{array}\right]$

Figura 6.17. Estado AND Visto através de seus Estados OR.

Uma observação simples das duas matrizes de transição já possibilita a dedução de uma característica importante do SFC da figura 6.16: se $p_{I}$ deve possuir o mesmo valor em ambas as matrizes, então $p_{I}=1$ (pois cada linha da matriz do estado OR A deve possuir soma de seus $p_{i j}=1$ ), o que implica em $p_{4}=0$ (na matriz do estado OR D), ou seja, na distribuição de probabilidades inicial, o sistema não tem possibilidade de transicionar de $\mathrm{F}$ para $\mathrm{E}$.

\subsubsection{Passos em SFC}

O tempo em que a cadeia de Markov (e conseqüentemente um SFC) passa num determinado estado é uma variável aleatória discreta (pelo enfoque restrito abordado nesta pesquisa). A unidade de tempo - tanto nas cadeias de Markov, quanto nos statecharts -pode ser chamada de "passo" (Kovacs, 96) (Harel, 87) e é o intervalo de tempo entre os instantes n+l e n.

Supondo-se que o SFC acaba de assumir o estado $i$, no instante n. O SFC permanecerá nesse estado no próximo passo $(n+1)$ com probabilidade $q_{\mathrm{ii}}$, e saíra do estado com probabilidade 1- $q_{i i}$. Se o SFC permanecer no estado i em $n+1$, a probabilidade que ele permaneça ainda em $i$ no passo $n+2$ será novamente $\mathrm{q}_{\mathrm{ii}} \mathrm{e}$, similarmente, a probabilidade (condicional, ou seja, acontecer um evento $A$, dado que tenha ocorrido um evento B) que o $S F C$ saia de i será $1-q_{i i}$. Da propriedade das cadeias de Markov, sabe-se que o fato da cadeia (por analogia, os SFC) ter permanecido no estado i por um número de passos (história passada) não afetará a probabilidade da cadeia sair do estado i no próximo passo (futuro). Essa independência implica em: 
$\mathrm{p}$ [tempo de permanência no estado i seja m passos 1 o SFC acaba de assumir o estado $\mathrm{i}]=\mathrm{q}_{\mathrm{ii}}{ }^{\mathrm{m}}\left(1-\mathrm{q}_{\mathrm{ii}}\right)$

Pode-se novamente recorrer ao exemplo da transmissão de pacotes em uma linha de comunicação da figura 6.8. Naquele exemplo, em algum instante pode-se querer determinar qual a probabilidade de, estando, por exemplo, no estado C (canal ocupado), retornar a $\mathrm{C}$ em m passos ( $\mathrm{m}$ intervalos de tempo), isto é, encontrar o canal ocupado em duas tentativas sucessivas, decorridos m passos.

Por exemplo, em um determinado passo, a probabilidade de estar no estado $\mathrm{C}$ é de $1 / 3$. Caso se deseje sạber qual a probabilidade do sistema se encontrar novamente no estado $\mathrm{C}$ em exatamente 4 passos $(m=4)$, então:

$\mathrm{p}$ [tempo de permanência no estado $\mathrm{C}$ seja 4 passos I o SFC acaba de assumir o estado $C]=(1 / 3)^{4}(1-1 / 3)=2 / 243 \cong 0,008$

Ou seja, para esse caso particular, há uma probabilidade muito pequena (menos de $1 \%$ ) para que aconteça de, em duas tentativas sucessivas, após a ocorrência de 4 passos, o pacote encontrar o canal novamente ocupado.

\subsection{Considerações Finais}

A idéia da análise de um sistema computacional através de suas probabilidades de transições é o limiar de um estudo que pode ser mais amplo. Para a realização desse estudo inicial, o autor criou algumas restrições que, de um modo geral, são "feridas" em um sistema real. Entretanto, o objetivo aqui é justamente esse: estabelecer a base para aprimoramento dos SFC.

A principal restrição aqui imposta se refere ao tempo. O tempo em SFC foi tratado como urn fenômeno discreto, o que não é verificado na realidade, onde essa grandeza se processa de maneira contínua. Graças a esse fato, em SFC não foram abordadas outras medidas que nāo fossem totalmente probabilísticas.

Algumas teorias abordadas durante esta dissertação apresentam o tempo como contínuo, e realizam, assim, uma análise mais completa que a proposta nos SFC. As redes de filas e as redes 
de Petri estocásticas são dois bons exemplos disso. Esse tipo de análise exige que o alicerce da técnica esteja edificado em cálculo diferencial e integral, além da teoria das probabilidades aqui apresentada. SFC também pode ser estendido nessa direção. Entretanto, somente a análise probabilística já extrapola a visão comportamental apresentada para os statecharts originais.

Das técnicas vistas neste trabalho, os statecharts são os mais claros em representação, pois só neles se pode representar explicitamente hierarquia (superestados e subestados) e concorrência (estados AND). Apesar disso, não há nenhuma formalização de comportamento estocástico proposto para eles. Os SFC pretendem ser o início de uma nova utilização para essa técnica com um cunho de representação e formalismo tão acentuado. 


\section{CAPÍTULO 7}

\section{Caso de Estudo: Servidor de Arquivos Baseado em Rede Local}

\subsection{Considerações Iniciais}

O caso de estudo exposto neste capítulo é apresentado com mais detalhes em "Tools and Methodologies For Performance Evaluation of Distributed Computing Systems - A Comparison Study" (Santana et. al., 97). Para a avaliação desejada, será feita uma explanação mais sucinta do problema.

O problema abordado em (Santana et. al., 97) implica em investigar o comportamento de um servidor de arquivos, sendo que o servidor pode assumir três formas apresentadas a seguir nos modelos de redes de filas e redes de Petri. Aqui, a abordagem se atém à análise probabilística do desempenho.

Vale ressaltar que a sintaxe e semântica dos modelos foram testadas usando-se duas ferramentas para esse propósito: o StatSim para os statecharts e o ASiA para as redes de filas.

O primeiro modelo (figura 7.1) representa um servidor em sua forma mais simples, isto é, uma requisiçāo vinda da rede entra em uma fila de um processador até ser atendida pelo mesmo quando ele estiver livre, e, a partir daŕ, a requisição ocupa o processador e, após o atendimento, retorna à rede.
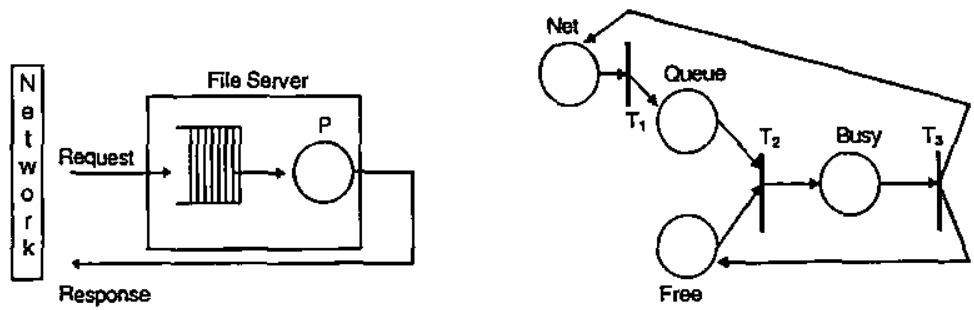

Figura 7.1. Modelo Fila + Processador Representado em Redes de Filas e de Petri.

Mais dois modelos em (Santana et. al., 97) ainda são estudados. Um modelo, de complexidade intermediária, apresenta uma variação do primeiro, incluindo-se, após o servidor, um disco e sua fila. Esse modelo intermediário é mostrado na figura 7.2. 

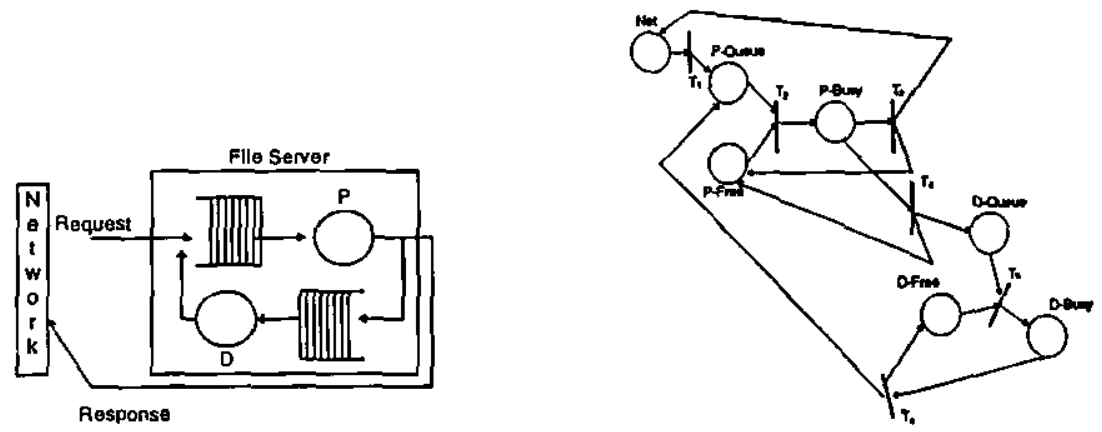

Figura 7.2. Modelo Fila do Processador + Processador + Fila do Disco + Disco Representado em Redes de Filas e de Petri.

Um último modelo ainda é discutido, sendo que é o de maior complexidade. Além dos elementos contidos no modelo anterior, são acrescidos mais dois processadores front-end de entrada e de saída (PFE-I e PFE-O, respectivamente). A figura 7.3 apresenta essa última variação do modelo Servidor de Arquivos.
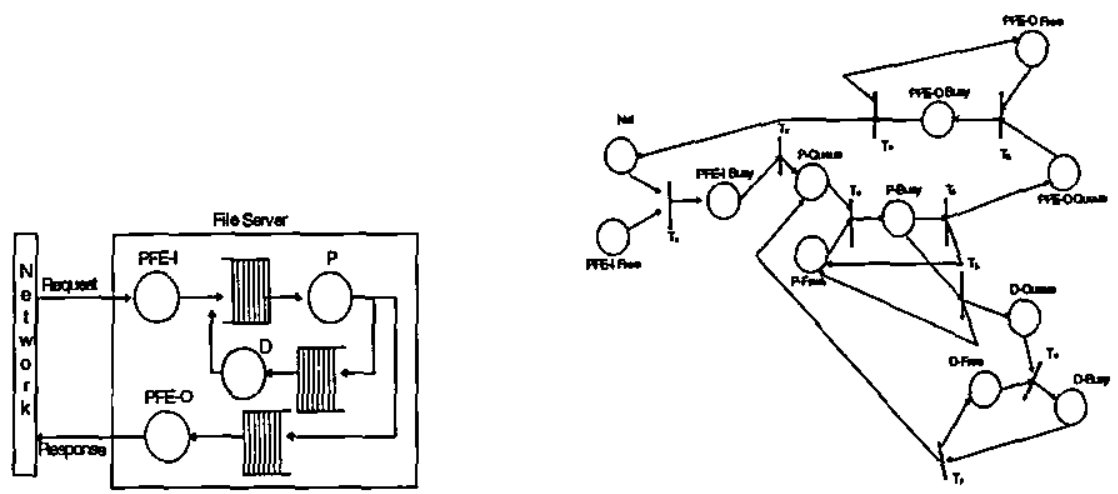

Figura 7.3. Fila do Processador + Processador + Fila do Disco +Disco + PFE-I + Fila do PFE-O + PFE-O em Redes de Filas e de Petri .

\subsection{Modelo Fila e Processador}

Para a situação mais simples, o gráfico SFC é mostrado a seguir (figura 7.4), ilustrando os passos da execução do modelo. Após, a semântica desse exemplo é apresentada. A tonalidade gris no diagrama representa o estado atual do SFC na execução, e a numeração sob cada passo indica a seqüência obedecida pela execução. 


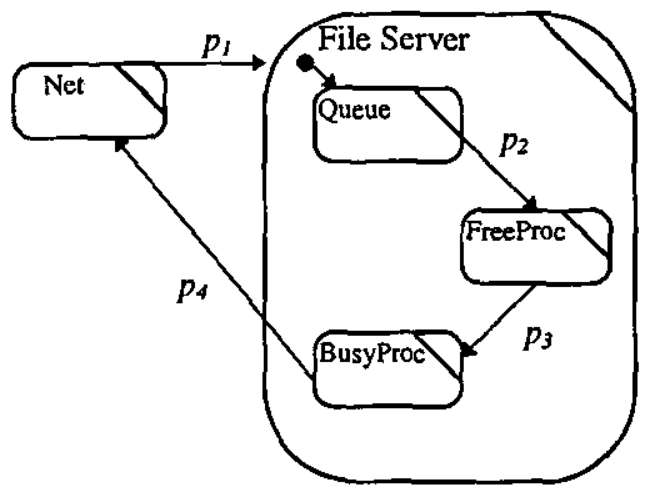

(1)

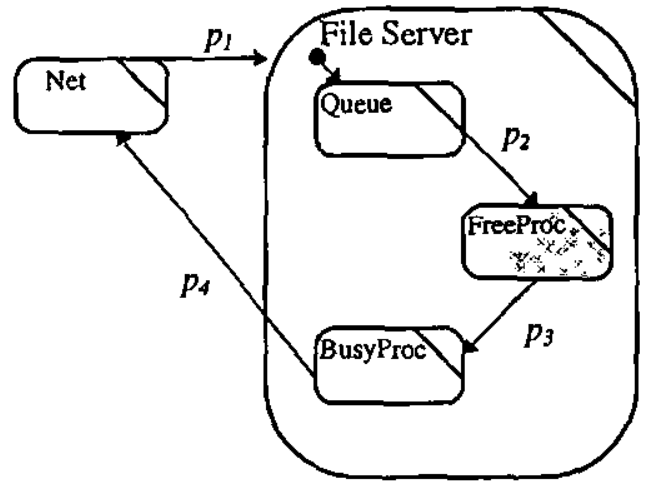

(3)

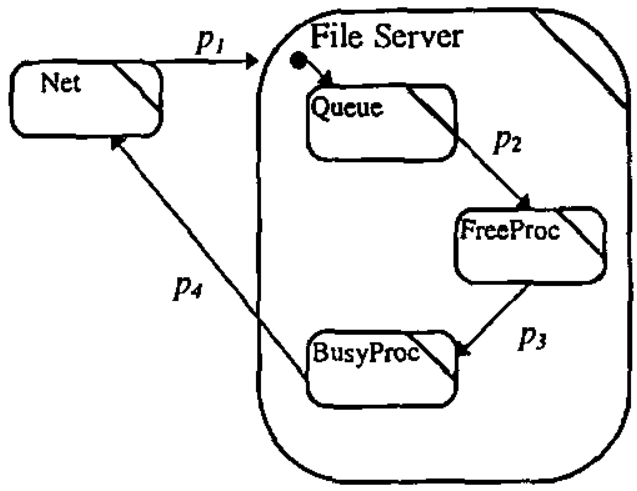

(2)

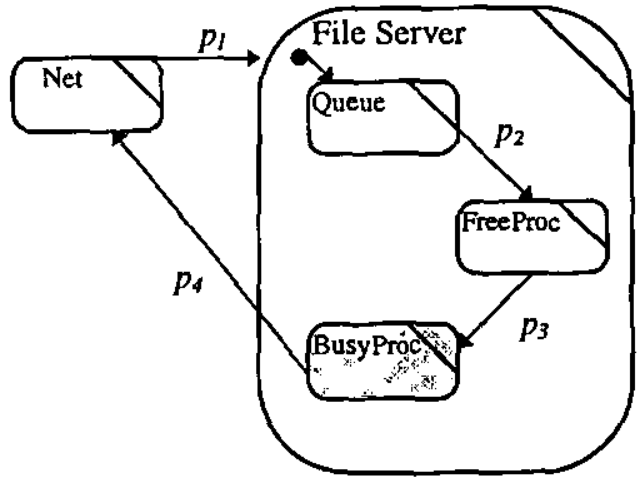

(4)

Figura 7.4. SFC do Servidor de Arquivos Mais Simples.

A semântica do SFC segue a idéia dos modelos em redes de Petri e redes de filas, ou seja, ao ocorrer uma requisição, o sistema passa de um estado Net (indicando que a requisição foi efetuada via rede) para um estado denominado File Server. Esse estado é um superestado, possuindo os subestados Queue (fila do processador), Free Proc (processador disponível) e Busy Proc (processador ocupado). O estado default de File Server é a fila (Queue), pois uma requisição vinda da rede, obrigatoriamente, deve entrar na fila do processador, mesmo que essa fila esteja vazia. Uma vez na fila, a requisição só muda de estado se o processador estiver disponível (estado Free Proc). Se a requisição ocupa o processador, ela leva o mesmo a um estado de ocupado (Busy Proc). Após o atendimento no processador, a requisição retorna à rede. A visão apresentada ignora a possibilidade da requisição não ser totalmente atendida em apenas uma etapa no sistema. tendo a requisição que retornar à rede para, possivelmente, retornar ao File Server posteriormente.

Através de uma observação do modelo, pode-se verificar que as transiçōes não ocorrem de maneira não-determinística, pois não há nenhuma situaçāo em que se tenha que optar entre mais de uma probabilidade para transicionar de um estado para o seguinte. Esse fato implica em 
forçar que as transições sejam sempre totalmente prováveis (probabilidades iguais a 1). Considerando-se esse fator, tem-se a seguinte matriz de transição $P$ para o SFC em questão (figura 7.5). Como forma de facilitar a representação, os estados estão representados pelas letras iniciais dos seus nomes (por exemplo, $\mathrm{N}$ para o estado $\mathrm{Net}$ ).

$$
\begin{aligned}
& \begin{array}{lllll}
N & F S & Q & F P & B P
\end{array}
\end{aligned}
$$

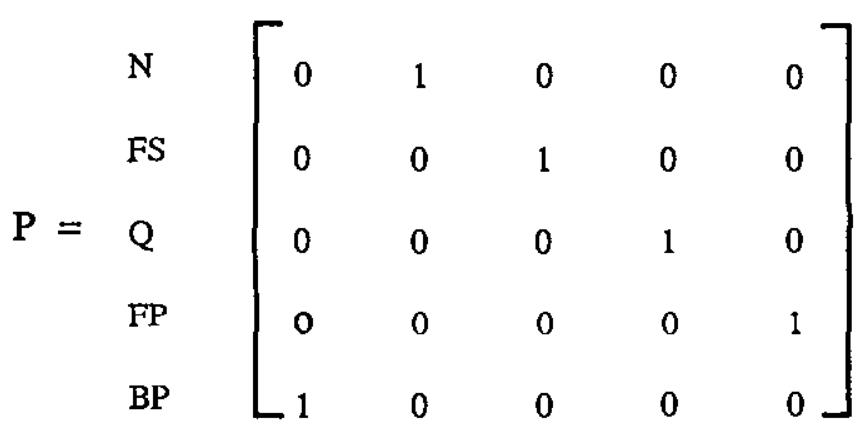

Figura 7.5. Matriz de Transição do SFC Fila + Processador.

Uma matriz estocástica como a anterior, apenas composta por zeros e uns não terá uma potência cujas entradas sejam todas positivas. Esse fato fica ainda mais claro quando se verifica que na quinta potência de $P$, há a ocorrência da matriz identidade, cuja diagonal principal é toda composta por ls. Portanto, se não há uma potência cujas entradas sejam todas positivas, então $P$ não é regular, logo não haverá uma etapa onde todos os estados tenham probabilidades de alcançar a todos os demais. Também não haverá um vetor único, cujas linhas da matriz de transição (dado um número $\mathrm{n}$ de etapas suficientemente grande) tenderão aos valores das componentes do vetor. A seguir (figura 7.6), são apresentadas as potências (até a quinta) da matriz $P$. 


$$
\begin{aligned}
& \begin{array}{lllll}
N & \text { FS } & \text { Q } & \text { FP } & \text { BP }
\end{array} \\
& P^{2}=\begin{array}{l}
\text { FS } \\
\text { FP } \\
\text { BP }
\end{array}\left[\begin{array}{lllll}
0 & 0 & 1 & 0 & 0 \\
0 & 0 & 0 & 1 & 0 \\
0 & 0 & 0 & 0 & 1 \\
1 & 0 & 0 & 0 & 0 \\
0 & 1 & 0 & 0 & 0
\end{array}\right] \\
& \begin{array}{lllll}
N & \text { FS } & \text { Q } & \text { FP } & \text { BP }
\end{array} \\
& P^{3}=\begin{array}{l}
\mathrm{N} \\
\mathrm{FP} \\
\mathrm{BP}
\end{array}\left[\begin{array}{lllll}
0 & 0 & 0 & 1 & 0 \\
0 & 0 & 0 & 0 & 1 \\
1 & 0 & 0 & 0 & 0 \\
0 & 1 & 0 & 0 & 0 \\
0 & 0 & 1 & 0 & 0
\end{array}\right] \\
& \begin{array}{lllll}
N & \text { FS } & \text { Q } & \text { FP } & \text { BP }
\end{array} \\
& P^{4}=\begin{array}{l}
\text { FS } \\
\text { FP } \\
\text { PP }
\end{array}\left[\begin{array}{lllll}
0 & 0 & 0 & 0 & 1 \\
1 & 0 & 0 & 0 & 0 \\
0 & 1 & 0 & 0 & 0 \\
0 & 0 & 1 & 0 & 0 \\
0 & 0 & 0 & 1 & 0
\end{array}\right] \\
& \begin{array}{lllll}
N & \text { FS } & \mathrm{Q} & \mathrm{FP} & \mathrm{BP}
\end{array} \\
& \mathrm{P}^{5}=\mathrm{N}
\end{aligned}
$$

Figura 7.6. Potências da Matriz Não Regular P.

A quinta potência de $\mathrm{P}$ é a matriz identidade, e, a partir dela, não se pode obter uma matriz cujas componentes sejam todas positivas. A interpretação desse fato implica em não ser possível para uma requisição poder alcançar (ou seja, ter probabilidade) mais de um estado na mesma etapa. Por exemplo, uma requisição que não completou o seu serviço (como nos casos dos sistemas operacionais de tempo compartilhado), volte à fila do processador (Queue), antes de retornar à rede. 


\subsection{Modelo Fila do Processador + Processador + Fila do Disco + Disco}

Para a situação intermediária, tem-se o SFC da figura 7.7 e sua respectiva matriz de transição $P$ (figura 7.8). O SFC apresenta um estado cuja transição pode enveredar para mais de um estado destino (no exemplo em questão, o estado Busy Proc transicionar ou para Queue-D ou para Net).

A semântica do SFC é idêntica à do primeiro modelo, exceto pela inclusão dos estados fila do disco $(Q u e u e-D)$, disco disponível (Free Disc) e disco ocupado (Busy Disc). Além disso, após ocupar o processador, a requisição pode tanto voltar para a rede (caso tenha sido completamente atendida), quanto ir para a fila do disco (caso necessite de alguma operação de entrada/saída de disco). Depois de passar por Busy Disc, a requisição volta para o servidor de arquivos (File Server), cujo default é a fila do processador.

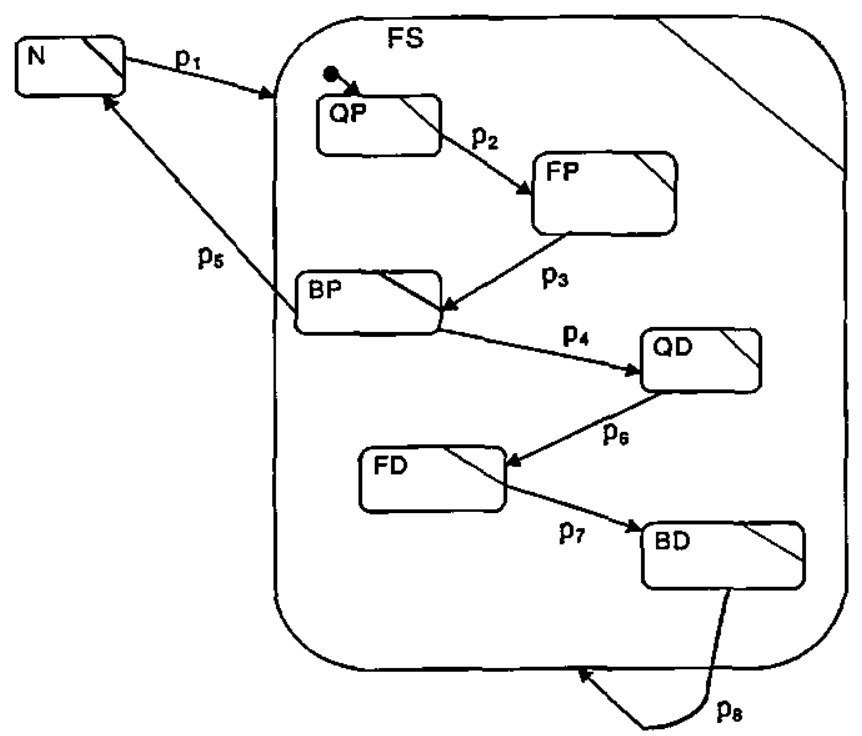

Figura 7.7. SFC de Fila do Processador + Processador + Fila do Disco + Disco.

A partir da matriz de transição inicial $\left(\mathrm{P}^{0}\right)$, vão-se obter algumas características do sistema representado pelo SFC. Essas conclusões são apresentadas a seguir:

1. O SFC é regular, pois sua matriz de transição também o é. Essa propriedade pode ser verificada de duas maneiras: 
- O SFC não possui estados absorventes, o que significa que o sistema nunca ficará retido em um determinado estado indefinidamente. Esse fato pode ser verificado pela ausência de ls na diagonal principal da matriz de transição inicial.

- A regularidade da matriz e do $S F C$ pode ser verificada através de suas potências $\left(\mathrm{P}^{\mathrm{n}}\right)$, caso seja verificado que há uma potência que possua todas as entradas $p_{i j}$ positivas. A potência $\mathrm{P}^{33}$ da matriz de transição original (figura 7.9) possui essa característica.

$\mathrm{N}$
$\mathrm{FS}$
$\mathrm{QP}$
$\mathrm{FP}$
$\mathrm{BP}$
$\mathrm{QD}$$\left[\begin{array}{cccccccc}0 & \mathrm{FP} & \mathrm{FP} & \mathrm{BP} & \mathrm{QD} & \mathrm{FD} & \mathrm{BD} \\ \mathrm{FD} & 0 & 0 & 0 & 0 & 0 & 0 & 0 \\ \mathrm{BD} & 0 & 0 & 1 & 0 & 0 & 0 & 0 \\ 0 & 0 & 0 & 0 & 1 & 0 & 0 & 0 \\ 1 / 2 & 0 & 0 & 0 & 0 & 1 / 2 & 0 & 0 \\ 0 & 0 & 0 & 0 & 0 & 0 & 1 & 0 \\ 0 & 1 & 0 & 0 & 0 & 0 & 0 & 0\end{array}\right]$

Figura 7.8. Matriz de Transição Inicial do SFC de Complexidade Intermediária.

2. A partir da primeira potência toda positiva $\left(\mathrm{P}^{33}\right)$, pode-se verificar que todos os estados são alcançáveis, isto é, partindo-se de um estado qualquer e, logicamente, passando pelos estados intermediários, a partir de 33 etapas, todos os estados têm probabilidades de serem alcançados. Por exemplo, na primeira etapa, o estado $\mathrm{N}$ (rede) não tem probabilidade de alcançar o estado FP (processador livre), pois N só pode transicionar para FS. Entretanto, em mais de uma etapa (nesse caso, exatamente em $\mathrm{P}^{8}$ ), $\mathrm{N}$ pode alcançar FP, através de outros estados, ou seja, a entrada da matriz que representa a interseção da linha $\mathrm{N}$ (rede) com a coluna FP (processador livre) possui valor positivo. 


$\mathrm{N}$
$\mathrm{FS}$
$\mathrm{P}$
$\mathrm{QP}$
$\mathrm{FP}$
$\mathrm{FP}$
$\mathrm{FD}$
$\mathrm{BD}$$\left[\begin{array}{cccccccc}\mathrm{N} & \mathrm{FS} & \mathrm{QP} & \mathrm{FP} & \mathrm{BP} & \mathrm{QD} & \mathrm{FD} & \mathrm{BD} \\ 0.15 & 0.16 & 0.1 & 0.31 & 0.02 & 0.15 & 0.03 & 0.08 \\ 0.01 & 0.23 & 0.16 & 0.1 & 0.31 & 0.01 & 0.15 & 0.03 \\ 0.15 & 0.05 & 0.23 & 0.16 & 0.1 & 0.15 & 0.01 & 0.15 \\ 0.06 & 0.28 & 0.07 & 0.24 & 0.14 & 0.06 & 0.12 & 0.03 \\ 0.08 & 0.06 & 0.3 & 0.04 & 0.24 & 0.08 & 0.05 & 0.15 \\ 0.11 & 0.25 & 0.08 & 0.32 & 0.03 & 0.11 & 0.06 & 0.04 \\ 0.03 & 0.1 & 0.3 & 0.02 & 0.3 & 0.04 & 0.09 & 0.12 \\ 0.15 & 0.16 & 0.1 & 0.31 & 0.02 & 0.15 & 0.03 & 0.08\end{array}\right]$

Figura 7.9. Matriz de Transição $\mathrm{P}^{33}$ com Todas as Entradas Positivas.

3. No caso estudado, o SFC é regular, logo pode-se encontrar um único vetor fixo de probabilidades, cujas componentes eqüivalem à tendência dos valores das potências $\mathrm{P}^{\mathrm{n}}$ (para n suficientemente grande). Isso significa que com o aumento do número de etapas a influência da distribuição de probabilidade inicial $p^{(0)}((0,1,0,0,0,0,0,0)$, nesse exemplo) desaparece. A figura 7.10 apresenta o cálculo do vetor fixo de probabilidade para a matriz de transição de 7.8 .

A observação do vetor fixo especifica que, para um número n suficientemente grande de etapas, a probabilidade de se alcançar um determinado estado tende à sua correspondente nesse vetor fixo. Assim, para o caso em estudo, a probabilidade do sistema se encontrar nos estados $\mathrm{N}$, QD, FD e BD é de $1 / 12$ (cerca de $8 \%$ ), e em FS, QP, FP e BP é de 1/6 (aproximadamente 16\%). Esses valores são totalmente diferentes daqueles contidos na distribuição de probabilidades inicial $p^{(0)}=(0,1,0,0,0,0,0,0)$, o que atesta a veracidade do teorema da distribuição estacionária.

4. Ainda se pode verificar um outro aspecto probabilístico, que está relacionado ao fato de que, em um sistema qualquer, um estado pode retornar a si mesmo, após a ocorrência de m passos (intervalos de tempos). Portanto, para o caso em estudo, pode-se, por exemplo, afirmar, qual 
seria a probabilidade de uma requisiçāo partir da rede e retomar a ela, em exatamente 3 passos, a partir etapa 33 conforme ilustrado a seguir.

$\mathrm{p}$ [tempo de permanência no estado $\mathrm{N}$ seja 3 passos I o SFC acaba de assumir o estado $\mathrm{N}]=(0,15)^{3}(1-0,15) \cong 0,002$

Ou seja, na etapa 33, a probabilidade de $\mathrm{N}$ permanecer em $\mathrm{N}$ é de 0,15 (conforme figura 7.9). Entretanto, a probabilidade de $\mathrm{N}$ retomar a $\mathrm{N}$ em 3 passos tende a zero.

\begin{tabular}{|c|c|c|c|c|c|c|c|c|c|}
\hline & & $\mathrm{N}$ & FS & $\mathrm{QP}$ & FP & $\mathrm{BP}$ & QD & FD & $\mathrm{BD}$ \\
\hline & $\mathbf{N}$ & 0 & 1 & 0 & 0 & 0 & 0 & 0 & 0 \\
\hline & FS & 0 & 0 & 1 & 0 & 0 & 0 & 0 & 0 \\
\hline & $\mathrm{QP}$ & 0 & 0 & 0 & 1 & 0 & 0 & 0 & 0 \\
\hline$(\mathrm{A}, \mathrm{B}, \mathrm{C}, \mathrm{D}, \mathrm{E}, \mathrm{F}, \mathrm{G}, \mathrm{H})$ & FP & 0 & 0 & 0 & 0 & 1 & 0 & 0 & 0 \\
\hline & $\mathrm{BP}$ & $1 / 2$ & 0 & 0 & 0 & 0 & $1 / 2$ & 0 & 0 \\
\hline & QD & 0 & 0 & 0 & 0 & 0 & 0 & 1 & 0 \\
\hline & $\mathrm{FD}$ & 0 & 0 & 0 & 0 & 0 & 0 & 0 & 1 \\
\hline & $\mathrm{BD}$ & 0 & 1 & 0 & 0 & 0 & 0 & 0 & 0 \\
\hline
\end{tabular}

$(1 / 12,1 / 6,1 / 6,1 / 6,1 / 6,1 / 12,1 / 12,1 / 12)$

Figura 7.10. Vetor Fixo de Probabilidades do Modelo Fila Processador + Processador + Fila Disco + Disco.

7.4. Modelo Fila do Processador + Processador + Fila do Disco +Disco + PFE-I + Fila do PFE-O + PFE-O

O último modelo apresenta uma variação do segundo caso. Porém, aqui são incluídos dois processadores front-end (um de entrada: PFE-I, e um de saída: PFE-O). O PFE de entrada não possui fila, isso significa que uma requisição é sempre atendida de forma imediata por ele, 
sem ter que entrar em uma fila de espera. Já o PFE de saída possui uma fila, ou seja, para retornar à rede, a requisição deve passar pela fila do PFE-O, para depois ser atendida por ele, e só aí poder regressar à rede. A figura 7.11 apresenta o SFC e sua matriz de transição para esse último modelo.

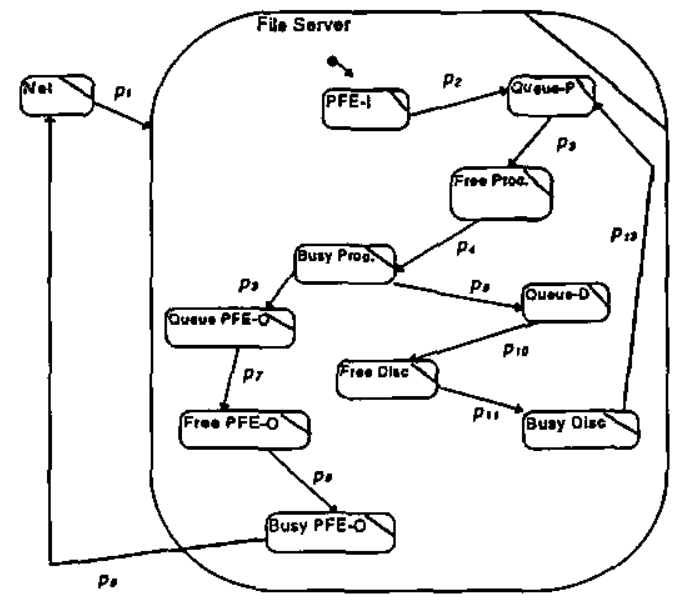

\begin{tabular}{|c|c|c|c|c|c|c|c|c|c|c|c|c|}
\hline & $\mathbf{N}$ & FS & PFEI & $\mathrm{QP}$ & $\mathrm{FP}$ & $\mathrm{BP}$ & $Q D$ & FD & $\mathrm{BD}$ & QPFEO & FPFEO & BPFEO \\
\hline $\mathrm{N}$ & 0 & 1 & 0 & 0 & 0 & 0 & 0 & 0 & 0 & 0 & 0 & 0 \\
\hline FS & 0 & 0 & 1 & 0 & 0 & 0 & 0 & 0 & 0 & 0 & 0 & 0 \\
\hline PFEI & 0 & 0 & 0 & 1 & 0 & 0 & 0 & 0 & 0 & 0 & 0 & 0 \\
\hline$Q P$ & 0 & 0 & 0 & 0 & 1 & 0 & 0 & 0 & 0 & 0 & 0 & 0 \\
\hline FP & 0 & 0 & 0 & 0 & 0 & 1 & 0 & 0 & 0 & 0 & 0 & 0 \\
\hline BP & 0 & 0 & 0 & 0 & 0 & 0 & $1 / 2$ & 0 & 0 & $1 / 2$ & 0 & 0 \\
\hline$Q D$ & 0 & 0 & 0 & 0 & 0 & 0 & 0 & 1 & 0 & 0 & 0 & 0 \\
\hline FD & 0 & 0 & 0 & 0 & 0 & 0 & 0 & 0 & 1 & 0 & 0 & 0 \\
\hline $\mathrm{BD}$ & 0 & 0 & 0 & 1 & 0 & 0 & 0 & 0 & 0 & 0 & 0 & 0 \\
\hline QPFEO & 0 & 0 & 0 & 0 & 0 & 0 & 0 & 0 & 0 & 0 & 1 & 0 \\
\hline FPFEO & 0 & 0 & 0 & 0 & 0 & 0 & 0 & 0 & 0 & 0 & 0 & 1 \\
\hline BPFEO & 1 & 0 & 0 & 0 & 0 & 0 & 0 & 0 & 0 & 0 & 0 & 0 \\
\hline
\end{tabular}

Figura 7.11. SFC e Matriz de Transição do Servidor de Arquivos de Maior Complexidade.

O SFC da figura anterior é regular, pois a potência $P^{60}$ da matriz de transição só possui entradas positivas, conforme figura 7.12. A partir dessa constatação, serão apresentadas algumas 
considerações a respeito do comportamento probabilístico do último modelo, que, às vezes, são extensíveis aos outros modelos, em algumas etapas específicas.

\begin{tabular}{|c|c|c|c|c|c|c|c|c|c|c|c|c|}
\hline & $\mathrm{N}$ & FS & PFEI & $Q P$ & $F P$ & $\mathrm{BP}$ & QD & $\mathrm{FD}$ & $\mathrm{BD}$ & QPFEO & FPFEO & BPFEC \\
\hline $\mathrm{N}$ & 0.10 & 0.07 & 0.05 & 0.13 & 0.12 & 0.11 & 0.09 & 0.06 & 0.06 & 0.09 & 0.10 & 0.02 \\
\hline FS & 0.06 & 0.14 & 0.01 & 0.06 & 0.32 & 0.01 & 0.04 & 0.15 & 0.11 & 0.04 & 0.06 & 0.04 \\
\hline PFEI & 0.04 & 0.01 & 0.14 & 0.22 & 0.01 & 0.28 & 0.07 & 0.01 & 0.01 & 0.07 & 0.04 & 0.10 \\
\hline$Q P$ & 0.09 & 0.05 & 0.07 & 0.14 & 0.07 & 0.16 & 0.09 & 0.05 & 0.05 & 0.09 & 0.07 & 0.07 \\
\hline FP & 0.07 & 0.13 & 0.01 & 0.07 & 0.28 & 0.02 & 0.05 & 0.13 & 0.11 & 0.05 & 0.07 & 0.01 \\
\hline BP & 0.05 & 0.01 & 0.13 & 0.20 & 0.01 & 0.25 & 0.08 & 0.01 & 0.01 & 0.08 & 0.05 & 0.12 \\
\hline$Q D$ & 0.06 & 0.05 & 0.09 & 0.17 & 0.10 & 0.17 & 0.06 & 0.05 & 0.05 & 0.06 & 0.06 & 0.08 \\
\hline FD & 0.10 & 0.07 & 0.05 & 0.13 & 0.12 & 0.11 & 0.09 & 0.06 & 0.06 & 0.08 & 0.09 & 0.04 \\
\hline $\mathrm{BD}$ & 0.06 & 0.14 & 0.01 & 0.06 & 0.28 & 0.01 & 0.04 & 0.15 & 0.14 & 0.04 & 0.06 & 0.01 \\
\hline QPFEO & 0.04 & 0.01 & 0.14 & 0.22 & 0.01 & 0.22 & 0.07 & 0.01 & 0.01 & 0.07 & 0.04 & 0.16 \\
\hline FPFEO & 0.06 & 0.13 & 0.02 & 0.07 & 0.29 & 0.02 & 0.05 & 0.13 & 0.13 & 0.05 & 0.06 & 0.02 \\
\hline BPFEO & 0.05 & $0.0 \mathrm{I}$ & 0.13 & 0.20 & 0.01 & 0.26 & 0.07 & 0.01 & 0.01 & 0.07 & 0.05 & 0.13 \\
\hline
\end{tabular}

Figura 7.12. Potência $P^{60}$ da Matriz de Transição do SFC de Maior Complexidade.

- Nas etapas próximas da matriz estocástica com todas as entradas positivas ( $P^{60}$ nesse caso, e $P^{33}$ no exemplo anterior), há uma probabilidade considerável do estado permanecer nele mesmo (em algumas linhas da matriz, é a entrada de valor mais alto). Esse fato pode ser verificado observando-se os valores da diagonal principal das potências elevadas, o que não ocorre nas etapas iniciais. Se tomar-se, particularmente, os estados Net e File Server, esse aspecto probabilístico pode indicar uma situação de sobrecarga no servidor, havendo, assim, uma tendência maior de uma requisição obter o servidor com maior dificuldade, após um certo número de iterações.

- Na etapa da matriz estocástica toda positiva, há uma tendência de probabilidade relativamente baixa de um estado transicionar para o seu consecutivo. Tomando-se como exemplo a matriz $P^{60}$ do último modelo abordado e, particularmente, dois de seus estados (Servidor de Arquivos (FS) e Processador front-end de entrada (PFEI)), há uma probabilidade de 0,01 (quase nula) para que FS transicione para PFEI. Em contrapartida, na 
distribuição de probabilidade inicial havia uma probabilidade igual a 1 (evento totalmente provável) dessa transição ocorrer.

- Um fato a ser observado também é o impacto que a realização do número de etapas acarreta no comportamento probabilístico do modelo. Tomando-se novamente o último modelo como base, e, em particular, o seu estado Net, pode-se observar empiricamente que a probabilidade de $N e t$ permanecer em Net é 0 (zero) até a nona etapa $\left(P^{9}\right)$, onde essa probabilidade passa de 0 para $0.50(50 \%)$, ou seja, de uma probabilidade nula para $1 / 2$ de probabilidade, o que é um aumento súbito. Especificamente, para esse caso, essa mudança abrupta pode indicar o início da saturação do servidor de arquivos.

- Esse comportamento anômalo se ratifica ainda mais quando, observada a faixa das potências que vai de $P^{10}$ a $P^{14}$, a probabilidade de Net permanecer em Net volta a ser zero. Portanto, $P^{9}$ mostra indícios de sobrecarga do servidor gerada nas etapas anteriores.

\subsection{Considerações Finais}

A apresentação de diferentes níveis de complexidade para um servidor de arquivos tem um propósito específico: mostrar possibilidades de análises probabilísticas diferentes para situações que sofram algumas modificações. No caso de estudo aqui apresentado, no primeiro modelo não havia escolha não-determinística entre estados-destino de um estado qualquer do SFC, o que já ocorria nos demais modelos. A partir da introdução dessa modificação nos modelos 2 e 3 , o resultado obtido nas análises foram significativamente diferentes.

A intenção da exemplificação realizada neste capítulo está em apresentar características discrepantes entre situações cotidianas (no caso, a utilização de um servidor de arquivos em uma rede local). Além da análise probabilística, havia a intenção que propiciar uma maior clareza do problema, através de uma representação de diagramas statecharts, que possuem grande capacidade de facilitar o entendimento de sistemas complexos.

O exemplo também pretende insinuar uma melhor aplicabilidade dos SFC, isto é, sistemas cujo caráter determinístico predomina não são ideais para uma análise SFC (como visto no primeiro modelo). Entretanto, sistemas que possuem um cunho de não-determinismo são mais propensos a interessantes representações e análises SFC. Um componente interessante de um sistema distribuído a ser analisado seria um protocolo de comportamento não-determinístico, como alguns que provêm acesso ao meio. 


\section{Conclusões}

\subsection{Considerações Iniciais}

Nesta pesquisa foi procedido um levantamento teórico bibliográfico sobre a análise de desempenho em sistemas computacionais. Apesar de, na maioria dos casos, serem abordados exemplos típicos de sistemas distribuídos, todas as técnicas aqui apresentadas são de propósito geral.

O objetivo deste trabalho pretende exceder o aspecto da formalização probabilística proposta nos SFC. A intenção também está em criar um arcabouço que sirva de base bibliográfica para futuros trabalhos que pretendam enveredar por essa área de conhecimento.

Naturalmente, houve pesquisas precedentes a esta no próprio grupo de Sistemas Distribuídos do ICMSC, como por exemplo (Orlandi, 95) e (Santana et. al., 96a). Apesar de todas elas se situarem no mesmo campo, cada uma dá um enfoque diferente a problemas semelhantes. Especificamente nesta dissertação, a preocupação está em descrever os métodos formais para modelagem de sistemas, culminando com a proposição de um método-extensão de uma das técnicas discutidas no decorrer do trabalho.

A formalização foi proposta tendo como base a teoria das cadeias de Markov, e a associação delas com os statecharts. Com o objetivo de validar os exemplos apresentados em (Santana et. al., 97), o mesmo caso de estudo foi avaliado, agora com o enfoque probabilístico SFC.

\subsection{Conclusões}

Como principais conclusões deste trabalho, destacam-se:

- Uma análise probabilística se torna fundamental em qualquer avaliação de desempenho realística. Tanto é assim, que o próprio idealizador dos statecharts, David Harel (Harel, 87), já havia sugerido um estudo probabilístico dos statecharts.

- A associação dos statecharts às cadeias de Markov se procede de maneira natural, pois em ambos o sistema é visto como um conjunto de estados de origem que transicionam para estados destino. Além disso, a ocorrência de um determinado estado $s_{j}$ só depende, no máximo, da ocorrência do estado anterior $s_{i}$.

- A análise deve ser feita basicamente através da matriz de transição $P$ do SFC (que é uma abstração do sistema real). Essa matriz $P$ deve ser estocástica, isto é, suas linhas devem ser vetores cuja soma de suas componentes não negativas é sempre igual a 1 . Portanto, se uma matriz de transição é estocástica $P$, quaisquer de suas potências também o serão. Isso significa que o modelador de SFC não deve se preocupar com a obtenção de matrizes estocásticas a partir do produto de estocásticas anteriores, ou mesmo com potências de uma matriz estocástica, pois elas serão obtidas naturalmente. 
- A partir da verificação da propriedade anterior, pode-se observar outra propriedade dos SFC através de sua(s) matriz(es) de transição estocástica(s): a Regularidade. Uma matriz estocástica $P$ será regular se somente se existir uma potência $P^{m}$ cujas entradas sejam todas positivas (como foi verificado para $P^{33}$ do caso de estudo 7.3). A conclusão é interessante: se todas as entradas de $P^{m}$ são positivas $\left(p_{i j}>0\right)$, então há sempre uma probabilidade de, decorrido aquele número de etapas (em 7.3, 33 etapas), qualquer estado do SFC alcancar outro qualquer naquele número de etapas, ou seja, mesmo que pequena, haverá uma probabilidade do SFC se encontrar em qualquer de seus estados em uma determinada etapa. Deve-se fazer aqui uma ressalva a respeito do termo "alcance". Dizer que um estado A tem probabilidade de alcançar um outro estado $D$, significa dizer que há uma probabilidade que $A$ alcance $D$, mesmo que tenha que passar por estados intermediários (por exemplo, B e C).

- Ainda em relação às matrizes de transição regulares (e consequientemente, aos SFC regulares), a partir de um determinado número $n$ de etapas suficientemente grande, todos os vetores de probabilidades (linhas da matriz de transição) tendem a um vetor fixo de probabilidades. Esse fato caracteriza que, para $n$ etapas, a probabilidade de um SFC se encontrar em um determinado estado tende ao valor da sua correspondente no vetor fixo, e independe das distribuições de probabilidades anteriores (inclusive da distribuição inicial).

- Se o SFC possui estado(s) absorvente(s), então uma vez alcançado(s) esse(s) estado(s), o SFC permanecerá nele(s) indefinidamente. Graficamente, os estados absorventes são caracterizados por não possuírem estados de saída, exceto eles próprios. Analiticamente, pode-se verificar a presença desses estados através da matriz de transição do SFC; assim, se há Is na diagonal, então há a ocorrência de absorção naquele estado.

- O tratamento discreto do tempo adotado nos SFC é mais realístico que a simples observação do comportamento de um statechart, entretanto não é ainda a análise mais próxima da realidade, pois precisa-se de uma observação contínua do tempo. Essa possibilidade é sugerida como continuação deste trabalho, em pesquisas vindouras.

- Os statecharts (e consequientemente os SFC) possuem um alto grau de representatividade, por, originalmente, conterem tanto a idéia de hierarquia, quanto de concorrência de estados. Essas características são fundamentais para representação de sistemas complexos, como por exemplo, os sistemas distribuídos. Diagramas de redes de filas, por exemplo, não representam de maneira explícita o movimento dos clientes através dos estados do sistema. Redes de Petri trazem a idéia de marca (token) que especificam o estado corrente. Os statecharts, analogamente às redes de Petri, incorporam a idéia de passos de execução, mostrando através de tonalidades diferentes o(s) estado(s) que está(ão) ativo(s).

\subsection{Contribuições deste Trabalho}

Entre as principais contribuições deste trabalho, destacam-se:

- A implementação da análise realizada através do SFC, por ser baseada em matrizes estocásticas, torna-se trivial em virtude das técnicas já bastante consolidadas para o tratamento de vetores e matrizes nas linguagens de programação existentes. Assim, a construção de programas relativamente simples pode automatizar a análise dos SFC. 
- Como consequiência da contribuição anterior, não há restrições de arquitetura, sistema operacional, compiladores ou linguagem de programação para se proceder a análise SFC pretendida.

- SFC é o início de uma pesquisa que pode culminar com uma teoria muito mais complexa, na qual o tempo seja tratado como contínuo, e que as distribuições de probabilidades sejam mais representativas de fenômenos reais.

\subsection{Trabalhos Futuros}

A análise de desempenho é uma área de pesquisa que possui uma utilidade inconteste. Apesar desse fato, não há uma preocupação em abordá-la de maneira mais direcionada, desviando-se um pouco o tom matemático dos livros de probabilidades e processos estocásticos. Baseando-se nesse raciocínio, o autor vislumbra as seguintes possibilidades:

- Elaborar Notas Didáticas, Relatórios Técnicos, além de artigos em periódicos e revistas especializadas, objetivando uma maior divulgação das técnicas e, além disso, aplicar uma visão mais voltada à aplicação nos fenômenos computacionais. Durante a realização da pesquisa, 0 autor encontrou dificuldade em obter bibliografia básica sobre 0 assunto (o que se encontram são artigos de revistas ou similares que trazem um enfoque bastante direcionado a um determinado problema.a

- Extrapolar a caracterização do tempo como a apresentada neste trabalho, possibilitando uma análise mais precisa, que colocará os SFC no mesmo patamar que as Stochastic Petri Nets (SPN), Generalized Stochastic Petri Nets (GSPN) e Redes de Filas.

Considerando-se os SFC a tempos discretos, podem-se desenvolver alguns eventos, como os listados a seguir:

- Incluir interface SFC e características probabilísticas no ASiA, desenvolvido pelo grupo de Sistemas Distribuídos e Programação Concorrente do ICMSC-USP. A idéia é aproveitar a interface amigável do ASiA, adicionando-se o maior poder de representatividade dos statecharts.

- Incluir características probabilísticas no StatSim, desenvolvido pelo grupo de Engenharia de Software do ICMSC-USP, objetivando adicionar um poder de análise de desempenho nessa ferramenta.

Considerando-se os SFC estendidos a tempos contínuos, podem-se desenvolver os seguintes experimentos:

- Elaborar algoritmos de migração entre os SFC e SPN (GSPN), ou entre SFC e Redes de Filas. Assim, poder-se-ia estender o ASiA para possibilitar a opção entre as técnicas e, uma vez escolhida uma, poder-se-ia obter o modelo correspondente nas outras técnicas. 
- Elaboração de livro texto sobre o assunto, apresentando uma visão computacional atualizada das técnicas abordadas nesta pesquisa, seguindo a linha do trabalho apresentado por Kleinrock (Kleinrock, 74) para os sistemas de filas. Assim, pretende-se expor o assunto sob um ponto de vista menos mítico (forma incorporada na maioria dos trabalhos correlatos). 


\section{Referências Bibliográficas}

ALLEN, A. O. Probability Statistic and Queueing Theory - with Computer Applications. Academic Press, 1990.

BEGUELIN, A. PVM: Parallel Virtual Machine. A User's Guide and Tutorial for Networked Parallel Computing. The MIT Press, 1994.

BERTSEKAS, D.; GALLAGER, R. Data Networks - Second Edition, Prentice Hall, Inc., 1992.

BOAR, B. Application Prototyping. Wiley-Interscience, 1984.

BOAVENTURA, I.A.G. Propriedades Dinâmicas de Statecharts. São Carlos, 1992. Dissertação de Mestrado, Instituto de Ciências Matemáticas de São Carlos (ICMSC), Universidade de São Paulo (USP).

CHIOLA, G., MARSAN M. A., CONTE, G. Generalized Stochastic Petri Nets: A Definition at the Net Level and Its Implications. IEEE Transactions on Software Engineering, vol. 19, Num.. 2, 1993.

COLLIN, S.M.H. MICHAELIS: Dicionário Prático de Informática. Melhoramentos, São Paulo, 1993.

COMER, D.E. Internetworking with TCP/IP - vol. 1 - Principles, Protocols and Architecture, $2^{a}$ ed., Prentice Hall, 1991.

COOLAHAN, J.E.; ROUSSOPOULOS, N. Timing Requirements for Time-Driven Systems Using Augmented Petri Nets, IEEE Transaction on Software Engineering, 1983.

COULOURIS, G.; DOLLIMORE, J.; KINDBERG, T. Distributed Systems - Concepts and Design, Addison-Wesley, 2a. ed., Addison-Wesley Publishing Company, 1994.

DITTRICH, G. Modeling of Complex Systems Using Hierarchical Petri Nets, Codesign Computer-Aided Software / Hardware Engineering, IEEE Press, 128-144, 1995.

FARIAS, A. A.; SOARES, J. F.; CESAR, C. C. Introduçāo d̀ Estatística, Guanabara Koogan S.A., 1991.

FISHWICK, PAUL A. (1995, January). Computer Simulation: Growth Through Extension. WWW: http://www.cs.wm.edu/ subhas/parsim.html.

HAREL, D.; Statecharts: a visual formalism for complex systems, Science of Computer Programming, Num. 8, 23I-274, North-Holland, 1987. 
JENSEN, K.; HUBER, P.; SHAPIRO, R. M. Hierarchies in Coloured Petri Nets, Lectures Notes in Computer Science, Vol.483, 313-341, Springer-Verlag, 1990.

KLEINROCK, L. Queueing Systems - Volume I: Theory, Wiley-Interscience, 1975.

KLEINROCK, L. Queueing Systems - Volume II: Computer Applications, Wiley-Interscience, 1976.

KOVACS, ZSOLT L. Teoria da Probabilidade e Processos Estocásticos. Edição ACADÊMICA, 1996.

LAZOWSKA, E.; ZAHORJAN, J.; GRAHAM; G. SEVICK, K. Quantitative System Performance - Computer System Analysis Usisng Queueing Network Models, PrenticeHall, Inc, N.J., 1984.

LIPSCHULTZ, S. Probabilidade, MAKRON BOOKS, 1994.

MACDOUGALL, M. H. Simulating Computing Systems Techniques and Tools, MT, 1987.

MACIEL, P.R.M.; LINS,R.D.; CUNHA, P. R. F. Introdução às Redes de Petri e Aplicações, $10^{\mathrm{a}}$ Escola de Computação, Campinas, Julho 1996.

MARÍAS, J. Introdução à Filosofia. $4^{\mathrm{a}}$ ed., Livraria Duas Cidades, 1985.

MEYER, PAUL L. Probabilidade: Aplicações à Estatística. LTC Livros Técnicos e Científicos, 1995.

MOLLOY, M.K. Performance Evaluation Using Stochastic Petri Nets. IEEE Trans. Comput., vol. C-31, no. 9, p. 913-917, set. 1982

MORSELLI Jr., J.C.M. Simulação Distribuída em uma Rede de Transputers Utilizando o Método CMB. São Carlos, 1995. Dissertação de Mestrado, Instituto de Ciências Matemáticas de São Carlos (ICMSC), Universidade de São Paulo (USP).

MÜLLENDER, S. Distributed Systems, ACM PRESS Frontier Series, Addison-Wesley Publishing Company, 1994.

MURATA, T. State Equation, Contrallability, and Maximal of Petri Nets, IEEE Trans. On Automatic Control, 1977.

MURATA, T. Petri Nets: Propriets, Analysis and Aplications, Proceding of The IEEE, 1989.

NAIR, E. A.; SAUER, C.H. Elements of Pratical Performance Modeling, Prentice Hall, N. Jersey, 1985. 
NEWELL, G.F.. Application of Queueing Theory - Second Edition, Chapman and Hall, 1982.

ORLANDI, R. C. G. S. Ferramentas para Análise de Desempenho de Sistemas Computacionais Distribuídos, São Carlos, 1995. Dissertação de Mestrugdo, Instituto de Ciências Matemáticas de São Carlos (ICMSC), Universidade de São Paulo (USP).

PEDGEN, C.D. Introduction to Simulation Using SIMAN, MacGrawHill, 1991.

PETERSON, J.L. Petri Nets na Introduction, Prentice Hall, Inc., 1981.

PNUELLI, A.; KENSTEN, Y.; Timed and Hybrid Statecharts and their textual representation. Formal Techniques in Real-Time and Fault-Tolerant Systems - Second International Symposium, Nijmegem, Holanda. Lecture Notes in Computer Science, vol. 571, 591-620. Springer Verlag. Jan. 1992.

PRICE, W. A Benchmark Tutorial, IEEE Micro, 28-43, Oct. 1989.

SANTANA, M.J.; SANTANA, R.H.C.; SPOLON, R.; SPOLON, R. Automatic Generation of Discret-System Simulation Programs in The Proceedings of the 1996 Summer Computer Simulation Conference, Portland, Oregon, USA, Jul. 1996, 133-138.

SANTANA, M.J.; SANTANA, R.H.C.; SPOLON, R.; SPOLON, R. A Graphical User-Interface for na Automatic Simulation System in The Proceedings of the 1996 Summer Computer Simulation Conference, Portland, Oregon, USA, Jul. 1996, 139-143.

SANTANA, M.J.; SANTANA, R.H.C.; FRANCÊS, C. R. L..; ORLANDI, R.C. Tools and Methodologies For Performance Evaluation of Distributed Systems - A Comparison Study, in The Proceedings of the 1997 Summer Computer Simulation Conference, Arlington, Virginia, USA, Jul. 1997, 124-128.

SHARMA, S.; LAUWRENCE, L.R. Modular Design for Simulation, Software - Pratice and Experience, v.18, n.10, 945-966, 1988.

SOARES, L. F.G. Modelagem e Simulação Discreta de Sistemas. Editora Campus Ltda, 1992.

SOUZA, P.S. L. de, Máquina Paralela Virtual no Ambiente Windows. São Carlos, 1996. Dissertação de Mestrado, Instituto de Ciências Matemáticas de São Carlos (ICMSC), Universidade de São Paulo, São Paulo (USP).

SOUZA, M.A. de. Avaliação das Rotinas de Comunicação Ponto-a-Ponto do MPI, São Carlos, 1997. Dissertação de Mestrado, Instituto de Ciências Matemáticas de São Carlos (ICMSC), Universidade de São Paulo, São Paulo (USP). 
SPOLON, R. Um Gerador de Aplicação para um Ambiente de Simulação Automático. São Carlos, 1994. Dissertação de Mestrado, Instituto de Ciências Matemáticas de São Carlos (ICMSC), Universidade de São Paulo (USP).

SPOLON, R. Um Editor Gráfico para um Ambiente de Simulação Automático. São Carlos, 1994. Dissertação de Mestrado, Instituto de Ciências Matemáticas de São Carlos (ICMSC), Universidade de São Paulo (USP).

SWAIN, J. J. Simulation Survey: Tools for Process Understanding and Improvement, ORMS Today, Aug. 1995.

TANENBAUM, A. S. Distributed Operating Systems, Prentice Hall International Inc., 1995.

TANENBAUM, A. S. Computer Networks, Prentice Hall International Inc., 1996.

TRINDADE, O. J.; ZALUSKA, E. Real Time Monitoring of Concurrent Computation, Anais do SEMISH 94, Caxambu, MG, Agosto 1994.

WEICKER, R. An Overview of Common Benchmarks, IEEE Computer, 65-75, Dec. 1990.

VALETTE, R.; COURVOISIER, M. Systèmes de Commande en Temps Réel. SCM Editions, 1980. 